\title{
NTP TECHNICAL REPORT ON THE TOXICITY STUDIES OF \\ a Gum Guggul Extract FORMULATION ADMINISTERED BY Gavage to Sprague DaWley (HSD:SPRAGUE DAWLEY ${ }^{\circledR}$ SD $^{\circledR}$ ) RATS AND B6C3F1/N MICE
}

NTP TOX 99

JUNE 2020 


\title{
NTP Technical Report on the Toxicity Studies of a Gum Guggul Extract Formulation Administered by Gavage to Sprague Dawley (Hsd:Sprague Dawley ${ }^{\circledR}$ SD $^{\circledR}$ ) Rats and B6C3F1/N Mice
}

Toxicity Report 99

June 2020

\author{
National Toxicology Program \\ Public Health Service \\ U.S. Department of Health and Human Services
}

ISSN: 2378-8992

Research Triangle Park, North Carolina, USA 


\section{Foreword}

The National Toxicology Program (NTP), established in 1978, is an interagency program within the Public Health Service of the U.S. Department of Health and Human Services. Its activities are executed through a partnership of the National Institute for Occupational Safety and Health (part of the Centers for Disease Control and Prevention), the Food and Drug Administration (primarily at the National Center for Toxicological Research), and the National Institute of Environmental Health Sciences (part of the National Institutes of Health), where the program is administratively located. NTP offers a unique venue for the testing, research, and analysis of agents of concern to identify toxic and biological effects, provide information that strengthens the science base, and inform decisions by health regulatory and research agencies to safeguard public health. NTP also works to develop and apply new and improved methods and approaches that advance toxicology and better assess health effects from environmental exposures.

The Toxicity Report series began in 1991. The studies described in the NTP Toxicity Report series are designed and conducted to characterize and evaluate the toxicological potential of selected substances in laboratory animals (usually two species, rats and mice). Substances (e.g., chemicals, physical agents, and mixtures) selected for NTP toxicity studies are chosen primarily on the basis of human exposure, level of commercial production, and chemical structure. The interpretive conclusions presented in the Toxicity Reports are derived solely from the results of these NTP studies, and extrapolation of these results to other species, including characterization of hazards and risks to humans, requires analyses beyond the intent of these reports. Selection for study per se is not an indicator of a substance's toxic potential.

NTP conducts its studies in compliance with its laboratory health and safety guidelines and the Food and Drug Administration Good Laboratory Practice Regulations and meets or exceeds all applicable federal, state, and local health and safety regulations. Animal care and use are in accordance with the Public Health Service Policy on Humane Care and Use of Laboratory Animals. Studies are subjected to retrospective quality assurance audits before they are presented for public review. Draft reports undergo external peer review before they are finalized and published.

The NTP Toxicity Reports are available free of charge on the NTP website and cataloged in PubMed, a free resource developed and maintained by the National Library of Medicine (part of the National Institutes of Health). Data for these studies are included in NTP's Chemical Effects in Biological Systems database.

For questions about the reports and studies, please email NTP or call 984-287-3211. 


\section{Table of Contents}

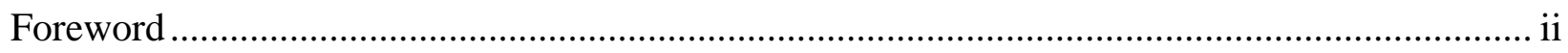

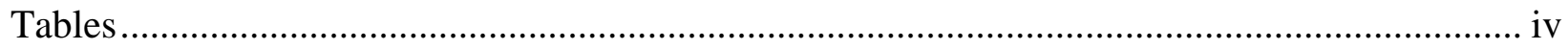

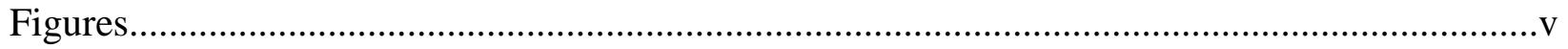

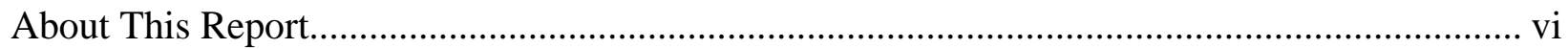

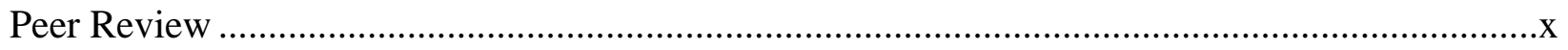

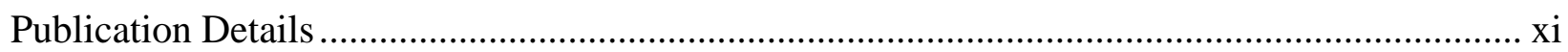

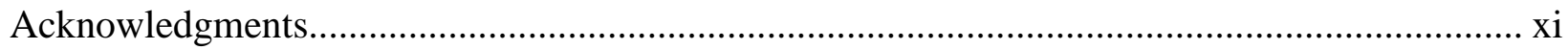

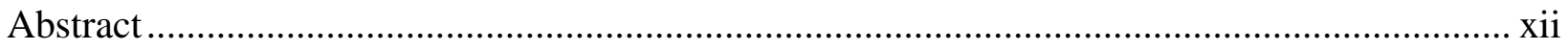

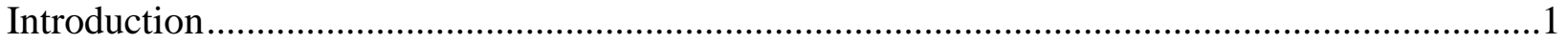

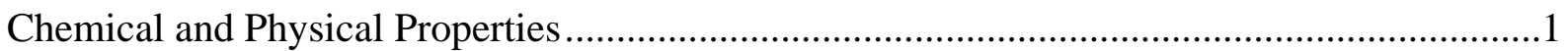

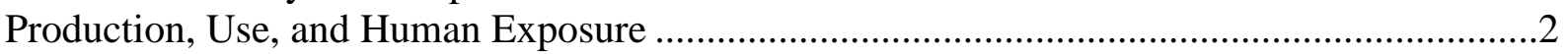

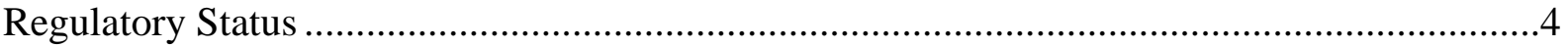

Absorption, Distribution, Metabolism, Excretion, and Toxicokinetics .......................................4

Experimental Animals ……………….....................................................................

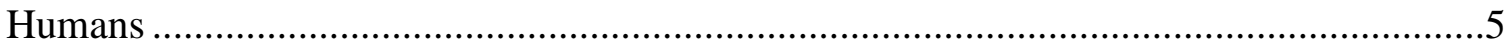

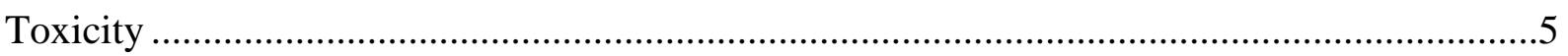

Experimental Animals ......................................................................................

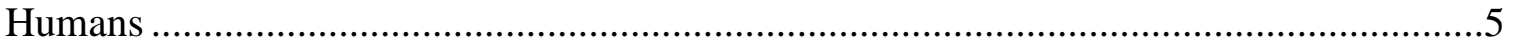

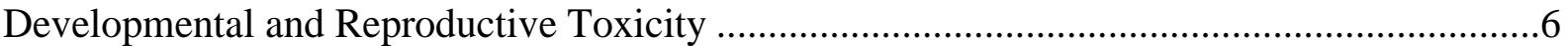

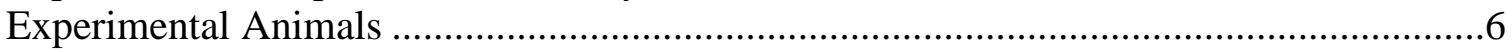

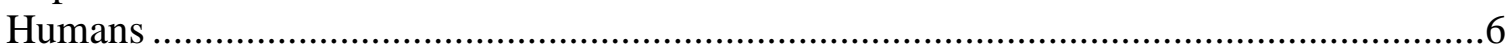

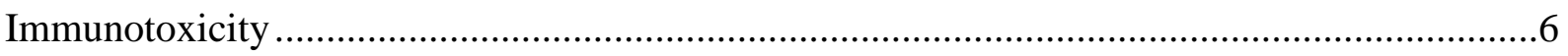

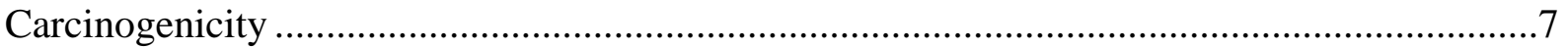

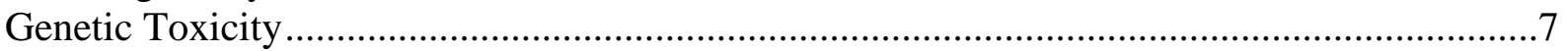

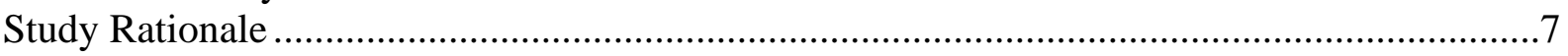

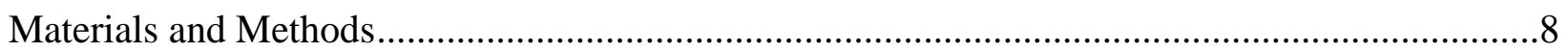

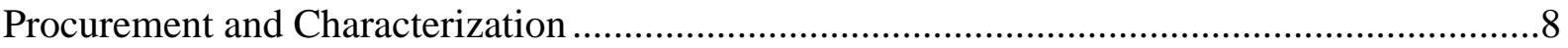

Gum Guggul Extract Formulation ...........................................................................

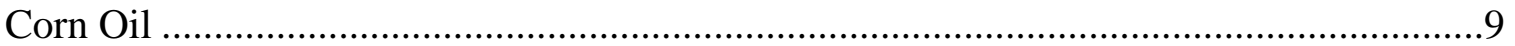

Preparation and Analysis of Dose Formulations....................................................................10

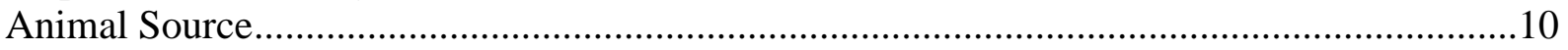

Animal Welfare ......................................................................................................10

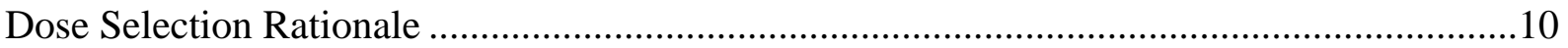

Three-month and Twenty-eight-day Interim Studies................................................................11

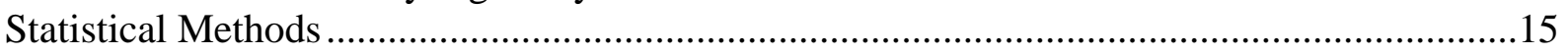

Calculation and Analysis of Nonneoplastic Lesion Incidences ..........................................15

Analysis of Continuous Variables .................................................................................15

Quality Assurance Methods ..........................................................................................16

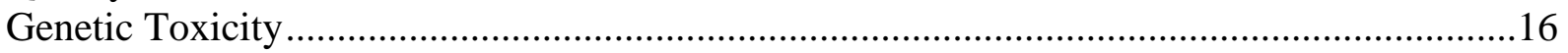

In Vivo Erythrocyte Micronucleus Assay..........................................................................16 


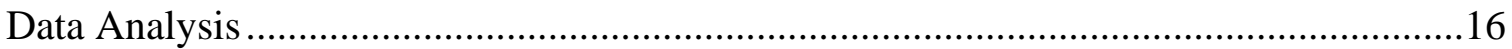

Human In Vitro Activity Assays.......................................................................................17

Cytochrome P450 Activity Assays ............................................................................17

P-glycoprotein ATPase Assay ......................................................................................17

$\mathrm{Na}^{+}$-Taurocholate Cotransporting Polypeptide Activity Assay ............................................17

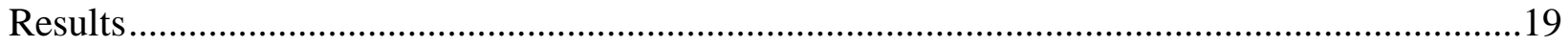

Data Availability ………………………………….............................................19

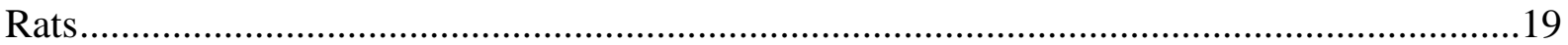

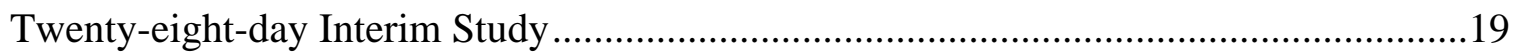

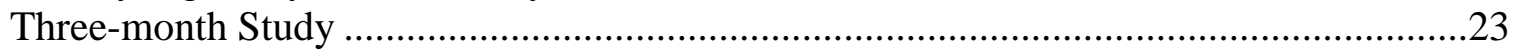

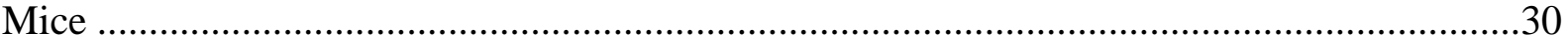

Twenty-eight-day Interim Study ................................................................................30

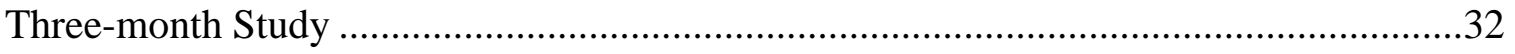

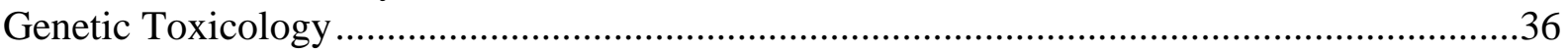

Human In Vitro Activity Assays.......................................................................................36

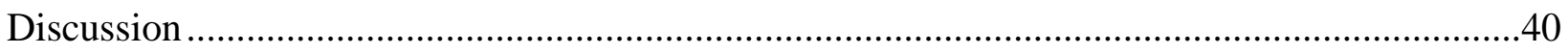

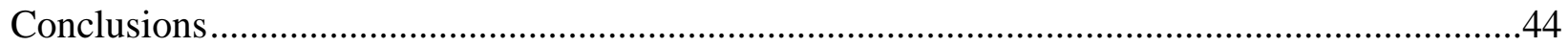

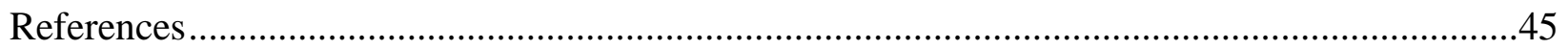

Appendix A. Estrous Cycle Characterization ...................................................................... A-1

Appendix B. Genetic Toxicology …………………....................................................

Appendix C. Chemical Characterization and Dose Formulation Studies........................................

Appendix D. Ingredients, Nutrient Composition, and Contaminant Levels in NTP2000 Rat and Mouse Ration ......................................................................... D-1

Appendix E. Sentinel Animal Program ..................................................................................

Appendix F. Supplemental Data ......................................................................................

\section{Tables}

Summary of Findings Considered Toxicologically Relevant in Rats and Mice Administered a Gum Guggul Extract Formulation by Gavage for Three Months........ xiv

Table 1. Summary of Results of Test Article Characterization ........................................................

Table 2. Experimental Design and Material and Methods in the Three-month and 28-day Interim Gavage Studies of a Gum Guggul Extract Formulation ......................................13

Table 3. Summary of Cytochrome P450 Activity Assays .............................................................18

Table 4. Survival and Body Weights of Rats in the Interim 28-day Gavage Study of Gum Guggul Extract.

Table 5. Select Organ Weights and Organ-Weight-to-Body-Weight Ratios for Rats in the Interim 28-day Gavage Study of Gum Guggul Extract...................................................20

Table 6. Select Clinical Chemistry Data for Rats in the Interim 28-day Gavage Study of Gum Guggul Extract................................................................................................21

Table 7. Cytochrome P450 Measurements for Rats in the Interim 28-day Gavage Study of Gum Guggul Extract. 
Table 8. Survival and Body Weights of Rats in the Three-month Gavage Study of Gum Guggul Extract...........................................................................................................23

Table 9. Select Organ Weights and Organ-Weight-to-Body-Weight Ratios for Rats in the Three-month Gavage Study of Gum Guggul Extract......................................................25

Table 10. Select Clinical Chemistry Data for Rats in the Three-month Gavage Study of

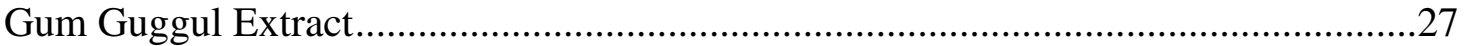

Table 11. Select Sperm Count Endpoints for Rats in the Three-month Gavage Study of Gum Guggul Extract...............................................................................................28

Table 12. Cytochrome P450 Measurements for Rats in the Three-month Gavage Study of Gum Guggul Extract............................................................................................29

Table 13. Survival and Body Weights of Mice in the Interim 28-day Gavage Study of Gum Guggul Extract.

Table 14. Cytochrome P450 Measurements for Mice in the Interim 28-day Gavage Study of Gum Guggul Extract .............................................................................................

Table 15. Survival and Body Weights of Mice in the Three-month Gavage Study of Gum Guggul Extract........................................................................................................32

Table 16. Select Clinical Chemistry Data for Mice in the Three-month Gavage Study of Gum Guggul Extract.....

Table 17. Select Sperm Count Endpoints for Mice in the Three-month Gavage Study of Gum Guggul Extract.

Table 18. Cytochrome P450 Measurements for Mice in the Three-month Gavage Study of Gum Guggul Extract

Table 19. Summary of Human In Vitro Enzyme Activity Following Exposure to Gum Guggul Extract.....

Table 20. Summary of Human In Vitro Enzyme Activity Following Exposure to E- or ZGuggulsterone.

\section{Figures}

Figure 1. Commiphora mukul, Botanical Species from Which Gum Guggul Oleoresin Is Harvested .....

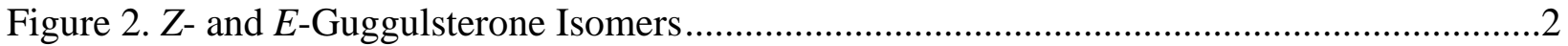

Figure 3. Growth Curves for Male and Female Rats Administered Gum Guggul Extract by Gavage for Three Months

Figure 4. Growth Curves for Male and Female Mice Administered Gum Guggul Extract by Gavage for Three Months 


\section{About This Report}

National Toxicology Program ${ }^{1}$

${ }^{1}$ Division of the National Toxicology Program, National Institute of Environmental Health

Sciences, Research Triangle Park, North Carolina, USA

\section{Collaborators}

T.D. Hubbard, S.A. Elmore, J.W. Algaier, K. Basham, S. Black, C.R. Blystone, B. Burback, K.A. Carrico, D.A. Contos, M.C. Cora, J.M. Fostel, R.P. Frawley, D.K. Gerken, D.R. Germolec, S.W. Graves, M. Hejtmancik, M.J. Hooth, A.P. King-Herbert, K.A.B. Knostman, L. Kooistra, D.E. Malarkey, M. Marr, J.M. Matthews, B.S. McIntyre, D. Messer, G.K. Roberts, M.J. Ryan, C.C. Shackelford, L. Siemann, A.J. Skowronek, M.D. Stout, G.S. Travlos, R.W. Tyl, M.K. Vallant, S. Waidyanatha, N.J. Walker, K.L. Witt, M.E. Wyde

Division of the National Toxicology Program, National Institute of Environmental Health Sciences, Research Triangle Park, North Carolina, USA

Evaluated and interpreted results and reported findings

T.D. Hubbard, Ph.D., Study Scientist

S.A. Elmore, D.V.M., Study Pathologist

C.R. Blystone, Ph.D.

M.C. Cora, D.V.M.

R.P. Frawley, M.S.

D.R. Germolec, Ph.D.

M.J. Hooth, Ph.D.

A.P. King-Herbert, D.V.M.

D.E. Malarkey, D.V.M., Ph.D.

B.S. McIntyre, Ph.D.

G.K. Roberts, Ph.D.

M.D. Stout, Ph.D.

G.S. Travlos, D.V.M.

M.K. Vallant, M.S., MT

S. Waidyanatha, Ph.D.

N.J. Walker, Ph.D.

K.L. Witt, M.S.

M.E. Wyde, Ph.D.

Provided oversight for data management

J.M. Fostel, Ph.D.

Battelle, Columbus, Ohio, USA

Conducted studies and evaluated pathology findings

M. Hejtmancik, Ph.D., Principal Investigator

D.A. Contos, M.S.

D.K. Gerken, Ph.D.

K.A.B. Knostman, D.V.M., Ph.D. 
M.J. Ryan, D.V.M., Ph.D.

A.J. Skowronek, D.V.M., Ph.D.

Conducted prestart chemistry activities and dose formulations

S.W. Graves, B.S., Principal Investigator

B. Burback, Ph.D.

K.A. Carrico, B.A.

D.A. Contos, M.S.

MRIGlobal, Kansas City, Missouri, USA

Conducted preliminary chemistry activities and contaminant analysis

J.W. Algaier, Ph.D., Principal Investigator

D. Messer, Ph.D.

L. Siemann, B.S.

Experimental Pathology Laboratories, Inc., Research Triangle Park, North Carolina, USA Conducted pathology quality assessment review

C.C. Shackelford, D.V.M., Ph.D.

Pathology Associates, A Division of Charles River Laboratories, Inc., Research Triangle

Park, North Carolina, USA

Conducted NTP Pathology Peer Review (3-month studies)

L. Kooistra, D.V.M., Ph.D.

RTI International, Research Triangle Park, North Carolina, USA

Conducted human in vitro activity assays

J.M. Matthews, Ph.D., Principal Investigator

S. Black, B.S.

Provided sperm count and vaginal cytology evaluation (SCVCE) analysis

R.W. Tyl, Ph.D., Principal Investigator

K. Basham, B.S.

M. Marr, B.A.

\section{Contributors}

Division of the National Toxicology Program, National Institute of Environmental Health Sciences, Research Triangle Park, North Carolina, USA

Provided oversight of external peer review

E.A. Maull, Ph.D.

M.S. Wolfe, Ph.D.

NTP Pathology Peer Review, National Institute of Environmental Health Sciences, Research Triangle Park, North Carolina, USA

Participated in NTP Pathology Peer Review (3-month studies) (October 5, 2011)

D.E. Malarkey, D.V.M., Ph.D., National Toxicology Program

D.B. Rao, D.V.M., ILS, Inc. 
Participated in NTP Pathology Peer Review, reevaluation of incidental lesions (3-month studies) (October 11, 2011)

L. Kooistra, D.V.M., Ph.D., Pathology Associates, Charles River Laboratories, Inc.

D.B. Rao, D.V.M., ILS, Inc.

Participated in NTP Pathology Peer Review, special review of testis and epididymis (3-month studies) (October 17, 2012)

A.E. Brix, D.V.M., Ph.D., Experimental Pathology Laboratories, Inc.

Experimental Pathology Laboratories, Inc., Research Triangle Park, North Carolina, USA Supervised pathology review

M.H. Hamlin, II, D.V.M., Principal Investigator

Integrated Laboratory Systems, Inc., Research Triangle Park, North Carolina, USA

Conducted micronucleus assays

L. Recio, Ph.D., Principal Investigator

C.A. Hobbs, Ph.D.

C.D. Swartz, D.V.M., Ph.D.CSS Corporation, Research Triangle Park, North Carolina, USA

Prepared quality assessment audits

S. Brecher, Ph.D., Principal Investigator

S. Iyer, B.S.

V.S. Tharakan, D.V.M.

ASRC Federal, Research Triangle Park, North Carolina, USA

Prepared data for report

J. Berke, B.S.

C. Myers, M.S.

N. Sayers, B.S.

E. Sheridan, M.S.

T. Silver, B.S.

V. Youn, B.S.

Social \& Scientific Systems, Inc., Research Triangle Park, North Carolina, USA

Provided statistical analyses

S. McBride, Ph.D., Principal Investigator

L.J. Betz, M.S.

ICF, Durham, North Carolina, USA

Provided contract oversight

D.F. Burch, M.E.M., Principal Investigator

J.C. Cleland, M.E.M.

J.A. Wignall, M.S.P.H. 
Prepared, edited, and formatted report

J. Frye, M.S.

S.R. Gunnels, M.A.

T. Hamilton, M.S.

A. Ichida, Ph.D.

B. Ingle, Ph.D.

P. Kellar, M.S.

W. Mitchell, B.S.

B.C. Riley, B.S.

K.A. Shipkowski, Ph.D.

Supported external peer review

C.N. Byrd, B.S.

M.C. Rooney, B.A. 


\section{Peer Review}

The draft NTP Technical Report on the Toxicity Studies of a Gum Guggul Extract Formulation Administered by Gavage to Sprague Dawley (Hsd:Sprague Dawley ${ }^{\circledR} S D^{\circledR}$ ) Rats and B6C3F1/N Mice was evaluated by the reviewers listed below. These reviewers served as independent scientists, not as representatives of any institution, company, or governmental agency. In this capacity, reviewers determined if the design and conditions of this NTP study were appropriate and ensured that this Toxicity Study Report presents the experimental results and conclusions fully and clearly.

\section{Bob Benson, Ph.D.}

Drinking Water Toxicologist

United States Environmental Protection Agency, Region 8

Denver, Colorado, USA

\section{John Pierce Wise, Sr., Ph.D.}

Professor, Pharmacology and Toxicology

Department of Pharmacology and Toxicology, School of Medicine

University of Louisville

Louisville, Kentucky, USA 


\section{Publication Details}

Publisher: National Toxicology Program

Publishing Location: Research Triangle Park, NC

ISSN: 2378-8992

DOI: https://doi.org/10.22427/NTP-TOX-99

Report Series: NTP Toxicity Report Series

Report Series Number: 99

Official citation: National Toxicology Program (NTP). 2020. NTP technical report on the toxicity studies of a gum guggul extract formulation administered by gavage to Sprague Dawley (Hsd:Sprague Dawley ${ }^{\circledR} \mathrm{SD}^{\circledR}$ ) rats and B6C3F1/N mice. Research Triangle Park, NC: National Toxicology Program. Toxicity Report 99.

\section{Acknowledgments}

This work was supported by the Intramural Research Program (ES103316, ES103318, and ES103319) at the National Institute of Environmental Health Sciences, National Institutes of Health and performed for the National Toxicology Program, Public Health Service, U.S. Department of Health and Human Services under contracts HHSN273201800006C, HHSN273201600020C, HHSN273201600011C, GS00Q14OADU417 (Order No. HHSN273201600015U), HHSN273201500006C, HHSN273201500012C, HHSN273201500014C, HHSN273201300009C, HHSN316201200054W, HHSN273201100001C, HHSN291200555552, N01-ES-75563, N01-ES-65557, and N01-ES-55536. 


\section{Abstract}

Gum guggul extracts (GGEs) are botanical preparations derived from the oleoresin of the Commiphora mukul tree. The preparations are traditionally used in Ayurvedic medicine to treat hyperlipidemia, obesity, diabetes, atherosclerosis, and inflammatory conditions such as arthritis. In the United States, GGEs are marketed as dietary supplements. GGE toxicity was evaluated due to widespread human exposure through increasing dietary supplement use, demonstrated metabolic and hormone-altering effects, and a lack of available information to adequately assess safe use in humans. Male and female Sprague Dawley (Hsd:Sprague Dawley ${ }^{\circledR} \mathrm{SD}^{\circledR}$ ) rats and B6C3F1/N mice were administered a GGE formulation in corn oil by gavage for 28 days or 3 months. Oral gavage was chosen as the route of exposure for these studies because human exposure primarily occurs by ingestion of encapsulated GGE supplements.

Groups of 10 male and 10 female rats were administered 0, 62.5, 125, 250, 500, or 1,000 mg GGE formulation/kg body weight/day in corn oil by gavage, 5 days per week for 3 months. Additional groups of 10 male and 10 female rats were administered the same doses for an interim 28-day study. All rats survived to the end of the study with the exception of three female rats, with a single death occurring in each of the 0,125 , and $500 \mathrm{mg} / \mathrm{kg} / \mathrm{day}$ groups. Terminal mean body weights of all dosed groups of rats for both the 28-day and 3-month studies were within 5\% of vehicle controls. No treatment-related clinical findings were observed. Dose-related increases in absolute and relative liver weights were evident in male and female rats at 28 days and 3 months. There were no dose-related microscopic findings at 28 days or 3 months. Clinical pathology changes observed at 28 days or 3 months in male and/or female rats were increased globulin concentration and decreased bile acid, cholesterol, and phospholipid concentrations. Increased hepatic cytochrome P450 (CYP) 2B and CYP3A activities were observed at 28 days and 3 months in all dosed groups of male and female rats.

Groups of 15 male and 15 female mice were administered 0, 15.5, 31, 62.5, 125, or 250 mg GGE formulation/kg body weight/day in corn oil by gavage, 5 days per week for 3 months. Additional groups of 10 male and 10 female mice were administered the same doses for an interim 28-day study. All mice survived to the end of the study. Terminal mean body weights of all dosed groups of mice for both 28-day and 3-month studies were within $7 \%$ of vehicle controls. No treatment-related clinical findings were observed. No treatment-related effects on organ weights were observed, and there were no dose-related microscopic findings in mice at 28 days or 3 months. In the 3-month study, elevated serum cholesterol and phospholipid concentrations were noted in female mice. Administration of the tested GGE formulation did not result in significant changes in reproductive organ histopathology of male and female mice. Male mice administered $\geq 62.5 \mathrm{mg} / \mathrm{kg} /$ day exhibited statistically significant lower mean total number of homogenization-resistant spermatids and mean total number of homogenization-resistant spermatids/mg testis relative to the vehicle control group. Mice dosed with $250 \mathrm{mg} / \mathrm{kg} / \mathrm{day}$ also displayed lower testicular weights (approximately 12\%, significant trend) and lower caudal sperm counts relative to vehicle controls, collectively indicating that the GGE formulation examined exhibits the potential to be a male reproductive toxicant. Increased hepatic CYP2B and CYP3A activities were observed in male and female mice at the highest tested dose, $250 \mathrm{mg} / \mathrm{kg} /$ day.

The genotoxic potential of the administered GGE formulation was evaluated by quantifying micronucleated reticulocytes or erythrocytes in rat and mouse peripheral blood samples, 
following 3 months of dosing. No apparent increases in the frequency of micronucleated erythrocytes/reticulocytes or changes in the percentage of immature erythrocytes were noted in rats or mice, suggesting that the tested GGE formulation did not induce bone marrow toxicity or alter erythropoiesis in rodents.

The potential effects of a GGE formulation on endogenous metabolism were evaluated using human in vitro models. Treatment with a marketed GGE formulation decreased CYP2C9, CYP3A4-mediated testosterone 6 $\beta$-hydroxylase, and CYP2C19 metabolic activity in human microsomal preparations. Additionally, treatment decreased taurocholate uptake in a human $\mathrm{Na}^{+}$taurocholate cotransporting polypeptide activity assay and heightened ATPase activity by human P-glycoprotein. Taken together, these data suggest that GGE constituents may act as substrates or cofactors that modify the activity of human metabolic enzymes and transporters.

Under the conditions of the 3-month gavage studies, administration of the selected GGE formulation resulted in increased globulin concentrations and decreased bile acid, cholesterol, and phospholipid concentrations in rats, whereas increases in cholesterol and phospholipid concentrations were observed in mice. Decreased mean number of homogenization-resistant spermatids was evident in mice administered the GGE formulation, suggesting the testes might be a target organ of GGE toxicity (lowest-observed-effect level [LOEL] $=62.5 \mathrm{mg} / \mathrm{kg} /$ day).

Male and female rats displayed significantly increased absolute and relative liver weights relative to the GGE formulation dose administered. Additionally, increased hepatic CYP3A and CYP2B activity was observed in both test species, and metabolic potential was altered in human in vitro assays, suggesting an increased potential for dietary supplement-drug pharmacokinetic interactions. 
Summary of Findings Considered Toxicologically Relevant in Rats and Mice Administered a Gum Guggul Extract Formulation by Gavage for Three Months

\begin{tabular}{|c|c|c|c|c|}
\hline & $\begin{array}{c}\text { Male } \\
\text { Sprague Dawley Rats }\end{array}$ & $\begin{array}{c}\text { Female } \\
\text { Sprague Dawley Rats }\end{array}$ & $\begin{array}{c}\text { Male } \\
\text { B6C3F1/N Mice }\end{array}$ & $\begin{array}{c}\text { Female } \\
\text { B6C3F1/N Mice }\end{array}$ \\
\hline Doses in Corn Oil & $\begin{array}{l}0,62.5,125,250,500 \text {, } \\
\text { or } 1,000 \mathrm{mg} / \mathrm{kg} / \text { day }\end{array}$ & $\begin{array}{l}0,62.5,125,250,500 \text {, } \\
\text { or } 1,000 \mathrm{mg} / \mathrm{kg} / \text { day }\end{array}$ & $\begin{array}{l}0,15.5,31,62.5 \text {, } \\
125, \text { or } \\
250 \mathrm{mg} / \mathrm{kg} / \mathrm{day}\end{array}$ & $\begin{array}{l}0,15.5,31,62.5, \\
125, \text { or } \\
250 \mathrm{mg} / \mathrm{kg} / \text { day }\end{array}$ \\
\hline Survival Rates & $\begin{array}{l}10 / 10,10 / 10,10 / 10 \\
10 / 10,10 / 10,10 / 10\end{array}$ & $\begin{array}{l}9 / 10,10 / 10,9 / 10 \\
10 / 10,9 / 10,10 / 10\end{array}$ & $\begin{array}{l}\text { 15/15, 15/15, } \\
\text { 15/15, 15/15, } \\
15 / 15,15 / 15\end{array}$ & $\begin{array}{l}15 / 15,15 / 15 \\
15 / 15,15 / 15 \\
15 / 15,15 / 15\end{array}$ \\
\hline Body Weights & $\begin{array}{l}\text { Dosed groups similar } \\
\text { to the vehicle control } \\
\text { group }\end{array}$ & $\begin{array}{l}\text { Dosed groups similar } \\
\text { to the vehicle control } \\
\text { group }\end{array}$ & $\begin{array}{l}\text { Dosed groups } \\
\text { similar to the } \\
\text { vehicle control } \\
\text { group }\end{array}$ & $\begin{array}{l}\text { Dosed groups } \\
\text { similar to the } \\
\text { vehicle control } \\
\text { group }\end{array}$ \\
\hline Clinical Findings & None $^{\mathrm{a}}$ & None & None & None \\
\hline Organ Weights & $\begin{array}{l}\uparrow \text { Absolute and } \\
\text { relative liver weight } \\
\uparrow \text { Relative kidney } \\
\text { weight } \\
\downarrow \text { Absolute and } \\
\text { relative thymus weight }\end{array}$ & $\begin{array}{l}\uparrow \text { Absolute and } \\
\text { relative liver weight }\end{array}$ & None & None \\
\hline Nonneoplastic Effects & None & None & None & None \\
\hline Clinical Pathology & None & $\begin{array}{l}\uparrow \text { Globulin } \\
\downarrow \text { A:G ratio } \\
\downarrow \text { Bile acids }\end{array}$ & None & $\begin{array}{l}\uparrow \text { Cholesterol } \\
\uparrow \text { Phospholipids }\end{array}$ \\
\hline $\begin{array}{l}\text { Reproductive } \\
\text { Findings }\end{array}$ & None & Not assessed & $\begin{array}{l}\downarrow \text { Number of } \\
\text { spermatid heads } \\
\downarrow \text { Cauda } \\
\text { epididymal sperm } \\
\text { count } \\
\downarrow \text { Number of } \\
\text { sperm/mg cauda } \\
\downarrow \text { Testis weight }\end{array}$ & Not assessed \\
\hline СYР2В/СYРЗА & $\uparrow \mathrm{CYP} 2 \mathrm{~B}$ & $\uparrow \mathrm{CYP} 2 \mathrm{~B}$ & $\uparrow$ CYP2B & 个 CYP2B \\
\hline Enzyme Activity & $\uparrow$ CYP3A & $\uparrow$ CYP3A & 个 CYP3A & 个 CYP3A \\
\hline
\end{tabular}

\section{Genetic Toxicology}

Micronucleated erythrocytes (in vivo):

Rat Negative in males and females

Mouse $\quad$ Negative in males and females

${ }^{\mathrm{a}}$ None $=$ no toxicologically relevant effects for this endpoint. 


\section{Introduction}

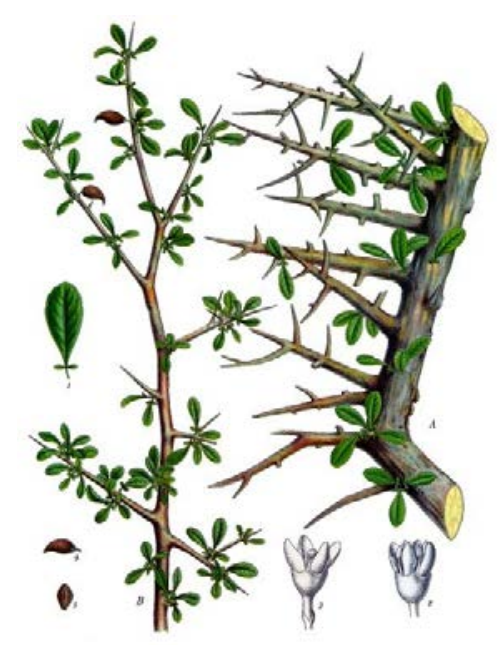

Figure 1. Commiphora mukul, Botanical Species from Which Gum Guggul Oleoresin Is Harvested

Botanical Name: Commiphora mukul.

Synonyms: “Gugal, the oleoresin," “Guggal, the oleo-gum resin from C. wightii,” "guggulu (resin from C. Mukul)," Indian bdellium, aflatan, bhavbhishtha, bhutahara, boejahudan, devadhupa, deveshta, dhurta, divya, goggle, gugal, gugali, gugar, guggala, guggul, guggulu, gulag, jatayu, javayu, juggulu, kumbholu, kumbholukhalaka, kunti, mahisaksh, mahishaksha, mahishakshaka, maisakshi, maishakshi, marudishta, moql, moqlearzaqi, mukul, mukulearahi, nishadhaka, palankasha, palnkash. pavandvishta, pura, puta, rakshoha, ranghanturb, ratadummula, sarvasaha, shamhava, shiva, uddipta, ulukhalaka, usha, vayughna.

\section{Chemical and Physical Properties}

Commiphora mukul is a flowering plant of the Burseraceae family endemic to the semiarid climates of Pakistan and West India (Figure 1). C. mukul is a hardy gynodioecious tree/shrub highly sought for its oleoresin (gum guggul), which is further processed by solvent extraction to produce gum guggul extract (GGE). ${ }^{1}$

C. mukul trees are 4-6 feet tall with ash-colored bark, free of foliage throughout most of the year, and are slow growing, requiring 5-6 years to attain the maturity necessary for harvesting of oleoresin. The oleo-gum resin is contained in the gum resin ducts within the primary and secondary phloem of larger veins present in the leaves and soft base of the stems. ${ }^{2-4}$

The crude oleo-gum resin exudate contains gums (32\%), oleo-gum resin (38\%), essential oils (1\%), minerals (20\%), organic matter (4\%), and unidentified components (5\%). ${ }^{1}$ The constituents of gum guggul include a complex mixture of diterpenoids, triterpenoids, steroids, flavonoids, long-chain aliphatic tetrols, aliphatic esters, ferulates, lignans, carbohydrates, amino acids, and numerous inorganic ions. ${ }^{5}$ Crude gum guggul oleo-gum resin is fractionated via solvent extraction by ethyl acetate to yield a soluble resin fraction (approximately 45\%) and an insoluble gum fraction (approximately 55\%). The soluble fraction is referred to as guggulipid and contains purported bioactive molecules, whereas the insoluble fraction contains constituents such as gums, minerals, and other components. ${ }^{6 ;} 5$ The soluble isolate can be fractionated further by use of $\mathrm{pH}$ gradients to yield acidic (4\%), basic (1\%), and neutral fractions (95\%). The neutral fraction is divided into ketonic (12\%) and nonketonic (88\%) subfractions. The nonketonic, inactive sub-fraction contains fatty alcohols, diterpenes, and lignans, whereas the neutral ketonic 
sub-fraction contains guggulsterones (35-40\%) from which Z- and E-guggulsterones (approximately 10\%) and other C21 and C27 sterols and ester molecules are derived. ${ }^{7 ; 8}$ The phytosteroids Z- and E-guggulsterone are widely considered the principal pharmacological components of gum guggul that impart its hypolipidemic and anti-inflammatory properties (Figure 2). ${ }^{9-13}$
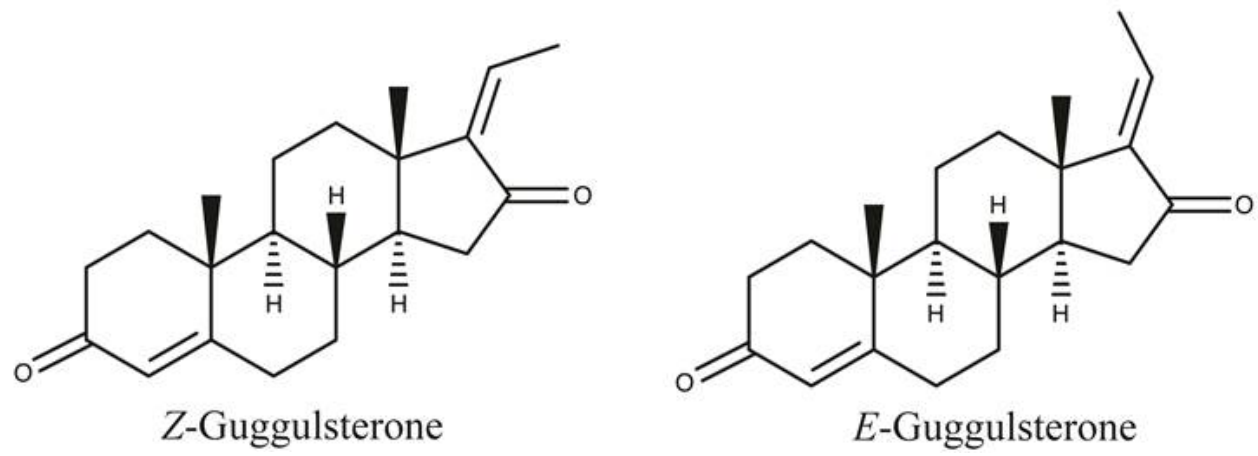

Figure 2. Z- and E-Guggulsterone Isomers

$Z$ - and E-guggulsterone isomers antagonize the farnesoid X receptor (FXR), which is a key regulator of bile acid signaling and cholesterol metabolism. ${ }^{14 ; 13}$ Guggulsterones transactivate the bile salt export pump (BSEP); the up-regulation of BSEP expression is dominant over its FXR-mediated antagonism. ${ }^{15}$ Guggulsterones also act as agonists for the pregnane $\mathrm{X}$ receptor (PXR), estrogen receptor- $\alpha$, and the progesterone receptor. ${ }^{16} \mathrm{GGE}$ contains additional, presumed bioactive, constituents including guggulsterols (I-VI), myrrhanol A, and myrrhanone A, among others, that might contribute to its asserted anti-inflammatory, hypolipidemic, and antitumor effects. ${ }^{5}$ The guggulsterone content of $C$. mukul varies by geographic location, with higher concentrations endemic to hyperarid agroclimatic regions. ${ }^{17}$

\section{Production, Use, and Human Exposure}

Gum guggul is harvested from the plant's soft underbark through the process of tapping, which involves making an incision in the tree bark of sufficient depth and positioning a vessel to collect the resin outflow. Harvest season is typically from February to June and is restricted to trees 5 years of age or older. Once tapped, a fluid exudes from the incision and slowly hardens to form the oleo-gum resin, which has a bitter taste and aromatic odor and is yellow, pale green, or reddish brown. The gum resin is typically collected every 10-12 days following the initial incision, with 700-900 g harvested from a single tree. ${ }^{18}$ In some cases, enhancer compounds, such as the plant growth regulator ethephon, are applied to trees to increase cumulative gum yield. ${ }^{18}$ After harvest, the oleoresin is graded for quality according to the extent of adulteration with particulates such as bark, soil, and sand. ${ }^{2}$ Guggul trees often die because of tapping, with pathogenesis associated with an outgrowth of the microbe Xanthomonas axonopodis pv. commiphorae. ${ }^{19}$ Commercial harvesting, poor seed set, low germination rates, and slow growth rates have led to a dwindling C. mukul population and placement on the International Union for Conservation of Nature (IUCN) Red List of Threatened Species as "critically endangered." 20 More recently, improved nondestructive harvesting techniques have been developed with parameters regarding cut size, technique, and use of enhancing compounds. ${ }^{21}$ Gum guggul production, as measured by the forest department of Kachchh, India, showed a decline in 
harvesting from the 1960s, when up to 30 tons were collected, and 1999, when only 2.42 tons were collected. ${ }^{22}$

GGE has been used in traditional Ayurvedic medicine for centuries, having been first described in Atharva Veda, circa 2000 BC. Indications of gum guggul described in the Ayurveda include atherosclerosis, hypercholesterolemia, skin disorders, broken bones, rheumatism, and obesity.; ${ }^{6 ;}$ Consumption of raw oleoresin is associated with the onset of skin rashes, irregular menstruation, intestinal discomfort, and hepatotoxicity. ${ }^{5}$ Traditional use often involves combining processed gum guggul with other flora or natural products such as dried fruits or plant components.

Human exposure to gum guggul occurs primarily by ingestion of homeopathic preparations, herbal/dietary supplements, and pharmaceuticals. Dosage forms include powdered oleo-gum resin, petroleum ether extracts, ethyl acetate extracts, or other galenical preparations. According to U.S. Pharmacopeia guidelines, the oleoresin gum should not contain less than $1 \% \mathrm{Z}$ - and $E$-guggulsterones, and extracts must contain at least $5 \% Z$ - and $E$-guggulsterones calculated on an anhydrous basis as Z-guggulsterone. ${ }^{23}$ In addition to consumptive use, gum guggul is used in the production of incense, lacquers, varnishes, ointments, and cosmetics and as a fixative agent in perfume.

Currently, standardized extracts of gum guggul are approved for marketing in India as lipid-lowering drugs and in the United States as dietary supplements. Use of herbal remedies and dietary supplements are becoming increasing popular in Western societies. According to the 2012 National Health Information Survey, an estimated 18\% of adults in the United States consumed a dietary supplement that was not vitamin/mineral based. ${ }^{24 ;} 25$ These products often lack sufficient data regarding quality, safety, or efficacy. Commercial guggulipid preparations are reported to contain $2.5-5 \% \mathrm{Z}$ - and E-guggulsterones. ${ }^{26}$ Analysis of six products marketed in the United States contained significantly less guggulsterones than the amount claimed on the label, some of which had no detectable levels. ${ }^{8}$ As summarized by the World Health Organization (WHO), suggested maximum daily intakes range from 3 to $4.5 \mathrm{~g}$ of the oleo-gum resin divided in three doses, or $500 \mathrm{mg}$ of petroleum ether extracts of the resin two or three times a day. ${ }^{27}$ The Indian Pharmacopeia recommends a maximum concentration of guggulsterones in supplements of $4 \%$ to $6 \%$ and that guggulipid preparations be taken in an amount equivalent to 25 mg guggulsterones three times a day. ${ }^{28}$ Although concern has been expressed regarding use of synthetic products standardized for up to $99 \%$ guggulsterone content, ${ }^{29}$ recommended doses are commonly based on doses used in available clinical trials. The composition of GGE formulations can vary between manufacturers and among lot preparations from an individual manufacturer.

Multiple human clinical trials have investigated the purported hypolipidemic effects of GGEs, with inconsistent results. Initial trials conducted in India using GGEs have demonstrated decreased total cholesterol, triglycerides, and low-density lipoproteins (LDL), and increased high-density lipoproteins (HDL) in hyperlipidemic cohorts. ${ }^{30-35}$ Many of these studies were not randomized, did not have a placebo control, contained a limited number of individuals, and did not control for variations in patient diet or exclude those taking additional medications to lower serum cholesterol or lipid concentrations. A well-designed trial in 61 individuals was conducted in which subjects were given $50 \mathrm{mg}$ of standardized GGE containing $25 \mathrm{mg}$ of guggulsterones twice a day for 24 weeks, in combination with dietary interventions that were low in cholesterol and saturated fat and high in soluble fiber. ${ }^{12}$ Consumption of the GGE was associated with decreased cholesterol (12\%), LDL (12.5\%), triglycerides (12\%), and total cholesterol/HDL ratio 
(11.1\%). Following a 12-week wash-out period, however, blood lipoprotein concentrations were significantly increased in individuals that had been taking GGE compared to controls. A short-term study of gum guggul efficacy was conducted in a Western population of healthy adults in which standardized GGE at doses of 3,000 mg (75 mg guggulsterones) or 6,000 mg (150 mg guggulsterones) was administered daily for 8 weeks. In contrast to previous beneficial findings, consumption of GGE was associated with increased LDL-cholesterol in low- and high-dose groups of 4\% and 5\%, respectively; reduced HDL-cholesterol concentrations; and no change in other lipoprotein measurements. ${ }^{36}$ Stimulation of thyroid function has been reported in animal studies, but not observed in human clinical studies. ${ }^{37}$

\section{Regulatory Status}

Dietary supplements are classified by the U.S. Food and Drug Administration (FDA) as products containing vitamins, minerals, amino acids, other dietary/nutritional substances, or herbs and other botanical species that are intended to supplement the diet. ${ }^{38}$ Products containing gum guggul oleoresin, extract, or its constituents, are marketed as dietary supplements and are therefore regulated under the Dietary Supplement Health and Education Act of 1994. The FDA must monitor reports of adverse effects associated with dietary supplement use and prove a product is unsafe to restrict its use or remove it from the market. Because products in this class are not regulated as drugs, manufacturers must adhere to 21 U.S.C. 343(r)(6), Section 403(r)(6) of the Federal Food, Drug, and Cosmetic Act and not "claim to diagnose, mitigate, treat, cure, or prevent a specific disease or class of diseases.” Products may also be removed from market if the label is false or misleading, for example, if nutrient content information is false or misleading.

\section{Absorption, Distribution, Metabolism, Excretion, and Toxicokinetics}

GGEs are complex mixtures of numerous chemical constituents, which has hindered the ability to fully characterize their pharmacokinetic profiles. Studies of absorption, distribution, metabolism, and excretion (ADME) and toxicokinetic profiles of GGE in animal models appear limited to profiles of $Z$ - and $E$-guggulsterones. Review of the available literature revealed no adequate pharmacokinetic evaluations of GGE in humans.

\section{Experimental Animals}

Comparative pharmacokinetic profiles of Z-guggulsterone have been generated following a single oral administration (50 mg/kg) or intravenous administration (18 mg/kg) in male Sprague Dawley rats. ${ }^{39}$ Z-guggulsterone displayed partial isomerization to E-guggulsterone in rat serum samples. Absolute bioavailability of Z-guggulsterone following oral administration was 42.9\%, suggesting significant first pass metabolism. $\mathrm{C}_{\max }$ (maximum serum concentration) values of $1.07 \mu \mathrm{g} / \mathrm{mL}$ and $0.97 \mu \mathrm{g} / \mathrm{mL}$, terminal half-life values of 4.48 hours and 3.56 hours, and area under the curve (AUC) values of $5.95 \mu \mathrm{g} / \mathrm{mL}$ and $4.75 \mu \mathrm{g} / \mathrm{mL}$ were estimated for $Z$ - and E-guggulsterones, respectively. ${ }^{39}$ Further studies have investigated the pharmacokinetic behavior following oral (30 mg/kg) and intravenous $(10 \mathrm{mg} / \mathrm{mL})$ administration of a (1:1) racemic mixture of $Z$ - and $E$-guggulsterones, which better mimics the racemic mixture found in GGEs. ${ }^{40}$ The pharmacokinetic properties of $Z$ - and $E$-isomers showed high clearance relative to the hepatic plasma flow rate and short elimination half-lives of $0.63 \pm 0.25$ hours and $0.74 \pm 0.35$ hours, respectively. The observed in vivo clearance and low metabolic stability of guggulsterones 
following incubation with rat hepatic microsomes suggest increased metabolic lability and susceptibility to pre-systemic hepatic elimination. Pharmacokinetic parameters such as AUC, volume of distribution $\left(\mathrm{V}_{\mathrm{d}}\right)$, clearance, and half-life displayed no evidence of stereoselectivity on co-administration of guggulsterone racemates in rats. ${ }^{40}$ In contrast, pharmacokinetic parameters displayed stereoselectivity in male New Zealand rabbits following intravenous administration of a 1:1 Z- to $E$-guggulsterone mixture. ${ }^{41}$ This suggests distinct pharmacokinetic differences between rats and rabbits.

\section{Humans}

The metabolism of GGEs and guggulsterones in humans is not well documented. Yang et al. evaluated the metabolism and regulation of cholesterol signaling by Z-guggulsterone in pooled human hepatic microsomes. ${ }^{42}$ The authors found that contrary to prior assumptions,

Z-guggulsterone and its metabolites did not induce CYP7A1, but significantly increased bile salt excretion pump activity facilitating cholesterol elimination. Metabolism of $Z$-guggulsterone was associated with increased activity of multiple CYP450 enzymes, with CYP3A4 being the most active. ${ }^{42}$ Consumption of guggulipid $(1 \mathrm{~g})$ decreased the bioavailability of the prescribed medications propranolol and diltiazem in healthy male volunteers. ${ }^{43}$ This result indicates a potential for adverse botanical-drug interactions that could alter bioavailability, efficacy, or toxicity of prescription drugs when taken concomitantly with products containing GGE.

\section{Toxicity}

\section{Experimental Animals}

In mice intraperitoneally injected with a standardized GGE, the $\mathrm{LD}_{50}$ (median lethal dose) was $1.6 \mathrm{~g} / \mathrm{kg}(5.12082 \mathrm{mmol} / \mathrm{kg})$. In rats and mice orally administered the same GGE, the LD50 was $1.6 \mathrm{~g} / \mathrm{kg} .{ }^{44}$ The observed LD 50 of orally administered guggul essential oil in mice was $1.7 \mathrm{~g} / \mathrm{kg} .{ }^{45}$

No adverse effects were observed in subchronic and chronic toxicity studies in rats, dogs, or rhesus monkeys administered a standardized GGE containing 2.5-7\% Z- and E-guggulsterone (125-500 mg/kg) for 90-180 days. ${ }^{44}$ No mortality was observed in dogs administered 1 g GGE daily for 3 months. ${ }^{33}$ Rats administered GGE ( $250 \mathrm{mg} / \mathrm{kg}$ ) daily (route unspecified) for 3 months had a mortality rate of $50 \%$, relative to $20 \%$ in controls. ${ }^{33}$

Numerous reports suggest that alteration of thyroid signaling pathways contribute to purported effects on serum lipid and cholesterol concentrations. Increased serum triiodothyronine $\left(\mathrm{T}_{3}\right)$ and $\mathrm{T}_{3} / \mathrm{T}_{4}$ (total thyroxine) ratios were measured in mice administered $0.2 \mathrm{~g} / \mathrm{kg}$ GGE (approximately $11.5 \%$ guggulsterones) orally for 15 days. ${ }^{46}$ This study also found that GGE significantly decreased hepatic lipid peroxidation. Measurements of thyroid function parameters such as iodine uptake by the thyroid gland, thyroid enzyme activity, thyroid hormone release, and oxygen consumption in various tissue were elevated in albino rats following oral gavage of isolated Z-guggulsterone $(0.1 \mathrm{mg} / \mathrm{kg}) .^{37}$

\section{Humans}

Several mild adverse effects associated with GGE ingestion have been described from postmarket surveillance, clinical trials, and several patient case reports. Gastrointestinal distress was among the most common side effects reported, typically described as one or more of the 
following symptoms: upper gastric fullness, eructation, hiccough, loose stools, and diarrhea. These symptoms have been observed across numerous clinical trials investigating the effects of consuming raw guggul or standardized GGEs. ${ }^{32-34 ; 36}$ Hypersensitivity skin reactions were noted in a clinical trial, occurring in $15 \%$ of participants receiving $50 \mathrm{mg}$ of guggulsterones three times daily and in 3\% of participants receiving $25 \mathrm{mg}$ of guggulsterones three times daily. ${ }^{36 ; 26}$ Symptoms typically presented within 48 hours of beginning the therapy regimen and resolved within 1 week following discontinuation of treatment. Administration of GGE was associated with alteration of hematologic parameters such as inhibition of platelet aggregation and increased fibrinolysis. ${ }^{44 ; 4 ;} 48$ These biological activities could increase an individual's risk of bleeding, but such adverse events have not been reported.

Numerous case reports involving gum guggul use were identified in the available literature and the FDA MedWatch database. In one report, a 62-year-old male patient presented with loose stools after consuming $1 \mathrm{~g}$ of a standardized GGE three times daily for a week. This patient was also concurrently using a nicotine patch, aspirin, saw palmetto, and lycopene. ${ }^{49}$ In another case, a 63-year-old woman presented with severe hypertransaminasemia that had occurred following consumption of a red yeast rice extract supplement containing guggulsterols. ${ }^{50}$ By 2014, 17 cases of adverse effects associated with consumption of gum guggul-containing products had been reported..$^{51}$ In most cases, subjects had also consumed products that contained additional botanical ingredients associated with adverse outcomes, such as kava or ephedra, or were taking additional medications or dietary supplements in combination with gum guggul-containing products. The multi-ingredient nature of some consumed products or consumption of additional dietary supplements/medications is fundamentally confounding to assignments of causality. ${ }^{23}$

\section{Developmental and Reproductive Toxicity}

\section{Experimental Animals}

A limited number of developmental and reproductive toxicity studies were identified in the literature. In a study by Amma et al., administration of a gum guggul emulsion $(200 \mathrm{mg} / \mathrm{kg})$ or the acidic GGE fraction (20 mg/kg) to adult female albino rats for 7 days reduced reproductive organ weights (uterus, ovaries, and cervix). ${ }^{52}$ In the same study, increased concentrations of glycogen and sialic acid were measured in reproductive tissues of gum guggul-exposed rats, suggesting antifertility effects.

\section{Humans}

No reports of human developmental and reproductive toxicity associated with gum guggul or guggulsterone consumption were identified in the literature. Gum guggul is used traditionally as an emmenagogue and has been reported in clinical trials to shorten the menstrual cycle and increase menstrual blood flow. ${ }^{53 ; 27}$ According to the WHO, safety of gum guggul use during pregnancy has not yet been established; therefore, use should be discontinued during pregnancy and lactation. ${ }^{27}$

\section{Immunotoxicity}

Guggulsterone has been used in traditional medicine for its anti-inflammatory effects, and has been reported to inhibit proinflammatory signaling, transcription of nuclear factor-kappa B, and 
tumor cell proliferation. ${ }^{54}$ The National Toxicology Program (NTP) performed a 28-day study of a GGE formulation (Lot \# G51177/H, approximately 2.45\% total guggulsterone content) in female B6C3F1/N mice to evaluate potential effects on the immune system at dose concentrations ranging between 31.25 and $500 \mathrm{mg} / \mathrm{kg}$, using the methods described in Frawley et al. ${ }^{55}$ At the dose concentrations examined, the GGE formulation had no effect on the antibody formation in the hemolytic plaque assay, sheep red blood cell ELISA, or keyhole limpet hemocyanin ELISA, all indicators of effects on humoral immunity. In addition, no effects were observed in assays used to evaluate cell-mediated and innate immunity. Select data for these studies can be found in Appendix F.

\section{Carcinogenicity}

No 2-year carcinogenicity studies of gum guggul, GGEs, or guggulsterones were identified in the available literature.

\section{Genetic Toxicity}

Aqueous extracts of the gum guggul oleoresin ( $40 \mathrm{mg} /$ plate) were not mutagenic in Salmonella/microsome assays using S. typhimurium strains TA98 and TA100. Treatments using a hot aqueous extract of gum guggul oleoresin ( $40 \mathrm{mg} /$ plate) inhibited aflatoxin B1-mediated mutagenesis in S. typhimurium TA98 and TA100 strains. Intraperitoneal injection of aqueous GGEs at doses 10-40 times purported therapeutic doses produced no chromosomal damage or evidence of micronuclei in the bone marrow of treated TAI mice. ${ }^{56}$ Numerous reports suggest guggulsterone constituents can impart antimutagenic and antitumorigenic activities. ${ }^{57 ; 58}$

\section{Study Rationale}

GGE was nominated for study by the National Institute of Environmental Health Sciences due to widespread human exposure through increasing dietary supplement use, demonstrated metabolic and hormone-altering effects, and lack of adequate toxicological data. NTP conducted 28-day interim and 3-month studies to evaluate the toxic effects of a GGE formulation administered by oral gavage in male and female Hsd:Sprague Dawley ${ }^{\circledR} \mathrm{SD}^{\circledR}$ rats and B6C3F1/N mice. Twenty-eight-day interim studies were included to provide additional information pertaining to the temporality of GGE effects on thyroid hormone homeostasis, serum cholesterol/lipid concentrations, and CYP induction potential, and to detect early-induced histopathological lesions. 
Gum Guggul, NTP TOX 99

\section{Materials and Methods}

\section{Procurement and Characterization}

\section{Gum Guggul Extract Formulation}

Gugulipid $^{\circledR}$, a marketed gum guggul extract (GGE) formulation, was obtained from Sabinsa Corporation (Piscataway, NJ) in two lots (G51177/H and G60493/H). Identity, purity, and stability analyses were conducted by the analytical chemistry laboratory at MRIGlobal (Kansas City, MO) and by the study laboratory at Battelle (Columbus, $\mathrm{OH}$ ) (Appendix C). Reports on analyses performed in support of these GGE formulation studies are on file at the National Institute of Environmental Health Sciences (NIEHS).

Gugulipid $^{\circledR}$ is a cream-to-pale yellow granular powder. Analysis of lots G51177/H and G60493/H by high-performance liquid chromatography (HPLC) with ultraviolet detection (UV) showed the levels of $Z$ - and $E$-guggulsterone, respectively, to be $0.85 \%$ and $1.30 \%$ in lot $\mathrm{G} 60493 / \mathrm{H}$ and $1.14 \%$ and $1.31 \%$ in lot $\mathrm{G} 51177 / \mathrm{H}$. These were similar to the manufacturer-reported guggulsterone values of 2.53\% (lot G60493/H) and 2.7\% (lot G51177/H). The lots were combined by Battelle (Columbus, OH) to create lot 04172009 and were subjected to gravity sieve using an 80-mesh sieve. The material that passed through was assigned lot 07172009 . Sieving was done to remove large clumps/particles to enhance the homogeneity of the material and subsequently to aid in the gavagability of the dose formulations.

Lots 04172009 and 07172009 were analyzed by the study laboratory using infrared (IR) spectroscopy, nuclear magnetic resonance (NMR) spectroscopy, weight loss by drying, water content by Karl Fischer analysis, scanning electron microscopy (SEM) with energy dispersive X-ray spectroscopy (EDS), magnesium content by inductively coupled plasma-atomic emission mass spectrometry, X-ray diffraction (XRD), and mass spectrometry. The purity determination and quantitation of $Z$ - and E-guggulsterone content were conducted by HPLC/UV detection. An aliquot of lots 04172009 and 07172009 was submitted to Covance Laboratories, Inc. (Madison, WI) for nutritional and contaminant analyses.

Both IR and NMR spectra were complex, and signatures of gum guggul-specific constituents could not be confirmed (data not shown). XRD analysis showed the presence of magnesium oxide, hydrated magnesium carbonate, and talc as excipients. HPLC/UV analysis detected 79 peaks with areas greater than or equal to $0.05 \%$ for both lots. The levels of $Z$ - and E-guggulsterone, respectively, were $0.87 \%$ and $1.22 \%$ in lot 04172009 and $0.65 \%$ and $0.82 \%$ in lot 07172009 . Mass spectrometric analyses (lot 04172009 only) confirmed the presence of $Z$ - and E-guggulsterone, isomers of Z-guggulsterol, 20- $\beta$-hydroxy-4-pregnen-3-one, 20- $\alpha$-hydroxy-4pregnen-3-one, guggulsterol VI, and guggulsterol V. Contaminant analyses showed the presence of low levels of lead, antimony, molybdenum. Arsenic, aflatoxins (B1, B2, G1, G2), ochratoxin, and zearalenone could not be determined due to matrix interferences. Pesticide levels were below the limits of quantitation of 0.01 or $0.02 \mathrm{ppm}$. Detectable contaminant levels were below the threshold limits accepted for drug products and dietary supplements by the International Council for Harmonisation of Technical Requirements for Pharmaceuticals for Human Use and the American Herbal Products Association. ${ }^{59 ; 60}$ Summary results of these analyses are shown in Table 1. 
Individual aliquots of lot 07172009 were removed for use as frozen reference standards and archive samples. The remaining material of lot 07172009 was stored in large, amber plastic bags at room temperature.

Table 1. Summary of Results of Test Article Characterization

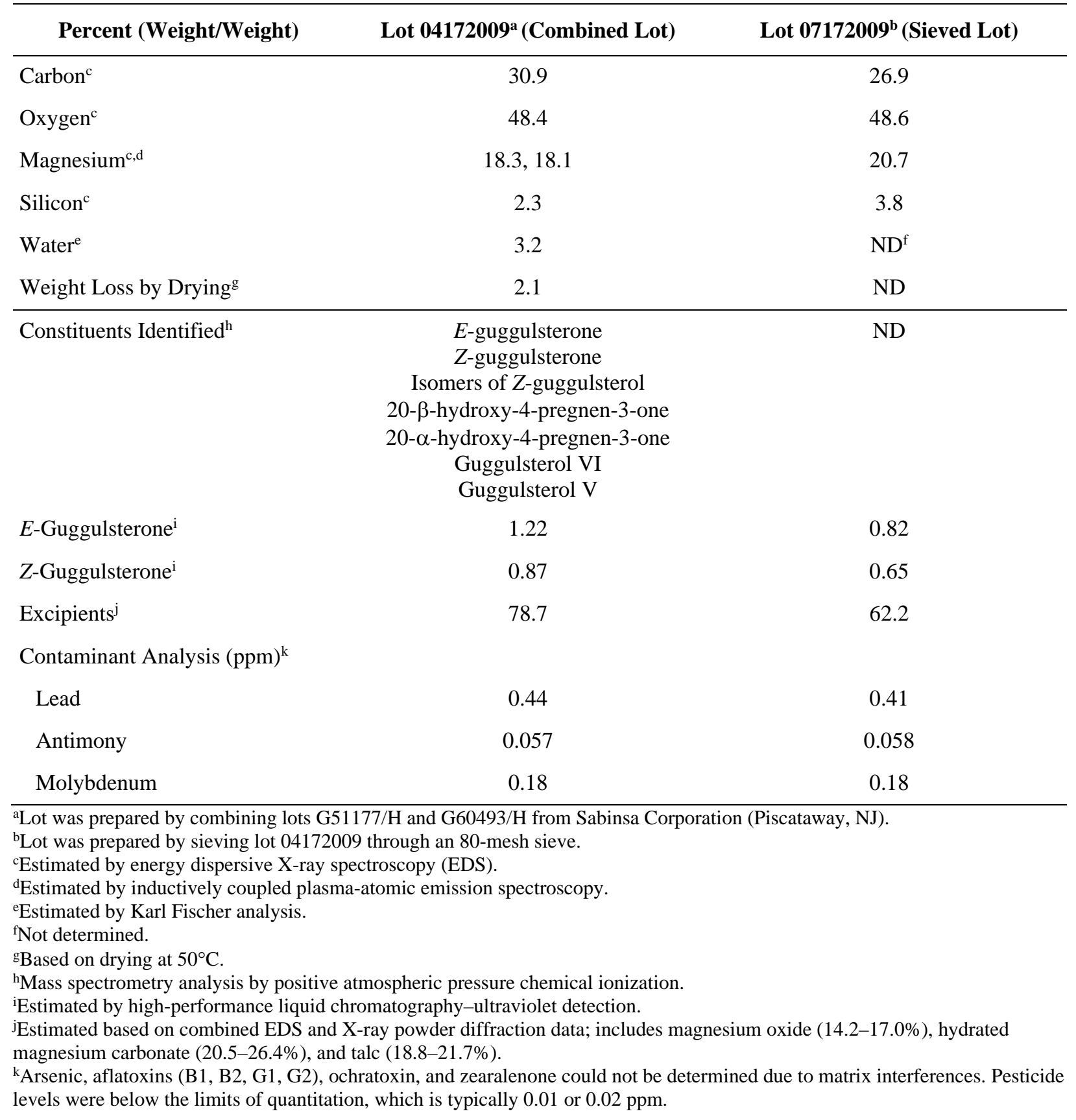

\section{Corn Oil}

Corn oil was obtained from Sigma-Aldrich (St. Louis, MO) in a single lot (128K0040), and used as the vehicle in the 3-month studies. Twice during the study period, potentiometric titration was used to determine the peroxide content, which was below the rejection level of $3 \mathrm{mEq} / \mathrm{kg}$. 


\section{Preparation and Analysis of Dose Formulations}

Dose formulations were prepared three times over the course of the study using the selected GGE formulation (lot 07172009) and corn oil (Table C-2). Formulations were prepared at concentrations of 12.5, 25, 50, 100, and $200 \mathrm{mg} / \mathrm{mL}$ (rats) and 1.55, 3.1, 6.25, 12.5, and $25 \mathrm{mg} / \mathrm{mL}$ (mice). Formulations were analyzed by quantitating combined $Z$ - and E-guggulsterone isomers using a validated HPLC/UV method. All pre- and postadministration samples were within $10 \%$ of the target concentrations and had relative standard deviations (RSDs) within 5\% (Table C-3).

Homogeneity studies of the 1.55, 12.5, 25, and $200 \mathrm{mg} / \mathrm{mL}$ formulations were also performed using HPLC/UV. RSDs were within 5\% of target for each concentration, and thus homogeneity was deemed sufficient. As the formulas were suspensions, continuous stirring was required to ensure homogeneity. Gavagability was confirmed using 25 and 200 mg/mL GGE formulations (lot 04172009) in corn oil.

Formulations were stored in sealed glass containers at concentrations of $1.55 \mathrm{mg} / \mathrm{mL}$ or higher at room temperature for up to 42 days. Stability of $Z$ - and $E$-guggulsterone isomers was confirmed for these conditions up to 42 days.

\section{Animal Source}

Male and female Sprague Dawley (Hsd:Sprague Dawley ${ }^{\circledR} \mathrm{SD}^{\circledR}$ ) rats were obtained from Harlan Laboratories, Inc. (now Envigo; Indianapolis, IN). B6C3F1/N mice were obtained from the National Toxicology Program (NTP) colony maintained at Taconic Biosciences, Inc. (Germantown, NY).

\section{Animal Welfare}

Animal care and use were in accordance with Public Health Service Policy on Humane Care and Use of Animals. All animal studies were conducted in an animal facility accredited by AAALAC International. Studies were approved by the Battelle Animal Care and Use Committee and conducted in accordance with all relevant National Institutes of Health and NTP animal care and use policies and applicable federal, state, and local regulations and guidelines.

\section{Dose Selection Rationale}

Initial dose selection for studies was confounded by the limited availability of toxicity studies in the literature and the inherent chemical variability among previously tested GGEs relative to the tested formulation. Dose concentrations selected for this study were limited to GGE formulation preparations that demonstrated adequate syringability and gavagability. For rat studies, concentrations of up to $200 \mathrm{mg} / \mathrm{mL}$ to be administered at $5 \mathrm{~mL} / \mathrm{kg}$ were passable through an 18-gauge gavage needle. Therefore, rats received the selected GGE formulation (lot 07172009) in corn oil vehicle via gavage at $0,62.5,125,250,500$, and $1,000 \mathrm{mg} / \mathrm{kg} / \mathrm{day}$, corresponding to 0 , 0.91,1.8, 3.7, 7.4, and $14.7 \mathrm{mg}$ guggulsterones/kg/day, respectively. Lower relative doses were selected for the mouse studies due to syringability issues related to the use of a smaller gauge gavage needle. For the mouse studies, concentrations of up to $25 \mathrm{mg} / \mathrm{mL}$ to be administered at $10 \mathrm{~mL} / \mathrm{kg}$ were passable through a 20-gauge gavage needle. Mice received the selected GGE formulation (lot 07172009 ) in corn oil vehicle via gavage at $0,15.5,31.0,62.5,125$, and 
$250 \mathrm{mg} / \mathrm{kg} / \mathrm{day}$, corresponding to $0,0.23,0.46,0.92,1.8$, and $3.7 \mathrm{mg}$ guggulsterones $/ \mathrm{kg} / \mathrm{day}$, respectively. Maximum administered doses were lower than the previously reported $\mathrm{LD}_{50}$ of orally administered guggul essential oil at $1,700 \mathrm{mg} / \mathrm{kg}$ in mice..$^{45}$ Moreover, the test formulation contained a limited fraction of gum guggul ethyl acetate extract (approximately 1.47\% guggulsterone content), suggesting limited concern of potential lethality at the selected doses.

\section{Three-month and Twenty-eight-day Interim Studies}

Rats and mice were approximately 4 to 5 weeks old on receipt. Animals were quarantined for 10 (rats) or 14 (mice) days, and both rats and mice were approximately 6 to 8 weeks old on the first day of the studies. Before the studies began, five male and five female rats and mice were randomly selected for parasite evaluation and gross observation for evidence of disease. Additionally, the health of the animals was monitored during the studies according to the protocols of the NTP Sentinel Animal Program (Appendix E). All test results were negative (Table E-1).

Groups of 10 male and 10 female core study rats and 15 male and 15 female core study mice were administered 0, 62.5, 125, 250, 500, or 1,000 mg GGE formulation/kg body weight/day (rats) and 0, 15.5, 31, 62.5, 125, or $250 \mathrm{mg}$ GGE formulation/kg body weight/day (mice) in corn oil by gavage 5 days per week for 3 months. Vehicle control animals were administered the corn oil vehicle alone; dosing volumes were $5 \mathrm{~mL} / \mathrm{kg}$ for rats and $10 \mathrm{~mL} / \mathrm{kg}$ for mice. Additional groups of 10 male and 10 female interim study rats or mice were administered the same doses by gavage for 28 days. Feed and water were available ad libitum. Rats and mice were housed individually (male mice) or up to five per cage (male and female rats, female mice). Rats and mice were observed twice daily for signs of mortality or moribundity. Clinical findings and body weights were recorded initially, weekly, and at the end of the studies. Details of the study design and animal maintenance are summarized in Table 2.

Blood was collected from the retroorbital plexus (rats) or sinus (mice) of interim study animals on day 28 (interim study) and of core study animals at the end of the 3-month studies for hematology, clinical chemistry (rats only), and thyroid hormone (rats only) analyses. Animals were anesthetized with a carbon dioxide/oxygen mixture and bled in a random order. Blood was collected into tubes containing ethylenediaminetetraacetic acid (EDTA) for hematology or into serum separator tubes for clinical chemistry. Hematology parameters were analyzed using the Advia 120 (Bayer Diagnostics Division, Tarrytown, NY). Clinical chemistry parameters, including total thyroxine ( $\mathrm{T}_{4}$ ), were analyzed using the Roche cobas c501 Chemistry Analyzer (Roche, Indianapolis, IN). Levels of serum thyroid stimulating hormone (TSH), total triiodothyronine ( $\left.\mathrm{T}_{3}\right)$, and free $\mathrm{T}_{4}$ were determined by radioimmunoassay on a Packard cobra II gamma counter (Perkin Elmer, Waltham, MA). The parameters measured are listed in Table 2.

At the end of the 3-month studies, samples were collected for sperm motility and vaginal cytology evaluations on rats in the $0,250,500$, and $1,000 \mathrm{mg} / \mathrm{kg} / \mathrm{day}$ groups and mice in the 0 , $62.5,125$, and $250 \mathrm{mg} / \mathrm{kg} /$ day groups. The parameters evaluated are listed in Table 2. For 16 consecutive days prior to scheduled study termination, the vaginal vaults of the females were moistened with saline, if necessary, and samples of vaginal fluid and cells were collected and subsequently stained. Relative numbers of leukocytes, nucleated epithelial cells, and large squamous epithelial cells were determined and used to ascertain estrous cycle stage (i.e., diestrus, proestrus, estrus, and metestrus). Due to low cellularity, estrous cyclicity could not be 
determined for female rats and mice. Estrous cyclicity was evaluated in female mice; however, missing values in the data set precluded conclusive interpretations regarding effects of the administered the GGE formulation. Measured parameters of cycle length, number of cycles, and time spent in any specific stage of the estrous cycle of female mice can be found in (Appendix A). Male animals were evaluated for sperm count and motility. The left testis and left epididymis were isolated and weighed. The tail of the epididymis (cauda epididymis) was then removed from the epididymal body (corpus epididymis) and weighed. Test yolk (rats) or modified Tyrode's buffer (mice) was applied to slides and a small incision was made at the distal border of the cauda epididymis. The sperm effluxing from the incision were dispersed in the buffer on the slides, and the numbers of motile and nonmotile spermatozoa were counted for five fields per slide by two observers. Following completion of sperm motility estimates, each left cauda epididymis was placed in buffered saline solution. Caudae were finely minced, and the tissue was incubated in the saline solution and then heat fixed at $65^{\circ} \mathrm{C}$. Sperm density was determined microscopically with the aid of a hemocytometer. To quantify spermatogenesis, the testicular spermatid head count was determined by removing the tunica albuginea and homogenizing the left testis in phosphate-buffered saline containing $10 \%$ dimethyl sulfoxide. Homogenization-resistant spermatid nuclei were counted with a hemocytometer.

At the 28-day interim and at study termination, a section of the left lateral lobe of the liver was collected from 10 rats/sex/dose group and 5 mice/sex/dose group, minced, frozen in liquid nitrogen, and stored frozen at $-80^{\circ} \mathrm{C}$ to $-60^{\circ} \mathrm{C}$. Microsomal suspensions were prepared and the liver tissue was analyzed for the microsomal mixed-function oxidase activity of CYP3A and CYP2B.

Necropsies were performed on all core study animals, with the exception of the five mice/sex/dose group used for CYP evaluations. Organ weights were determined for the heart, right kidney, liver, lung, spleen, right testis, and thymus from 5 (interim study) or 10 (core study) mice/sex/dose group and all rats. Tissues for microscopic examination were fixed and preserved in 10\% neutral buffered formalin (except eyes, which were first fixed in Davidson's solution, and testes, vaginal tunics, and epididymides, which were first fixed in modified Davidson's solution), processed and trimmed, embedded in paraffin, sectioned to a thickness of 4 to $6 \mu \mathrm{m}$, and stained with hematoxylin and eosin. Complete histopathologic examinations were performed by the study laboratory pathologist on all vehicle control and 1,000 mg/kg/day rats and all vehicle control group and $250 \mathrm{mg} / \mathrm{kg} /$ day mice. Table 2 lists the tissues and organs routinely examined.

After a review of the laboratory reports and selected histopathology slides by a quality assessment (QA) pathologist, the findings and reviewed slides were submitted to an NTP Pathology Working Group (PWG) coordinator for a second independent review. Any inconsistencies in the diagnoses made by the study laboratory and QA pathologists were resolved by the NTP pathology peer-review process. Final diagnoses for reviewed lesions represent a consensus of the PWG or a consensus between the study laboratory pathologist, NTP pathologist, QA pathologist(s), and the PWG coordinator. Details of these review procedures have been described, in part, by Maronpot and Boorman ${ }^{61}$ and Boorman et al. ${ }^{62}$ 
Table 2. Experimental Design and Material and Methods in the Three-month and 28-day Interim Gavage Studies of a Gum Guggul Extract Formulation

Three-month and 28-day Interim Studies

Study Laboratory

Battelle (Columbus, OH)

Strain and Species

Sprague Dawley (Hsd:Sprague Dawley ${ }^{\circledR} \mathrm{SD}^{\circledR}$ ) rats

B6C3F1/N mice

\section{Animal Source}

Rats: Harlan Laboratories, Inc. (now Envigo, Indianapolis, IN)

Mice: Taconic Biosciences, Inc. (Germantown, NY)

Time Held before Studies

Rats: 10 days

Mice: 14 days

Average Age When Studies Began

6 to 8 weeks

\section{Date of First Dose}

Rats: July 23 (males) or 24 (females), 2009

Mice: July 30 (females) or 31 (males), 2009

\section{Duration of Dosing}

5 days a week for 4 (interim study) or 14 (core study) weeks

\section{Date of Last Dose}

Rats: October 21 (males) or 22 (females), 2009

Mice: October 28 (females) or 29 (males), 2009

\section{Necropsy Dates}

Interim study (day 28):

Rats: August 19 (males) or 20 (females), 2009

Mice: August 26 (females) or 27 (males), 2009

Core study (day 92):

Rats: October 22 (males) or 23 (females), 2009

Mice: October 29 (females) or 30 (males), 2009

\section{Average Age at Necropsy}

Interim study (day 28): 10 to 12 weeks

Core study (day 92): 19 to 21 weeks

\section{Size of Study Groups}

Rats: 10 males and 10 females (interim study and core study)

Mice: 10 males and 10 females (interim study), 15 males and 15 females (core study)

\section{Method of Distribution}

Animals were distributed randomly into groups of approximately equal initial mean body weights.

\section{Animals per Cage}

Rats: Up to 5

Mice: 1 (male), 5 (females)

Method of Animal Identification

Tail tattoo 


\section{Three-month and 28-day Interim Studies}

Diet

Irradiated NTP-2000 open formula wafer feed (Zeigler Brothers, Inc., Gardners, PA), available ad libitum, changed at least weekly

Water

Tap water (City of Columbus, OH municipal supply) via automatic watering system (Edstrom Industries, Inc., Waterford, WI), available ad libitum

Cages

Polycarbonate (Lab Products, Inc., Seaford, DE), changed at least twice (rats, female mice) or once (male mice) weekly

Bedding

Heat-treated, irradiated hardwood Sani-Chips ${ }^{\circledR}$ (P.J. Murphy Forest Products Corp., Montville, NJ), changed at least twice (rats, female mice) or once (male mice) weekly

Rack Filters

Spun-bonded polyester (Snow Filtration Company, Cincinnati, OH), changed every 2 weeks

Racks

Stainless steel (Lab Products, Inc., Seaford, DE), changed every 2 weeks

Animal Room Environment

Temperature: $70^{\circ} \mathrm{F}-76^{\circ} \mathrm{F}$ (rats), $69^{\circ} \mathrm{F}-74^{\circ} \mathrm{F}$ (mice)

Relative humidity: 39\%-58\% (rats), 38\%-89\% (mice)

Room fluorescent light:12 hours/day

Room air changes: at least 10/hour

Doses

Rats: 0 (vehicle control), 62.5, 125, 250, 500, 1,000 mg/kg/day

Mice: 0 (vehicle control), 15.5, 31, 62.5, 125, 250 mg/kg/day

\section{Type and Frequency of Observation}

Observed twice daily; animals were weighed, and clinical observations were recorded initially, weekly thereafter, and at the end of the studies.

\section{Method of Euthanasia}

$100 \%$ carbon dioxide

\section{Necropsy}

Necropsies were performed on all animals. Organs weighed were heart, right kidney, liver, lung, right testis, and thymus.

\section{Clinical Pathology}

Blood was collected from the retroorbital plexus and the retroorbital sinus, respectively, of the interim study rats and mice on day 28 and from the core study rats and mice at the end of the study for clinical chemistry, thyroid hormones, and hematology in rats and clinical chemistry in mice.

Hematology: hematocrit, hemoglobin, erythrocyte, reticulocyte, platelet counts, mean cell volume, mean cell hemoglobin, mean cell hemoglobin concentration, and leukocyte count and differentials Clinical chemistry (rats): urea nitrogen, creatinine, glucose, total protein, albumin, globulin, A:G ratio, cholesterol, triglycerides, alanine aminotransferase, alkaline phosphatase, creatine kinase, sorbitol dehydrogenase, bile acids, and phospholipids

Clinical chemistry (mice): glucose, cholesterol, triglycerides, and phospholipids

Thyroid hormones: total and free thyroxine, thyroid stimulating hormone, and total triiodothyronine 
Gum Guggul, NTP TOX 99

Three-month and 28-day Interim Studies

\begin{abstract}
Histopathology
Complete histopathology was performed on rats in the vehicle control and $1,000 \mathrm{mg} / \mathrm{kg} / \mathrm{day}$ groups and mice in the vehicle control and $250 \mathrm{mg} / \mathrm{kg} /$ day groups. In addition to gross lesions and tissue masses, the following tissues were examined: adrenal glands, bone (femur) with marrow, brain, carcass, clitoral glands, epididymides, esophagus, eyes, gallbladder (mice), heart and aorta, large intestine (cecum, colon, and rectum), small intestine (duodenum, jejunum, and ileum), kidneys, liver, lungs and mainstem bronchi, lymph nodes (mandibular and mesenteric), mammary gland and adjacent (inguinal) skin, nasal cavity with turbinates, ovaries, pancreas, parathyroid glands, pituitary gland, preputial glands, prostate, salivary glands, seminal vesicles, spinal cord, spleen, stomach (forestomach and glandular), testes, thymus, thyroid gland, trachea, urinary bladder, and uterus.
\end{abstract}

\title{
Sperm Motility and Vaginal Cytology
}

At the end of the studies, sperm samples were collected from male rats in the vehicle control, 250, 500, and $1,000 \mathrm{mg} / \mathrm{kg} /$ day groups and male mice in the vehicle control, 62.5, 125, and $250 \mathrm{mg} / \mathrm{kg} /$ day groups for sperm motility evaluations. The following parameters were evaluated: spermatid heads per testis and per gram testis, and epididymal spermatozoal motility and concentration. The left cauda, left epididymis, and left testis were weighed. Vaginal samples were collected for up to 16 consecutive days prior to the end of the studies from female rats in the vehicle control, 250, 500, and 1,000 mg/kg/day groups and female mice in the vehicle control, 62.5, 125, and $250 \mathrm{mg} / \mathrm{kg} /$ day groups for vaginal cytology evaluations.

\section{Cytochrome P450 Studies}

At the day 28 interim and at study termination, a section of the left lateral lobe of the liver was collected for CYP evaluation. Microsomal suspensions were prepared and analyzed for the microsomal mixed-function oxidase activity of CYP2B and CYP3A.

\section{Statistical Methods}

\section{Calculation and Analysis of Nonneoplastic Lesion Incidences}

The incidences of nonneoplastic lesions are presented as numbers of animals bearing such lesions at a specific anatomic site and the numbers of animals with that site examined microscopically. The Fisher exact test, ${ }^{63}$ a procedure based on the overall proportion of affected animals, was used to determine significance between exposed and vehicle control animals, and the Cochran-Armitage trend test was used to test for significant trends. ${ }^{64}$

\section{Analysis of Continuous Variables}

Two approaches were employed to assess the significance of pairwise comparisons between dosed and control groups in the analysis of continuous variables. Organ and body weight data, which historically have approximately normal distributions, were analyzed with the parametric multiple comparison procedures of Dunnett ${ }^{65}$ and Williams. ${ }^{66 ; 67}$ Hematology, hormone data, clinical chemistry, spermatid, and epididymal spermatozoal data, which have typically skewed distributions, were analyzed using the nonparametric multiple comparison methods of Shirley ${ }^{68}$ (as modified by Williams ${ }^{69}$ ) and Dunn. ${ }^{70}$ Jonckheere's test $^{71}$ was used to assess the significance of the dose-related trends and to determine whether a trend-sensitive test (the Williams or Shirley tests) was more appropriate for pairwise comparisons than would be a test that does not assume a monotonic dose-related trend (Dunnett's or Dunn's test). Prior to statistical analysis, extreme values identified by the outlier test of Dixon and Massey ${ }^{72}$ were examined by NTP personnel, and implausible values were eliminated from the analysis.

For the human in vitro activity assays, the data were assumed to have a skewed distribution and were analyzed using Jonckheere's (trend) and Shirley's or Dunn’s (pairwise) tests, as described 
above. For the pairwise comparisons of positive control to negative control for these data, Wilcoxon ${ }^{73}$ rank-sum tests were used.

\section{Quality Assurance Methods}

The 3-month studies were conducted in compliance with FDA Good Laboratory Practice Regulations. ${ }^{74}$ In addition, as records from the 3-month studies were submitted to the NTP Archives, these studies were audited retrospectively by an independent QA contractor. Separate audits covered completeness and accuracy of the pathology data, pathology specimens, final pathology tables, and a draft of this NTP Toxicity Study Report. Audit procedures and findings are presented in the reports and are on file at NIEHS. The audit findings were reviewed and assessed by NTP staff, and all comments were resolved or otherwise addressed during the preparation of this Toxicity Study Report.

\section{Genetic Toxicity}

\section{In Vivo Erythrocyte Micronucleus Assay}

Peripheral blood samples collected in EDTA tubes from male and female B6C3F1/N mice and Sprague Dawley rats after 3 months of gavage exposure were shipped on ice packs by overnight courier to the analytical laboratory and processed for flow cytometric evaluation of micronucleated reticulocytes (RET; polychromatic erythrocytes, PCE) and mature erythrocytes (normochromatic erythrocytes; NCE) as described previously. ${ }^{75}$ Briefly, on arrival at the laboratory, cells were fixed in ultracold methanol and labeled using a MicroFlow ${ }^{\text {PLUS }}$ Kit (Litron Laboratories, Rochester, NY) according to the manufacturer's instructions. For each blood sample, 20,000 immature reticulocytes (as determined by the presence of an active CD71 transferrin receptor on the cell surface) and approximately $10^{6}$ mature erythrocytes (CD71) were analyzed using a flow cytometer to determine the frequency of micronucleated cells of each type $;^{76}$ in addition, the percentage of reticulocytes among total erythrocytes was calculated as a measure of bone marrow toxicity.

\section{Data Analysis}

Prior experience with the large number of cells scored using flow cytometric scoring techniques ${ }^{77 ; 76}$ suggests it is reasonable to assume that the proportion of micronucleated reticulocytes is approximately normally distributed. NTP uses Levene's test at $\alpha=0.05$ to test for equal variances among the treatment groups. In the case of equal variances, linear regression was used to test for a dose-related trend, and the Williams test ${ }^{66 ; 67}$ was used to test for pairwise differences between each treatment group and the vehicle control group. In the case of unequal variances, Jonckheere's test ${ }^{71}$ was used to test for a linear trend and pairwise differences with the vehicle control group were tested using Dunn's test. ${ }^{70}$ Trend tests and pairwise comparisons with the vehicle controls are considered statistically significant for PCEs and NCEs when the one-sided p value is less than 0.025, and for percent PCEs when the two-sided p value is less than 0.05. Bonferroni's method was used to adjust for multiple comparisons. 


\section{Human In Vitro Activity Assays}

The effects of a GGE formulation (lot G51177/H), Z-guggulsterone, and E-guggulsterone on CYP enzyme activity, P-glycoprotein (Pgp), and human $\mathrm{Na}^{+}$taurocholate cotransporting polypeptide (hNTCP) activity were evaluated using human in vitro activity assays. $Z$ - and E-guggulsterones were acquired from ChromaDex (Santa Ana, CA). The guggulsterone content of the GGE formulation was determined using a previously established HPLC method. ${ }^{8}$ Guggulsterones were detected and quantified via measurement of UV absorbance at $248 \mathrm{~nm}$.

\section{Cytochrome P450 Activity Assays}

Human liver microsomes were acquired from CellzDirect (Pittsboro, NC). Microsomes were incubated with the GGE formulation, Z-guggulsterone, or E-guggulsterone, all normalized to 0.3, 1.0 , or $10 \mu \mathrm{M}$ guggulsterones. Following incubation, specific assay reaction mixtures were added for determination of CYP enzyme activity; details are provided in Table 3.

\section{P-glycoprotein ATPase Assay}

Human Pgp, expressed in a baculovirus expression system, was obtained from BD Biosciences (Woburn, MA) for evaluating ATPase activity. Pgp membranes were incubated with 0, 0.3, 1, or $10 \mu \mathrm{M}$ of the GGE formulation, Z-guggulsterone, or E-guggulsterone, all normalized to 0.3, 1, or $10 \mu \mathrm{M}$ guggulsterones; verapamil was used as a positive control. Additional control mixtures were prepared containing sodium orthovanadate, an inhibitor of Pgp, to determine non-Pgp mediated ATPase activity. Reactions were initiated via addition of MgATP and the liberation of inorganic phosphate was quantified by measuring absorbance at $630 \mathrm{~nm}$.

\section{$\mathrm{Na}^{+}$-Taurocholate Cotransporting Polypeptide Activity Assay}

Xenopus laevis oocytes expressing hNTCP were obtained from BD Biosciences (Woburn, MA) and used to evaluate the effects of a GGE formulation on human NTCP-mediated transporter activity. Oocytes were incubated with sodium uptake buffer, $\left[{ }^{3} \mathrm{H}\right]$ taurocholic acid, and the GGE formulation normalized to $0,0.3$, 1 , or $10 \mu \mathrm{M}$ guggulsterones. Radioactivity in oocytes was determined by liquid scintillation spectroscopy. 
Table 3. Summary of Cytochrome P450 Activity Assays

\begin{tabular}{|c|c|c|}
\hline CYP & Enzymatic Marker & Assay Reaction Mixture \\
\hline CYP1A2 ${ }^{\mathrm{a}}$ & Phenacetin O-deethylase activity & $\begin{array}{l}\text { Potassium phosphate buffer }(0.1 \mathrm{M}) \text {, NADPH }(1 \mathrm{mM}) \text {, microsomal } \\
\text { protein }(0.8 \mathrm{mg}) \text {, phenacetin }(50 \mu \mathrm{M})\end{array}$ \\
\hline CYP2A6 ${ }^{\mathrm{b}}$ & Coumarin-7-hydroxylation & $\begin{array}{l}\text { Potassium phosphate buffer }(100 \mathrm{mM}) \text {, EDTA }(1 \mathrm{mM}), \mathrm{NADPH} \\
(10 \mathrm{mM}) \text {, microsomal protein }(0.01 \mathrm{mg}) \text {, coumarin }(5 \mu \mathrm{M})\end{array}$ \\
\hline CYP2C8 & Paclitaxel $6 \alpha$-hydroxylation & $\begin{array}{l}\text { Potassium phosphate buffer (100 mM), } \mathrm{MgCl}_{2}(3.3 \mathrm{mM}), \mathrm{NADPH} \\
(1 \mathrm{mM}), \text { microsomal protein }(0.2 \mathrm{mg}) \text {, paclitaxel }(20 \mu \mathrm{M})\end{array}$ \\
\hline CYP2C9 & Tolbutamide hydroxylation & $\begin{array}{l}\text { Phosphate buffer }(0.1 \mathrm{M}), \mathrm{NADPH}(1 \mathrm{mM}) \text {, microsomal protein } \\
(0.2 \mathrm{mg}) \text {, tolbutamide }(240 \mu \mathrm{M})\end{array}$ \\
\hline CYP2C19 & Mephenytoin-4-hydroxylation & $\begin{array}{l}\text { Potassium phosphate buffer }(100 \mathrm{mM}) \text {, EDTA }(1 \mathrm{mM}), \text { NADPH } \\
(1 \mathrm{mM}) \text {, microsomal protein }(0.08 \mathrm{mg}),(\mathrm{S}) \text {-mephenytoin }(0.1 \mathrm{mM})\end{array}$ \\
\hline CYP2E1 $1^{\mathrm{e}}$ & p-Nitrophenol hydroxylation & $\begin{array}{l}\text { Ascorbate (1 mM), NADPH (1 mM), microsomal protein (1 mg), } \\
\text { p-nitrophenol }(0.1 \mathrm{M})\end{array}$ \\
\hline CYP2D6 ${ }^{f}$ & Dextromethorphan O-demethylation & $\begin{array}{l}\text { Phosphate buffer }(0.1 \mathrm{M}) \text {, NADPH }(1 \mathrm{mM}) \text {, microsomal protein } \\
(0.02 \mathrm{mg}) \text {, dextromethorphan hydrobromide }(20 \mu \mathrm{M})\end{array}$ \\
\hline CYP4A119 & Lauric acid $\omega$-hydroxylation & $\begin{array}{l}\text { Tris buffer }(50 \mathrm{mM}) \text {, NADPH }(0.44 \mathrm{mM}) \text {, microsomal protein } \\
(0.6 \mathrm{mg}),\left[{ }^{14} \mathrm{C}\right] \text { lauric acid }(0.1 \mu \mathrm{Ci}, 20 \mathrm{mM})\end{array}$ \\
\hline \multirow[t]{2}{*}{ CYP3A $4^{\mathrm{h}}$} & Midazolam 1-hydroxylation & $\begin{array}{l}\text { Phosphate buffer ( } 50 \mathrm{mM}), \mathrm{NADPH}(1 \mathrm{mM}) \text {, microsomal protein } \\
(0.06 \mathrm{mg}) \text {, midazolam }(6 \mu \mathrm{M})\end{array}$ \\
\hline & $\begin{array}{l}\text { Testosterone } 6 \beta \text {-hydroxylase } \\
\text { activity }\end{array}$ & $\begin{array}{l}\text { Potassium phosphate buffer ( } 50 \mu \mathrm{mol}) \text {, sucrose }(25 \mu \mathrm{mol}), \mathrm{MgCl}_{2} \\
(1.5 \mu \mathrm{mol}) \text {, NADPH }(0.5 \mu \mathrm{mol}) \text {, microsomal protein }(0.05 \mathrm{mg}) \text {, } \\
\text { testosterone ( } 125 \mathrm{nmol})\end{array}$ \\
\hline
\end{tabular}

NADPH $=$ reduced nicotinamide adenine dinucleotide phosphate.

${ }^{a}$ Activity measured as described by BD Biosciences (Woburn, MA).

${ }^{\mathrm{b}}$ Activity measured using the methods of Hickman et al. ${ }^{78}$

cActivity measured using a modified method of Harris et al. ${ }^{79}$

${ }^{\mathrm{d} A c t i v i t y}$ measured using the methods of Miners et al. ${ }^{80}$

eActivity measured using the methods of Koop. ${ }^{81}$

${ }^{\mathrm{f}}$ Activity measured using the methods of Hickman et al. ${ }^{78}$ with a modification of the HPLC analysis method of Laurenzana et al. ${ }^{82}$ ${ }^{\text {g} A c t i v i t y ~ m e a s u r e d ~ u s i n g ~ t h e ~ m e t h o d s ~ o f ~ C l a r k e ~ e t ~ a l . ~}{ }^{83}$

${ }^{\mathrm{h}}$ Activity measured using the methods of Patki et al. ${ }^{84}$ (midazolam) or Wood et al. ${ }^{85}$ (testosterone). 


\section{Results}

\section{Data Availability}

The National Toxicology Program (NTP) evaluated all study data. Data relevant for evaluating toxicological findings are presented here. All study data are available in the NTP Chemical Effects in Biological Systems (CEBS) database: https://doi.org/10.22427/NTP-DATA-TOX99. ${ }^{86}$

\section{Rats}

\section{Twenty-eight-day Interim Study}

All rats survived to the end of the study (Table 4). There were no significant treatment-related clinical observations in male or female rats. The final mean body weights of male and female rats in all dosed groups remained within $5 \%$ of the vehicle control body weights (Table 4).

Table 4. Survival and Body Weights of Rats in the Interim 28-day Gavage Study of Gum Guggul Extract $^{\mathrm{a}}$

\begin{tabular}{|c|c|c|c|c|c|}
\hline $\begin{array}{l}\text { Concentration } \\
\text { (mg/kg/day) }\end{array}$ & Survival $^{\mathrm{b}}$ & $\begin{array}{c}\text { Initial Body } \\
\text { Weight } \\
\text { (g) }\end{array}$ & $\begin{array}{c}\text { Final Body } \\
\text { Weight } \\
\text { (g) }\end{array}$ & $\begin{array}{c}\text { Changes in } \\
\text { Body Weight } \\
\text { (g) }\end{array}$ & 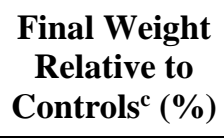 \\
\hline \multicolumn{6}{|l|}{ Male } \\
\hline 0 & $10 / 10$ & $160.8 \pm 4.0$ & $299.5 \pm 5.5$ & $138.7 \pm 3.2$ & - \\
\hline 62.5 & $10 / 10$ & $160.9 \pm 2.9$ & $298.4 \pm 5.2$ & $137.5 \pm 3.4$ & -0.39 \\
\hline 125 & $10 / 10$ & $160.5 \pm 2.5$ & $295.1 \pm 7.0$ & $134.6 \pm 5.5$ & -1.47 \\
\hline 250 & $10 / 10$ & $161.6 \pm 3.6$ & $297.2 \pm 6.9$ & $135.6 \pm 4.2$ & -0.79 \\
\hline 500 & $10 / 10$ & $161.5 \pm 2.4$ & $300.5 \pm 6.6$ & $139.0 \pm 6.2$ & 0.32 \\
\hline 1,000 & $10 / 10$ & $162.0 \pm 3.3$ & $309.0 \pm 5.7$ & $147.0 \pm 5.6$ & 3.16 \\
\hline \multicolumn{6}{|l|}{ Female } \\
\hline 0 & $10 / 10$ & $120.3 \pm 2.1$ & $196.3 \pm 2.4$ & $76.0 \pm 2.7$ & - \\
\hline 62.5 & $10 / 10$ & $119.7 \pm 2.6$ & $191.9 \pm 4.2$ & $72.3 \pm 2.8$ & -2.24 \\
\hline 125 & $10 / 10$ & $120.3 \pm 2.7$ & $188.6 \pm 4.2$ & $68.3 \pm 2.6$ & -3.93 \\
\hline 250 & $10 / 10$ & $119.1 \pm 2.5$ & $188.4 \pm 4.8$ & $69.3 \pm 3.3$ & -4.04 \\
\hline 500 & $10 / 10$ & $119.6 \pm 2.0$ & $199.2 \pm 3.6$ & $79.6 \pm 3.5$ & 1.49 \\
\hline 1,000 & $10 / 10$ & $120.4 \pm 2.7$ & $200.7 \pm 4.5$ & $80.3 \pm 3.1$ & 2.25 \\
\hline
\end{tabular}

${ }^{a}$ Weights and weight changes are given as mean \pm standard error. Differences from the vehicle control group are not significant by Dunnett's test.

bNumber of animals surviving at 28 days/number initially in group.

'[(dosed group mean - control group mean)/control group mean $] \times 100$.

Dose-related increases in absolute and relative liver weights were observed in male and female rats (Table 5). The mean absolute liver weights were significantly greater than those of vehicle controls in 1,000 mg/kg/day males (approximately 15\%) and in 500 and 1,000 mg/kg/day 
females (approximately 16\% and 30\%, respectively). Relative liver weights were significantly greater than those of vehicle controls in $1,000 \mathrm{mg} / \mathrm{kg} /$ day males and females administered $125 \mathrm{mg} / \mathrm{kg} /$ day or greater. A dose-related increase in absolute kidney weights was observed in female rats. The mean absolute and relative kidney weights of $1,000 \mathrm{mg} / \mathrm{kg} / \mathrm{day}$ females were significantly greater than those of vehicle controls. The mean absolute kidney weight of $1,000 \mathrm{mg} / \mathrm{kg} /$ day females was approximately $11 \%$ greater than that of vehicle controls. Mean absolute and relative thymus weights were significantly less than those of vehicle controls in $125 \mathrm{mg} / \mathrm{kg} /$ day males; however, this finding was not dose dependent and did not occur in both sexes, suggesting that it is a spurious finding and not treatment related (Appendix F).

There were no dose-related microscopic findings (Appendix F).

Table 5. Select Organ Weights and Organ-Weight-to-Body-Weight Ratios for Rats in the Interim 28-day Gavage Study of Gum Guggul Extract ${ }^{\mathrm{a}, \mathrm{b}}$

\begin{tabular}{|c|c|c|c|c|c|c|}
\hline & 0 mg/kg/day & $62.5 \mathrm{mg} / \mathrm{kg} / \mathrm{day}$ & $125 \mathrm{mg} / \mathrm{kg} /$ day & $250 \mathrm{mg} / \mathrm{kg} /$ day & $500 \mathrm{mg} / \mathrm{kg} /$ day & $1,000 \mathrm{mg} / \mathrm{kg} /$ day \\
\hline $\mathbf{n}$ & 10 & 10 & 10 & 10 & 10 & 10 \\
\hline \multicolumn{7}{|l|}{ Male } \\
\hline Necropsy Body Wt. (g) & $299.5 \pm 5.5$ & $298.4 \pm 5.2$ & $295.1 \pm 7.0$ & $297.2 \pm 6.9$ & $300.5 \pm 6.6$ & $309.0 \pm 5.7$ \\
\hline \multicolumn{7}{|l|}{ R. Kidney } \\
\hline Absolute (g) & $0.97 \pm 0.03$ & $0.93 \pm 0.02$ & $0.95 \pm 0.03$ & $0.97 \pm 0.03$ & $0.98 \pm 0.04$ & $1.10 \pm 0.09$ \\
\hline Relative (mg/g) & $3.23 \pm 0.05$ & $3.12 \pm 0.06$ & $3.23 \pm 0.06$ & $3.26 \pm 0.11$ & $3.25 \pm 0.07$ & $3.53 \pm 0.25$ \\
\hline \multicolumn{7}{|l|}{ Liver } \\
\hline Absolute (g) & $12.18 \pm 0.40 * *$ & $12.09 \pm 0.33$ & $12.39 \pm 0.57$ & $12.74 \pm 0.38$ & $13.03 \pm 0.62$ & $13.98 \pm 0.41 * *$ \\
\hline Relative (mg/g) & $40.61 \pm 0.88 * *$ & $40.47 \pm 0.60$ & $41.83 \pm 1.15$ & $42.92 \pm 1.19$ & $43.17 \pm 1.12$ & $45.18 \pm 0.60 * *$ \\
\hline \multicolumn{7}{|l|}{ Female } \\
\hline Necropsy Body Wt. (g) & $196.3 \pm 2.4$ & $191.9 \pm 4.2$ & $188.6 \pm 4.2$ & $188.4 \pm 4.8$ & $199.2 \pm 3.6$ & $200.7 \pm 4.5$ \\
\hline \multicolumn{7}{|l|}{ R. Kidney } \\
\hline Absolute (g) & $0.64 \pm 0.01 *$ & $0.65 \pm 0.01$ & $0.63 \pm 0.02$ & $0.65 \pm 0.02$ & $0.65 \pm 0.01$ & $0.71 \pm 0.03^{*}$ \\
\hline Relative (mg/g) & $3.25 \pm 0.07$ & $3.42 \pm 0.06$ & $3.32 \pm 0.08$ & $3.44 \pm 0.06$ & $3.28 \pm 0.04$ & $3.51 \pm 0.07^{*}$ \\
\hline \multicolumn{7}{|l|}{ Liver } \\
\hline Absolute (g) & $7.89 \pm 0.13^{* *}$ & $8.12 \pm 0.25$ & $8.12 \pm 0.30$ & $8.58 \pm 0.39$ & $9.18 \pm 0.21^{* *}$ & $10.27 \pm 0.31 * *$ \\
\hline Relative (mg/g) & $40.18 \pm 0.50 * *$ & $42.28 \pm 0.69$ & $42.96 \pm 0.95^{*}$ & $45.34 \pm 1.02 * *$ & $46.08 \pm 0.62 * *$ & $51.10 \pm 0.66^{* *}$ \\
\hline
\end{tabular}

Statistical significance for a treatment group indicates a significant pairwise test compared to the vehicle control group. Statistical significance for the vehicle control group indicates a significant trend test.

*Statistically significant at $\mathrm{p} \leq 0.05 ;{ }^{* *} \mathrm{p} \leq 0.01$.

${ }^{a}$ Organ weights (absolute weights) and body weights are given in grams; organ-weight-to-body-weight ratios (relative weights) are given as mg organ weight/g body weight (mean \pm standard error).

bStatistical analysis performed by Jonckheere's (trend) and the Williams or Dunnett (pairwise) tests.

In female rats, on day 28, lymphocyte counts were significantly decreased in several dosed groups, relative to vehicle controls (Appendix F). This particular change is most consistent with stress (i.e., corticosterone induced). All other significant hematological changes were mild and inconsistent and not considered related to treatment.

In males, alkaline phosphatase (ALP) activity was significantly decreased in the 500 and $1,000 \mathrm{mg} / \mathrm{kg} /$ day groups, relative to vehicle controls. In females, ALP activity was significantly decreased in all dosed groups, relative to vehicle controls (Table 6). The mechanism for these 
decreases is not known but indicates an alteration in ALP metabolism; there is no known toxicological relevance for decreases in ALP activity.

Cholesterol concentration was significantly decreased in $1,000 \mathrm{mg} / \mathrm{kg} /$ day males, and phospholipid concentrations were significantly decreased in 500 and 1,000 mg/kg/day males, relative to vehicle controls (Table 6). These changes were not observed in females (Appendix F). Globulin concentrations were significantly increased in $1,000 \mathrm{mg} / \mathrm{kg} / \mathrm{day}$ males and in $500 \mathrm{mg} / \mathrm{kg} /$ day and $1,000 \mathrm{mg} / \mathrm{kg} /$ day females, relative to vehicle controls, causing a significant increase in total protein and decrease in the albumin/globulin (A/G) ratio in 1,000 mg/kg/day females (Table 6). Bile acid concentrations were significantly decreased in 1,000 mg/kg/day males, relative to vehicle controls (Table 6). Other statistically significant biochemical changes were small or inconsistent relative to dose, and not considered to be due to the administration of the tested gum guggul extract (GGE) formulation.

A panel of thyroid hormones was measured in males and females. Thyroid stimulating hormone (TSH) was significantly increased in several female dosed groups, relative to vehicle controls; this was not accompanied by any changes in free thyroxine $\left(\mathrm{T}_{4}\right)$, total $\mathrm{T}_{4}$, or triiodothyronine $\left(\mathrm{T}_{3}\right)$ (Appendix F). No changes were observed in male thyroid hormones. The changes in TSH were not interpreted to be associated with the administration of the tested GGE formulation.

Table 6. Select Clinical Chemistry Data for Rats in the Interim 28-day Gavage Study of Gum Guggul Extract ${ }^{\mathrm{a}, \mathrm{b}}$

\begin{tabular}{|c|c|c|c|c|c|c|}
\hline & $0 \mathrm{mg} / \mathrm{kg} /$ day & $62.5 \mathrm{mg} / \mathrm{kg} / \mathrm{day}$ & $125 \mathrm{mg} / \mathrm{kg} /$ day & $250 \mathrm{mg} / \mathrm{kg} /$ day & $500 \mathrm{mg} / \mathrm{kg} / \mathrm{day}$ & $1,000 \mathrm{mg} / \mathrm{kg} /$ day \\
\hline n & 10 & 10 & 10 & 10 & 10 & 10 \\
\hline \multicolumn{7}{|l|}{ Male } \\
\hline Total Protein (g/dL) & $6.37 \pm 0.09 *$ & $6.31 \pm 0.04$ & $6.25 \pm 0.06$ & $6.57 \pm 0.11$ & $6.44 \pm 0.09$ & $6.55 \pm 0.09$ \\
\hline Globulin (g/dL) & $1.99 \pm 0.06 * *$ & $1.97 \pm 0.03$ & $1.91 \pm 0.03$ & $2.10 \pm 0.05$ & $2.03 \pm 0.05$ & $2.16 \pm 0.04^{*}$ \\
\hline Albumin (g/dL) & $4.38 \pm 0.04$ & $4.34 \pm 0.05$ & $4.34 \pm 0.04$ & $4.47 \pm 0.07$ & $4.41 \pm 0.04$ & $4.39 \pm 0.06$ \\
\hline A/G Ratio & $2.21 \pm 0.06^{*}$ & $2.21 \pm 0.05$ & $2.28 \pm 0.03$ & $2.13 \pm 0.04$ & $2.18 \pm 0.04$ & $2.04 \pm 0.04$ \\
\hline $\begin{array}{l}\text { Alkaline Phosphatase } \\
\text { (IU/L) }\end{array}$ & $326.0 \pm 16.1^{* *}$ & $352.2 \pm 15.5$ & $283.9 \pm 4.3$ & $274.7 \pm 14.3$ & $247.2 \pm 9.3^{* *}$ & $215.7 \pm 6.7^{* *}$ \\
\hline Cholesterol (mg/dL) & $111.1 \pm 3.4^{* *}$ & $113.2 \pm 3.5$ & $104.3 \pm 2.6$ & $108.9 \pm 3.0$ & $103.1 \pm 2.8$ & $99.0 \pm 4.6^{*}$ \\
\hline $\begin{array}{l}\text { Phospholipids } \\
\text { (mg/dL) }\end{array}$ & $202.9 \pm 6.2^{* *}$ & $203.3 \pm 4.2$ & $191.1 \pm 4.3$ & $194.7 \pm 5.2$ & $185.2 \pm 5.7^{*}$ & $180.4 \pm 6.5^{*}$ \\
\hline $\begin{array}{l}\text { Bile Salt/Acids } \\
\quad(\mu \mathrm{mol} / \mathrm{L})\end{array}$ & $37.2 \pm 5.4^{* *}$ & $57.3 \pm 12.8$ & $34.5 \pm 3.0$ & $30.3 \pm 3.0$ & $34.2 \pm 2.4$ & $24.6 \pm 2.4^{*}$ \\
\hline \multicolumn{7}{|l|}{ Female } \\
\hline Total Protein (g/dL) & $6.09 \pm 0.07 *$ & $6.23 \pm 0.08$ & $6.19 \pm 0.11$ & $6.24 \pm 0.05$ & $6.28 \pm 0.07$ & $6.38 \pm 0.06^{*}$ \\
\hline Globulin (g/dL) & $1.78 \pm 0.02 * *$ & $1.89 \pm 0.04$ & $1.82 \pm 0.05$ & $1.86 \pm 0.02$ & $1.90 \pm 0.04^{*}$ & $2.06 \pm 0.03^{* *}$ \\
\hline Albumin (g/dL) & $4.31 \pm 0.06$ & $4.34 \pm 0.05$ & $4.37 \pm 0.07$ & $4.38 \pm 0.05$ & $4.38 \pm 0.06$ & $4.32 \pm 0.06$ \\
\hline A/G Ratio & $2.42 \pm 0.04 * *$ & $2.31 \pm 0.05$ & $2.41 \pm 0.06$ & $2.36 \pm 0.03$ & $2.31 \pm 0.06$ & $2.10 \pm 0.05^{* *}$ \\
\hline $\begin{array}{l}\text { Alkaline Phosphatase } \\
\text { (IU/L) }\end{array}$ & $270.3 \pm 17.2^{* *}$ & $213.4 \pm 12.5^{*}$ & $217.3 \pm 9.1^{*}$ & $209.4 \pm 17.4^{*}$ & $192.6 \pm 9.8^{* *}$ & $151.5 \pm 7.2^{* *}$ \\
\hline $\begin{array}{l}\text { Bile Salt/Acids } \\
\qquad(\mu \mathrm{mol} / \mathrm{L})\end{array}$ & $28.2 \pm 2.8^{* *}$ & $35.9 \pm 7.2$ & $25.7 \pm 3.6$ & $23.1 \pm 2.9$ & $21.6 \pm 1.9$ & $22.4 \pm 2.7$ \\
\hline
\end{tabular}


Both male and female rats exhibited dose-related increases in hepatic cytochrome P450 (CYP) 2B and CYP3A activity following administration of the GGE formulation, suggesting increased constitutive androstane receptor (CAR) and pregnane $\mathrm{X}$ receptor (PXR) activities (Table 7). A sex-related difference in the magnitude of induction of CYP2B was observed with up to a sixfold increase in males and a twofold increase in females, relative to vehicle controls. CYP3A activity was up to twofold higher in males and sixfold higher in females, relative to vehicle controls.

Table 7. Cytochrome P450 Measurements for Rats in the Interim 28-day Gavage Study of Gum Guggul Extract ${ }^{\text {a,b }}$

\begin{tabular}{|c|c|c|c|c|c|c|}
\hline & $0 \mathrm{mg} / \mathrm{kg} /$ day & $62.5 \mathrm{mg} / \mathrm{kg} /$ day & $125 \mathrm{mg} / \mathrm{kg} /$ day & $250 \mathrm{mg} / \mathrm{kg} /$ day & $500 \mathrm{mg} / \mathrm{kg} /$ day & $1,000 \mathrm{mg} / \mathrm{kg} /$ day \\
\hline $\mathbf{n}$ & 10 & 10 & 10 & 10 & 10 & 10 \\
\hline \multicolumn{7}{|l|}{ Male } \\
\hline $\begin{array}{l}\text { СYР2B } \\
(\text { pmol/mg/min) }\end{array}$ & $5.535 \pm 0.558^{* *}$ & $8.167 \pm 1.114^{*}$ & $7.581 \pm 0.709 *$ & $11.237 \pm 1.274^{* *}$ & $20.957 \pm 2.754^{* *}$ & $38.700 \pm 6.105^{* *}$ \\
\hline $\begin{array}{l}\text { CYP3A } \\
\quad(\mathrm{pmol} / \mathrm{mg} / \mathrm{min})\end{array}$ & $922.1 \pm 83.2^{* *}$ & $1,294.0 \pm 74.8^{* *}$ & $1,197.6 \pm 60.1^{*}$ & $1,288.0 \pm 97.9 *$ & $1,654.0 \pm 142.0^{* *}$ & $1,982.0 \pm 100.3^{* *}$ \\
\hline \multicolumn{7}{|l|}{ Female } \\
\hline $\begin{array}{l}\text { CYP2B } \\
\text { (pmol/mg/min) }\end{array}$ & $2.458 \pm 0.155^{* *}$ & $3.069 \pm 0.084$ & $2.660 \pm 0.123$ & $2.824 \pm 0.206$ & $4.109 \pm 0.311^{* *}$ & $6.788 \pm 1.255^{* *}$ \\
\hline $\begin{array}{l}\text { CYP3A } \\
\quad(\mathrm{pmol} / \mathrm{mg} / \mathrm{min})\end{array}$ & $112.9 \pm 6.9^{* *}$ & $171.8 \pm 13.9 * *$ & $189.8 \pm 12.3^{* *}$ & $293.1 \pm 31.2^{* *}$ & $452.1 \pm 24.1^{* *}$ & $731.1 \pm 60.2^{* *}$ \\
\hline
\end{tabular}

Statistical significance for a treatment group indicates a significant pairwise test compared to the vehicle control group. Statistical significance for the vehicle control group indicates a significant trend test.

*Statistically significant at $\mathrm{p} \leq 0.05 ; * * \mathrm{p} \leq 0.01$.

CYP = cytochrome P450.

a Data are presented as mean \pm standard error.

bStatistical analysis performed by Jonckheere’s (trend) and Shirley’s or Dunn’s (pairwise) tests. 


\section{Three-month Study}

All rats survived to the end of the study with the exception of three female rats, with a single death occurring in each of the 0,125 , and $500 \mathrm{mg} / \mathrm{kg} /$ day groups (Table 8). The three deaths occurred between days 50 and 57 and were not considered treatment related. There were no significant treatment-related clinical observations in male or female rats. The final mean body weights of male and female rats in all dosed groups were within $5 \%$ of the vehicle control body weights (Table 8; Figure 3).

Table 8. Survival and Body Weights of Rats in the Three-month Gavage Study of Gum Guggul Extract $^{\mathbf{a}}$

\begin{tabular}{cccccc}
\hline $\begin{array}{c}\text { Concentration } \\
\text { (mg/kg/day) }\end{array}$ & Survival $^{\mathbf{b}}$ & $\begin{array}{c}\text { Initial Body } \\
\text { Weight } \\
\text { (g) }\end{array}$ & $\begin{array}{c}\text { Final Body } \\
\text { Weight } \\
\text { (g) }\end{array}$ & $\begin{array}{c}\text { Changes in } \\
\text { Body Weight } \\
\text { (g) }\end{array}$ & $\begin{array}{c}\text { Final Weight } \\
\text { Relative to } \\
\text { Controls }^{\mathbf{( \% )}}\end{array}$ \\
\hline Male & & & & & \\
0 & $10 / 10$ & $162.1 \pm 2.7$ & $406.9 \pm 13.5$ & $244.7 \pm 12.1$ & - \\
62.5 & $10 / 10$ & $162.4 \pm 3.2$ & $421.6 \pm 8.8$ & $259.2 \pm 7.7$ & 3.63 \\
125 & $10 / 10$ & $160.7 \pm 3.3$ & $405.7 \pm 8.4$ & $244.9 \pm 8.1$ & -0.30 \\
250 & $10 / 10$ & $163.5 \pm 3.5$ & $407.6 \pm 9.0$ & $244.1 \pm 8.0$ & 0.18 \\
500 & $10 / 10$ & $164.7 \pm 3.4$ & $405.6 \pm 9.6$ & $240.9 \pm 8.4$ & -0.31 \\
1,000 & $10 / 10$ & $162.8 \pm 3.5$ & $404.3 \pm 7.2$ & $241.5 \pm 6.7$ & -0.63 \\
\hline Female & & & & & \\
0 & $9 / 10$ & $119.3 \pm 1.9$ & $245.9 \pm 5.9$ & $126.1 \pm 5.6$ & - \\
62.5 & $10 / 10$ & $119.5 \pm 3.0$ & $255.2 \pm 8.0$ & $135.8 \pm 5.6$ & 3.82 \\
125 & $9 / 10$ & $118.4 \pm 2.1$ & $248.7 \pm 3.9$ & $130.1 \pm 3.4$ & 1.15 \\
250 & $10 / 10$ & $119.7 \pm 1.9$ & $241.9 \pm 4.0$ & $122.2 \pm 3.5$ & -1.63 \\
500 & $9 / 10$ & $121.0 \pm 1.9$ & $247.0 \pm 4.5$ & $126.6 \pm 3.5$ & 0.45 \\
1,000 & $10 / 10$ & $119.8 \pm 2.0$ & $257.2 \pm 7.0$ & $137.4 \pm 6.0$ & 4.61 \\
\hline
\end{tabular}

${ }^{a}$ Weights and weight changes are given as mean \pm standard error. Differences from the vehicle control group are not significant by Dunnett's test.

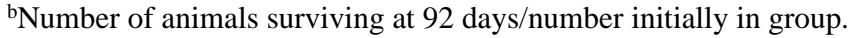

'[(dosed group mean - control group mean)/control group mean $] \times 100$. 

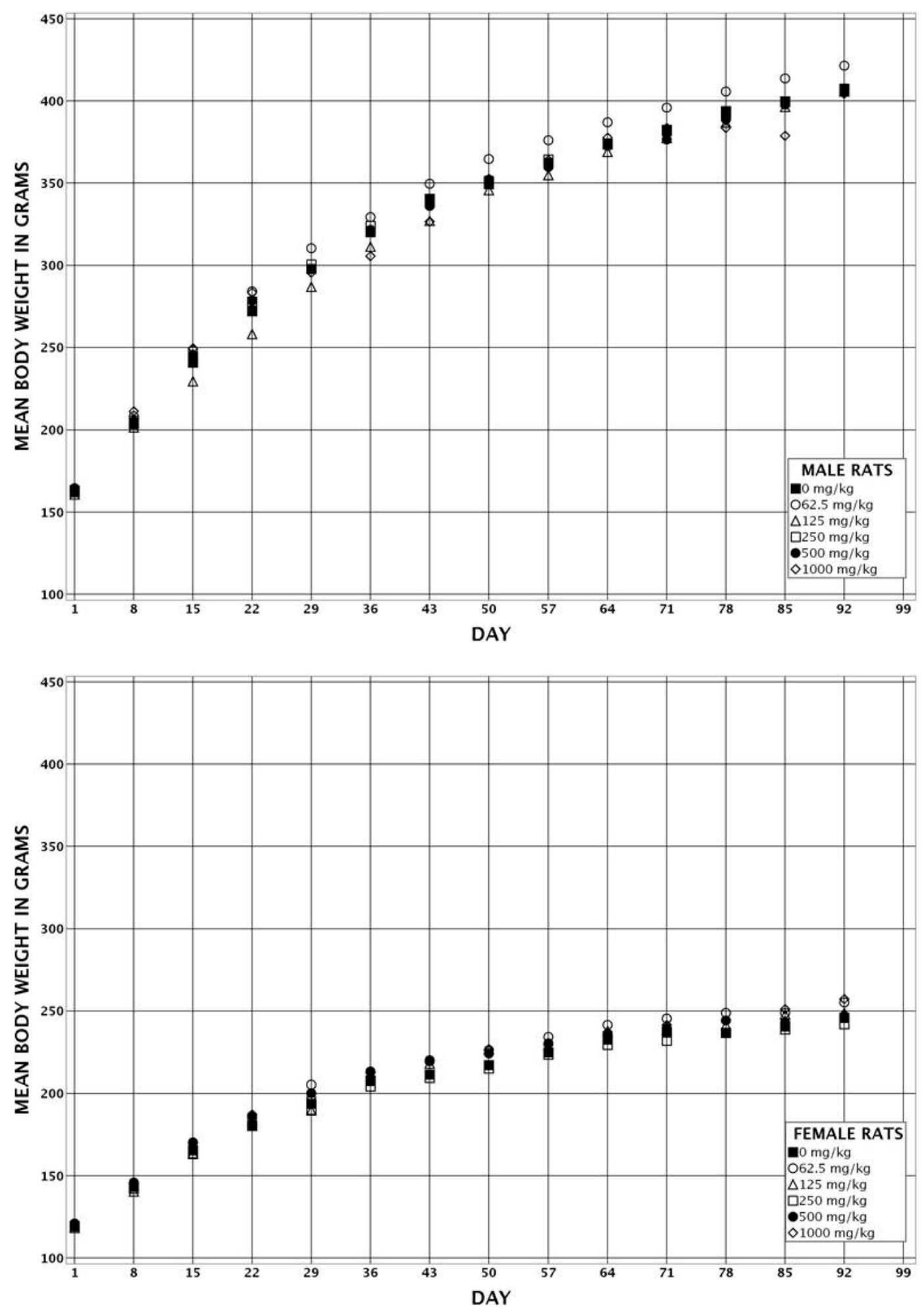

Figure 3. Growth Curves for Male and Female Rats Administered Gum Guggul Extract by Gavage for Three Months 
Dose-related increases in absolute and relative liver weights were observed in male and female rats (Table 9). The mean absolute liver weights were significantly greater than those of vehicle controls in 1,000 mg/kg/day males (approximately 20\%) and in 500 and 1,000 mg/kg/day females (approximately 25\% and 43\%, respectively). Relative liver weights were significantly greater than vehicle controls in males administered $250 \mathrm{mg} / \mathrm{kg} /$ day or greater and females administered 500 or $1,000 \mathrm{mg} / \mathrm{kg} /$ day. A dose-related increase in relative and absolute kidney weights was observed in female rats; a dose-related increase in relative kidney weights was observed in male rats. The relative kidney weight of $1,000 \mathrm{mg} / \mathrm{kg} /$ day males was significantly greater than that of vehicle controls. Dose-related increases in absolute and relative heart weights were observed in female rats, although no dose group exhibited significantly greater absolute or relative heart weights. The mean absolute and relative thymus weights of $1,000 \mathrm{mg} / \mathrm{kg} / \mathrm{day}$ males were significantly less than those of vehicle controls. The mean absolute thymus weight of $1,000 \mathrm{mg} / \mathrm{kg} /$ day males was $23 \%$ lower than that of vehicle controls.

There were no dose-related microscopic findings (Appendix F).

Table 9. Select Organ Weights and Organ-Weight-to-Body-Weight Ratios for Rats in the Three-month Gavage Study of Gum Guggul Extract ${ }^{\mathrm{a}, \mathrm{b}}$

\begin{tabular}{|c|c|c|c|c|c|c|}
\hline & 0 mg/kg/day & $62.5 \mathrm{mg} / \mathrm{kg} / \mathrm{day}$ & $125 \mathrm{mg} / \mathrm{kg} / \mathrm{day}$ & $250 \mathrm{mg} / \mathrm{kg} /$ day & $500 \mathrm{mg} / \mathrm{kg} / \mathrm{day}$ & $1,000 \mathrm{mg} / \mathrm{kg} / \mathrm{day}$ \\
\hline \multicolumn{7}{|l|}{ Male } \\
\hline $\mathbf{n}$ & 10 & 10 & 10 & 10 & 10 & 10 \\
\hline Necropsy Body Wt. (g) & $406.9 \pm 13.5$ & $421.6 \pm 8.8$ & $409.1 \pm 8.6$ & $407.6 \pm 9.0$ & $405.6 \pm 9.6$ & $404.3 \pm 7.2$ \\
\hline \multicolumn{7}{|l|}{ R. Kidney } \\
\hline Absolute (g) & $1.13 \pm 0.04$ & $1.18 \pm 0.02$ & $1.16 \pm 0.04$ & $1.16 \pm 0.03$ & $1.17 \pm 0.04$ & $1.23 \pm 0.03$ \\
\hline Relative (mg/g) & $2.78 \pm 0.05^{* *}$ & $2.80 \pm 0.04$ & $2.82 \pm 0.06$ & $2.86 \pm 0.06$ & $2.88 \pm 0.07$ & $3.03 \pm 0.04^{* *}$ \\
\hline \multicolumn{7}{|l|}{ Liver } \\
\hline Absolute (g) & $13.22 \pm 0.56^{* *}$ & $14.20 \pm 0.37$ & $13.72 \pm 0.34$ & $14.15 \pm 0.48$ & $14.27 \pm 0.48$ & $15.91 \pm 0.48^{* *}$ \\
\hline Relative (mg/g) & $32.42 \pm 0.40 * *$ & $33.66 \pm 0.42$ & $33.53 \pm 0.40$ & $34.65 \pm 0.57 * *$ & $35.14 \pm 0.65^{* *}$ & $39.28 \pm 0.61^{* *}$ \\
\hline \multicolumn{7}{|l|}{ Thymus } \\
\hline Absolute (g) & $0.347 \pm 0.022 *$ & $0.325 \pm 0.015$ & $0.329 \pm 0.030$ & $0.316 \pm 0.018$ & $0.309 \pm 0.018$ & $0.268 \pm 0.017 *$ \\
\hline Relative (mg/g) & $0.85 \pm 0.04^{*}$ & $0.77 \pm 0.03$ & $0.81 \pm 0.08$ & $0.77 \pm 0.04$ & $0.76 \pm 0.04$ & $0.66 \pm 0.04^{*}$ \\
\hline \multicolumn{7}{|l|}{ Female } \\
\hline $\mathbf{n}$ & 9 & 10 & 9 & 10 & 9 & 10 \\
\hline Necropsy Body Wt. (g) & $245.9 \pm 5.9$ & $255.2 \pm 8.0$ & $248.7 \pm 3.9$ & $241.9 \pm 4.0$ & $247.0 \pm 4.5$ & $257.2 \pm 7.0$ \\
\hline \multicolumn{7}{|l|}{ R. Kidney } \\
\hline Absolute (g) & $0.75 \pm 0.02 *$ & $0.74 \pm 0.02$ & $0.73 \pm 0.01$ & $0.74 \pm 0.01$ & $0.79 \pm 0.02$ & $0.79 \pm 0.01$ \\
\hline Relative (mg/g) & $3.07 \pm 0.07 *$ & $2.89 \pm 0.03$ & $2.92 \pm 0.05$ & $3.05 \pm 0.07$ & $3.18 \pm 0.06$ & $3.07 \pm 0.07$ \\
\hline \multicolumn{7}{|l|}{ Liver } \\
\hline Absolute (g) & $8.27 \pm 0.27^{* *}$ & $8.88 \pm 0.39$ & $8.72 \pm 0.34$ & $8.85 \pm 0.21$ & $10.36 \pm 0.53 * *$ & $11.83 \pm 0.46^{* *}$ \\
\hline Relative (mg/g) & $33.65 \pm 0.79 * *$ & $34.72 \pm 0.77$ & $35.02 \pm 1.08$ & $36.62 \pm 0.72$ & $41.87 \pm 1.74^{* *}$ & $45.98 \pm 1.07 * *$ \\
\hline
\end{tabular}


$0 \mathrm{mg} / \mathrm{kg} /$ day $\quad 62.5 \mathrm{mg} / \mathrm{kg} /$ day $125 \mathrm{mg} / \mathrm{kg} /$ day $250 \mathrm{mg} / \mathrm{kg} / \mathrm{day} \quad 500 \mathrm{mg} / \mathrm{kg} / \mathrm{day} \quad 1,000 \mathrm{mg} / \mathrm{kg} / \mathrm{day}$

\begin{tabular}{lcccccc}
\hline Thymus & & & & & \\
Absolute (g) & $0.217 \pm 0.022$ & $0.262 \pm 0.010$ & $0.232 \pm 0.017$ & $0.234 \pm 0.010$ & $0.207 \pm 0.014$ & $0.241 \pm 0.016$ \\
Relative (mg/g) & $0.88 \pm 0.08$ & $1.03 \pm 0.05$ & $0.93 \pm 0.06$ & $0.97 \pm 0.05$ & $0.83 \pm 0.05$ & $0.93 \pm 0.05$ \\
\hline
\end{tabular}

Statistical significance for a treatment group indicates a significant pairwise test compared to the vehicle control group. Statistical significance for the vehicle control group indicates a significant trend test.

*Statistically significant at $\mathrm{p} \leq 0.05 ; * * \mathrm{p} \leq 0.01$.

${ }^{a}$ Organ weights (absolute weights) and body weights are given in grams; organ-weight-to-body-weight ratios (relative weights) are given as mg organ weight/g body weight (mean \pm standard error).

bStatistical analysis performed by Jonckheere's (trend) and the Williams or Dunnett (pairwise) tests.

Significant decreases in hematocrit and hemoglobin concentrations were observed in the $1,000 \mathrm{mg} / \mathrm{kg} /$ day male rats at day 92 (Appendix F). These decreases were mild and not considered toxicologically relevant. All other significant hematological changes were mild and inconsistent and considered not due to treatment.

In males, ALP activity was significantly decreased in $250 \mathrm{mg} / \mathrm{kg} /$ day or greater groups. In females, ALP activity was significantly decreased in $125 \mathrm{mg} / \mathrm{kg} /$ day or greater groups (Table 10). The mechanism for these decreases is not known but indicates an alteration in ALP metabolism; there is no known toxicologic relevance for decreases in ALP activity.

Globulin concentrations were significantly increased in 500 and 1,000 mg/kg/day females, relative to vehicle controls (Table 10), causing a significant decrease in the A/G ratio of the same dosed groups. Bile acid concentrations were significantly decreased in all dosed female groups (Table 10).

A panel of thyroid hormones was measured in males and females, and several statistically significant changes were observed in the male rats (Appendix F). These changes were small or inconsistent relative to dose, or lacked a dose response, and therefore were not interpreted to be associated with administration of the tested GGE formulation. 
Table 10. Select Clinical Chemistry Data for Rats in the Three-month Gavage Study of Gum Guggul Extract ${ }^{\mathrm{a}, \mathrm{b}}$

\begin{tabular}{|c|c|c|c|c|c|c|}
\hline & 0 mg/kg/day & $62.5 \mathrm{mg} / \mathrm{kg} / \mathrm{day}$ & 125 mg/kg/day & $250 \mathrm{mg} / \mathrm{kg} /$ day & $500 \mathrm{mg} / \mathrm{kg} / \mathrm{day}$ & $1,000 \mathrm{mg} / \mathrm{kg} / \mathrm{day}$ \\
\hline \multicolumn{7}{|l|}{ Male } \\
\hline $\mathbf{n}$ & 10 & 10 & 10 & 10 & 10 & 10 \\
\hline $\begin{array}{l}\text { Alkaline Phosphatase } \\
\text { (IU/L) }\end{array}$ & $205.2 \pm 11.1^{* *}$ & $223.9 \pm 14.6$ & $190.0 \pm 6.1$ & $161.8 \pm 8.0^{* *}$ & $155.0 \pm 8.2^{* *}$ & $142.0 \pm 6.4^{* *}$ \\
\hline Total Protein (g/dL) & $6.63 \pm 0.05$ & $6.68 \pm 0.07$ & $6.71 \pm 0.08$ & $6.68 \pm 0.06$ & $6.78 \pm 0.07$ & $6.53 \pm 0.05$ \\
\hline Albumin (g/dL) & $4.47 \pm 0.04^{* *}$ & $4.38 \pm 0.03$ & $4.46 \pm 0.05$ & $4.42 \pm 0.04$ & $4.44 \pm 0.05$ & $4.21 \pm 0.04^{* *}$ \\
\hline Globulin (g/dL) & $2.16 \pm 0.05$ & $2.30 \pm 0.06$ & $2.25 \pm 0.03$ & $2.26 \pm 0.05$ & $2.34 \pm 0.05$ & $2.32 \pm 0.04$ \\
\hline A/G Ratio & $2.08 \pm 0.06^{* *}$ & $1.91 \pm 0.05$ & $1.98 \pm 0.02$ & $1.96 \pm 0.05$ & $1.91 \pm 0.05$ & $1.82 \pm 0.04^{* *}$ \\
\hline $\begin{array}{l}\text { Bile Salt/Acids } \\
\quad(\mu \mathrm{mol} / \mathrm{L})\end{array}$ & $28.5 \pm 2.6^{*}$ & $26.5 \pm 2.6$ & $30.5 \pm 3.7$ & $25.8 \pm 2.5$ & $22.8 \pm 3.2$ & $19.5 \pm 2.2$ \\
\hline \multicolumn{7}{|l|}{ Female } \\
\hline n & 9 & 10 & 9 & 10 & 9 & 10 \\
\hline $\begin{array}{l}\text { Alkaline Phosphatase } \\
\text { (IU/L) }\end{array}$ & $194.9 \pm 11.0^{* *}$ & $163.3 \pm 9.4$ & $160.7 \pm 9.4^{*}$ & $114.7 \pm 5.2^{* *}$ & $106.8 \pm 6.0^{* *}$ & $93.1 \pm 7.1 * *$ \\
\hline Total Protein (g/dL) & $6.78 \pm 0.07$ & $6.70 \pm 0.06$ & $6.92 \pm 0.11$ & $6.67 \pm 0.09$ & $6.88 \pm 0.14$ & $6.88 \pm 0.06$ \\
\hline Albumin (g/dL) & $4.80 \pm 0.05$ & $4.72 \pm 0.06$ & $4.84 \pm 0.11$ & $4.71 \pm 0.07$ & $4.69 \pm 0.12$ & $4.70 \pm 0.05$ \\
\hline Globulin (g/dL) & $1.98 \pm 0.07^{* *}$ & $1.98 \pm 0.04$ & $2.08 \pm 0.04$ & $1.96 \pm 0.03$ & $2.19 \pm 0.07^{*}$ & $2.18 \pm 0.03^{* *}$ \\
\hline A/G Ratio & $2.45 \pm 0.09 * *$ & $2.40 \pm 0.07$ & $2.34 \pm 0.08$ & $2.41 \pm 0.04$ & $2.17 \pm 0.11^{*}$ & $2.16 \pm 0.03^{*}$ \\
\hline $\begin{array}{l}\text { Bile Salt/Acids } \\
\quad(\mu \mathrm{mol} / \mathrm{L})\end{array}$ & $34.4 \pm 3.3^{* *}$ & $19.2 \pm 2.6^{* *}$ & $20.2 \pm 2.9^{* *}$ & $26.2 \pm 2.9 *$ & $20.4 \pm 1.9 *$ & $16.3 \pm 1.4^{* *}$ \\
\hline \multicolumn{7}{|c|}{$\begin{array}{l}\text { Statistical significance for a treatment group indicates a significant pairwise test compared to the } \\
\text { significance for the vehicle control group indicates a significant trend test. } \\
* \text { Statistically significant at } \mathrm{p} \leq 0.05 ; * \mathrm{p} \leq 0.01 \text {. } \\
\text { a'Data are presented as mean } \pm \text { standard error. } \\
\text { bStatistical analysis performed by Jonckheere’s (trend) and Shirley's or Dunn's (pairwise) tests. }\end{array}$} \\
\hline \multicolumn{7}{|c|}{$\begin{array}{l}\text { Male rats administered } 250 \text { and } 1,000 \mathrm{mg} / \mathrm{kg} / \text { day displayed an increase (15-16\%) in the mean } \\
\text { total number of homogenization-resistant spermatids with a statistically significant difference } \\
\text { between the } 1,000 \mathrm{mg} / \mathrm{kg} / \text { day group and the vehicle control group (Table } 11 \text { ). Male rats } \\
\text { administered } 1,000 \mathrm{mg} / \mathrm{kg} / \text { day also displayed statistically higher (approximately } 18 \% \text { ) mean total } \\
\text { number of homogenization-resistant spermatids/mg. Both respective spermatid values in the } \\
500 \mathrm{mg} / \mathrm{kg} / \text { day group were similar to those of vehicle controls. Cauda epididymal sperm counts } \\
\text { and motility of all dosed groups were similar to those of vehicle controls. There were no GGE- } \\
\text { related effects on testicular weight, epididymal weights, or histopathology. Given the apparent } \\
\text { increase in spermatid head counts was not dose-related, and the absence of concurrent increases } \\
\text { in sperm counts or histopathological findings, these effects are considered not related to } \\
\text { administration of the tested GGE formulation. }\end{array}$} \\
\hline
\end{tabular}


Table 11. Select Sperm Count Endpoints for Rats in the Three-month Gavage Study of Gum Guggul Extract ${ }^{\mathrm{a}}$

$0 \mathrm{mg} / \mathrm{kg} /$ day $250 \mathrm{mg} / \mathrm{kg} /$ day $500 \mathrm{mg} / \mathrm{kg} /$ day $1,000 \mathrm{mg} / \mathrm{kg} / \mathrm{day}$

\begin{tabular}{|c|c|c|c|c|}
\hline n & 10 & 10 & 10 & 10 \\
\hline \multicolumn{5}{|l|}{ Weights (g) ${ }^{b}$} \\
\hline L. cauda epididymis & $0.211 \pm 0.007$ & $0.211 \pm 0.006$ & $0.216 \pm 0.006$ & $0.204 \pm 0.005$ \\
\hline L. epididymis & $0.602 \pm 0.012$ & $0.591 \pm 0.009$ & $0.601 \pm 0.012$ & $0.590 \pm 0.011$ \\
\hline L. testis & $1.884 \pm 0.047$ & $1.862 \pm 0.043$ & $1.865 \pm 0.044$ & $1.898 \pm 0.053$ \\
\hline \multicolumn{5}{|l|}{ Spermatid Measurements $^{c}$} \\
\hline Spermatid heads ( $10^{3} / \mathrm{mg}$ testis) & $155.0 \pm 5.7$ & $179.2 \pm 5.2^{*}$ & $160.0 \pm 5.9$ & $180.0 \pm 5.6^{*}$ \\
\hline Spermatid heads (106/testis) & $291.8 \pm 12.2^{*}$ & $332.7 \pm 9.5$ & $299.6 \pm 15.1$ & $342.9 \pm 17.6^{*}$ \\
\hline \multicolumn{5}{|l|}{ Epididymal Spermatozoal Measurements ${ }^{c}$} \\
\hline Sperm motility (\%) & $83.6 \pm 0.6$ & $85.1 \pm 0.6$ & $85.3 \pm 0.6$ & $85.0 \pm 0.3$ \\
\hline Sperm (103/mg cauda epididymis) & $760.8 \pm 28.7$ & $776.9 \pm 36.6$ & $796.3 \pm 30.3$ & $764.1 \pm 51.3$ \\
\hline Cauda epididymis sperm count (millions) & $160.4 \pm 6.9$ & $163.4 \pm 8.1$ & $171.5 \pm 7.0$ & $155.4 \pm 9.2$ \\
\hline
\end{tabular}

Statistical significance for a treatment group indicates a significant pairwise test compared to the vehicle control group. Statistical significance for the vehicle control group indicates a significant trend test.

*Statistically significant at $\mathrm{p} \leq 0.05 ; * * \mathrm{p} \leq 0.01$.

a Data are presented as mean \pm standard error.

bStatistical analysis performed by Jonckheere's (trend) and the Williams or Dunnett (pairwise) tests.

'Statistical analysis performed by Jonckheere’s (trend) and Shirley’s or Dunn's (pairwise) tests.

Both male and female rats exhibited dose-related increases in hepatic CYP2B and CYP3A activity following administration of the tested GGE formulation, suggesting increased CAR and PXR activities (Table 12). CYP2B activity was up to approximately 11-fold higher in males and threefold higher in females, relative to vehicle controls. A sex-related difference in the magnitude of induction of CYP3A was observed with up to approximately twofold increase in males and ninefold increase in females, relative to vehicle controls. CYP2B and CYP3A activities were increased in males relative to females at all doses, including basal concentrations in vehicle controls. 
Gum Guggul, NTP TOX 99

Table 12. Cytochrome P450 Measurements for Rats in the Three-month Gavage Study of Gum Guggul Extract ${ }^{\mathrm{a}, \mathrm{b}}$

\begin{tabular}{|c|c|c|c|c|c|c|}
\hline & 0 mg/kg/day & $62.5 \mathrm{mg} / \mathrm{kg} / \mathrm{day}$ & $125 \mathrm{mg} / \mathrm{kg} /$ day & $250 \mathrm{mg} / \mathrm{kg} /$ day & $500 \mathrm{mg} / \mathrm{kg} /$ day & $1,000 \mathrm{mg} / \mathrm{kg} /$ day \\
\hline \multicolumn{7}{|l|}{ Male } \\
\hline $\mathbf{n}$ & 10 & 10 & 10 & 10 & 10 & 10 \\
\hline $\begin{array}{l}\text { CYP2B } \\
\text { (pmol/mg/min) }\end{array}$ & $5.686 \pm 0.381^{* *}$ & $6.544 \pm 0.641$ & $8.994 \pm 0.933^{* *}$ & $12.960 \pm 1.765^{* *}$ & $33.930 \pm 3.768^{* *}$ & $61.820 \pm 5.718^{* *}$ \\
\hline $\begin{array}{l}\text { CYP3A } \\
(\text { (pmol/mg/min) }\end{array}$ & $1,174.4 \pm 81.9^{* *}$ & $1,363.0 \pm 126.9$ & $1,449.0 \pm 44.6$ & $1,653.0 \pm 133.5^{* *}$ & $2,005.0 \pm 138.5^{* *}$ & $1,905.0 \pm 135.5^{* *}$ \\
\hline \multicolumn{7}{|l|}{ Female } \\
\hline $\mathbf{n}$ & 9 & 10 & 9 & 10 & 9 & 10 \\
\hline $\begin{array}{l}\text { СYР2B } \\
\quad(\mathrm{pmol} / \mathrm{mg} / \mathrm{min})\end{array}$ & $3.237 \pm 0.226^{* *}$ & $3.118 \pm 0.181$ & $3.738 \pm 0.309$ & $3.708 \pm 0.231$ & $5.118 \pm 0.594^{*}$ & $10.875 \pm 2.284^{* *}$ \\
\hline $\begin{array}{l}\text { CYP3A } \\
\text { (pmol/mg/min) }\end{array}$ & $71.2 \pm 3.7^{* *}$ & $140.5 \pm 7.9 * *$ & $219.3 \pm 19.9 * *$ & $300.8 \pm 20.8^{* *}$ & $411.7 \pm 36.8^{* *}$ & $666.7 \pm 40.7 * *$ \\
\hline \multicolumn{7}{|c|}{$\begin{array}{l}\text { Statistical significance for a treatment group indicates a significant pairwise test compared to the } \\
\text { significance for the vehicle control group indicates a significant trend test. } \\
\text { *Statistically significant at } \mathrm{p} \leq 0.05 ; * * \mathrm{p} \leq 0.01 \text {. } \\
\mathrm{CYP}=\text { cytochrome P } 450 \text {. } \\
\text { aData are presented as mean } \pm \text { standard error. } \\
\text { 'Statistical analysis performed by Jonckheere's (trend) and Shirley’s or Dunn’s (pairwise) tests. }\end{array}$} \\
\hline
\end{tabular}




\section{Mice}

\section{Twenty-eight-day Interim Study}

All mice survived to the end of the study (Table 13). There were no significant treatment-related clinical observations in male or female mice. The final mean body weights of male and female mice in all dosed groups remained within $5 \%$ of the vehicle control body weights (Table 13).

Table 13. Survival and Body Weights of Mice in the Interim 28-day Gavage Study of Gum Guggul Extract $^{\mathrm{a}}$

\begin{tabular}{cccccc}
\hline $\begin{array}{c}\text { Concentration } \\
\text { (mg/kg/day) }\end{array}$ & Survival $^{\mathbf{b}}$ & $\begin{array}{c}\text { Initial Body } \\
\text { Weight } \\
\text { (g) }\end{array}$ & $\begin{array}{c}\text { Final Body } \\
\text { Weight } \\
\text { (g) }\end{array}$ & $\begin{array}{c}\text { Changes in } \\
\text { Body Weight } \\
\text { (g) }\end{array}$ & $\begin{array}{c}\text { Final Weight } \\
\text { Relative to } \\
\text { Controls }^{\mathbf{( \% )}}\end{array}$ \\
\hline Male & & & & & \\
0 & $10 / 10$ & $24.8 \pm 0.5$ & $28.4 \pm 0.8$ & $3.6 \pm 0.6$ & - \\
15.5 & $10 / 10$ & $23.9 \pm 0.4$ & $27.2 \pm 0.6$ & $3.3 \pm 0.2$ & -4.26 \\
31.0 & $10 / 10$ & $24.0 \pm 0.5$ & $27.1 \pm 0.7$ & $3.1 \pm 0.4$ & -4.54 \\
62.5 & $10 / 10$ & $24.2 \pm 0.4$ & $27.3 \pm 0.5$ & $3.1 \pm 0.3$ & -3.98 \\
125 & $10 / 10$ & $24.1 \pm 0.4$ & $27.9 \pm 0.4$ & $3.7 \pm 0.3$ & -1.83 \\
250 & $10 / 10$ & $24.5 \pm 0.6$ & $28.3 \pm 1.0$ & $3.8 \pm 0.5$ & -0.21 \\
\hline Female & & & & & \\
0 & $10 / 10$ & $18.5 \pm 0.3$ & $22.0 \pm 0.3$ & $3.5 \pm 0.3$ & - \\
15.5 & $10 / 10$ & $18.3 \pm 0.3$ & $21.2 \pm 0.2$ & $2.9 \pm 0.2$ & -3.64 \\
31.0 & $10 / 10$ & $18.8 \pm 0.3$ & $21.5 \pm 0.3$ & $2.7 \pm 0.4$ & -2.23 \\
62.5 & $10 / 10$ & $18.7 \pm 0.3$ & $21.1 \pm 0.4$ & $2.4 \pm 0.3 *$ & -4.10 \\
125 & $10 / 10$ & $19.0 \pm 0.4$ & $22.5 \pm 0.4$ & $3.6 \pm 0.2$ & 2.46 \\
250 & $10 / 10$ & $18.6 \pm 0.3$ & $22.1 \pm 0.4$ & $3.5 \pm 0.2$ & 0.68 \\
\hline
\end{tabular}

Statistical significance for a treatment group indicates a significant pairwise test compared to the vehicle control.

*Statistically significant at $\mathrm{p} \leq 0.05$ by Dunnett's test.

${ }^{a}$ Weights and weight changes are given as mean \pm standard error.

${ }^{b}$ Number of animals surviving at 28 days/number initially in group.

'[(dosed group mean - control group mean)/control group mean $] \times 100$.

Mean relative thymus weights were significantly decreased relative to the vehicle control groups in $125 \mathrm{mg} / \mathrm{kg} /$ day females; however, this finding was not dose dependent and did not occur in both sexes, suggesting that the finding is spurious and not treatment related. Therefore, no statistically significant organ weight changes were related to administration of the tested GGE formulation (Appendix F).

There were no dose-related microscopic findings (Appendix F).

No changes in the clinical chemistry values of male and female mice were attributable to administration of the tested GGE formulation (Appendix F).

Both male and female mice exhibited a dose-related increase in hepatic CYP3A activity following GGE administration, suggesting increased PXR activity (Table 14). CYP3A activity was significantly increased in male mice administered 125 and $250 \mathrm{mg} / \mathrm{kg} /$ day, relative to the vehicle control group. 
Gum Guggul, NTP TOX 99

Table 14. Cytochrome P450 Measurements for Mice in the Interim 28-day Gavage Study of Gum Guggul Extract ${ }^{\mathrm{a}, \mathrm{b}}$

\begin{tabular}{|c|c|c|c|c|c|c|}
\hline & 0 mg/kg/day & $15.5 \mathrm{mg} / \mathrm{kg} / \mathrm{day}$ & 31 mg/kg/day & $62.5 \mathrm{mg} / \mathrm{kg} / \mathrm{day}$ & $125 \mathrm{mg} / \mathrm{kg} /$ day & $250 \mathrm{mg} / \mathrm{kg} /$ day \\
\hline \multicolumn{7}{|l|}{ Male } \\
\hline $\mathbf{n}$ & 5 & 4 & 5 & 5 & 5 & 5 \\
\hline $\begin{array}{l}\text { СYP2B } \\
\text { (pmol/mg/min) }\end{array}$ & $8.600 \pm 0.796$ & $7.955 \pm 0.996$ & $7.396 \pm 0.459$ & $7.172 \pm 0.553$ & $8.244 \pm 0.398$ & $9.466 \pm 0.935$ \\
\hline $\begin{array}{l}\text { CYP3A } \\
\text { (pmol/mg/min) }\end{array}$ & $850.0 \pm 59.6^{* *}$ & $856.8 \pm 54.8$ & $849.4 \pm 47.9$ & $938.8 \pm 68.0$ & $1098.0 \pm 71.7^{*}$ & $1548.0 \pm 146.7^{* *}$ \\
\hline \multicolumn{7}{|l|}{ Female } \\
\hline $\mathbf{n}$ & 5 & 5 & 5 & 5 & 5 & 5 \\
\hline $\begin{array}{l}\text { CYP2B } \\
(\text { pmol/mg/min) }\end{array}$ & $14.880 \pm 0.635$ & $14.340 \pm 0.440$ & $13.344 \pm 1.914$ & $12.320 \pm 0.514$ & $13.718 \pm 1.929$ & $17.400 \pm 1.211$ \\
\hline $\begin{array}{l}\text { CYP3A } \\
(\text { pmol/mg/min })\end{array}$ & $1020.0 \pm 63.6^{*}$ & $945.6 \pm 77.3$ & $872.8 \pm 121.3$ & $1091.2 \pm 76.0$ & $1013.6 \pm 123.1$ & $1376.0 \pm 49.2$ \\
\hline
\end{tabular}

$\overline{\text { Statistical significance for a treatment group indicates a significant pairwise test compared to the vehicle control group. Statistical }}$ significance for the vehicle control group indicates a significant trend test.

*Statistically significant at $\mathrm{p} \leq 0.05 ; * * \mathrm{p} \leq 0.01$.

CYP = cytochrome P450.

a Data are presented as mean \pm standard error.

'Statistical analysis performed by Jonckheere's (trend) and Shirley’s or Dunn's (pairwise) tests. 


\section{Three-month Study}

All mice survived to the end of the study (Table 15). There were no significant treatment-related clinical observations in male or female mice. The final mean body weights of male and female mice in all dosed groups remained within $7 \%$ of the vehicle control body weights (Table 15; Figure 4).

Table 15. Survival and Body Weights of Mice in the Three-month Gavage Study of Gum Guggul Extract $^{\mathrm{a}}$

\begin{tabular}{|c|c|c|c|c|c|}
\hline $\begin{array}{c}\text { Concentration } \\
\text { (mg/kg/day) }\end{array}$ & Survival $^{\mathrm{b}}$ & $\begin{array}{c}\text { Initial Body } \\
\text { Weight } \\
\text { (g) }\end{array}$ & $\begin{array}{l}\text { Final Body } \\
\text { Weight } \\
\text { (g) }\end{array}$ & $\begin{array}{l}\text { Changes in } \\
\text { Body Weight } \\
\text { (g) }\end{array}$ & $\begin{array}{c}\text { Final Weight } \\
\text { Relative to } \\
\text { Controls }^{c}(\%)\end{array}$ \\
\hline \multicolumn{6}{|l|}{ Male } \\
\hline 0 & $15 / 15$ & $24.1 \pm 0.3$ & $35.6 \pm 1.2$ & $11.5 \pm 0.9$ & - \\
\hline 15.5 & $15 / 15$ & $24.1 \pm 0.3$ & $34.8 \pm 0.6$ & $10.7 \pm 0.5$ & -2.12 \\
\hline 31.0 & $15 / 15$ & $24.5 \pm 0.4$ & $36.7 \pm 0.9$ & $12.1 \pm 0.7$ & 3.04 \\
\hline 62.5 & $15 / 15$ & $24.2 \pm 0.4$ & $36.5 \pm 1.1$ & $12.3 \pm 0.8$ & 2.74 \\
\hline 125 & $15 / 15$ & $24.2 \pm 0.4$ & $36.1 \pm 1.2$ & $11.9 \pm 0.8$ & 1.41 \\
\hline 250 & $15 / 15$ & $24.0 \pm 0.4$ & $36.2 \pm 1.5$ & $12.1 \pm 1.2$ & 1.67 \\
\hline \multicolumn{6}{|l|}{ Female } \\
\hline 0 & $15 / 15$ & $18.4 \pm 0.2$ & $27.0 \pm 0.6$ & $8.6 \pm 0.4$ & - \\
\hline 15.5 & $15 / 15$ & $18.5 \pm 0.3$ & $26.8 \pm 0.6$ & $8.3 \pm 0.4$ & -0.76 \\
\hline 31.0 & $15 / 15$ & $18.5 \pm 0.3$ & $27.1 \pm 0.6$ & $8.6 \pm 0.5$ & 0.05 \\
\hline 62.5 & $15 / 15$ & $18.6 \pm 0.3$ & $28.7 \pm 0.8$ & $10.1 \pm 0.7$ & 6.26 \\
\hline 125 & $15 / 15$ & $18.6 \pm 0.2$ & $28.5 \pm 0.8$ & $9.9 \pm 0.6$ & 5.30 \\
\hline 250 & $15 / 15$ & $18.4 \pm 0.2$ & $28.3 \pm 0.8$ & $9.9 \pm 0.7$ & 4.58 \\
\hline
\end{tabular}

${ }^{a}$ Weights and weight changes are given as mean \pm standard error. Differences from the vehicle control group are not significant by the Williams or Dunnett tests.

${ }^{b}$ Number of animals surviving at 92 days/number initially in group.

'[(dosed group mean - control group mean)/control group mean] $\times 100$. 

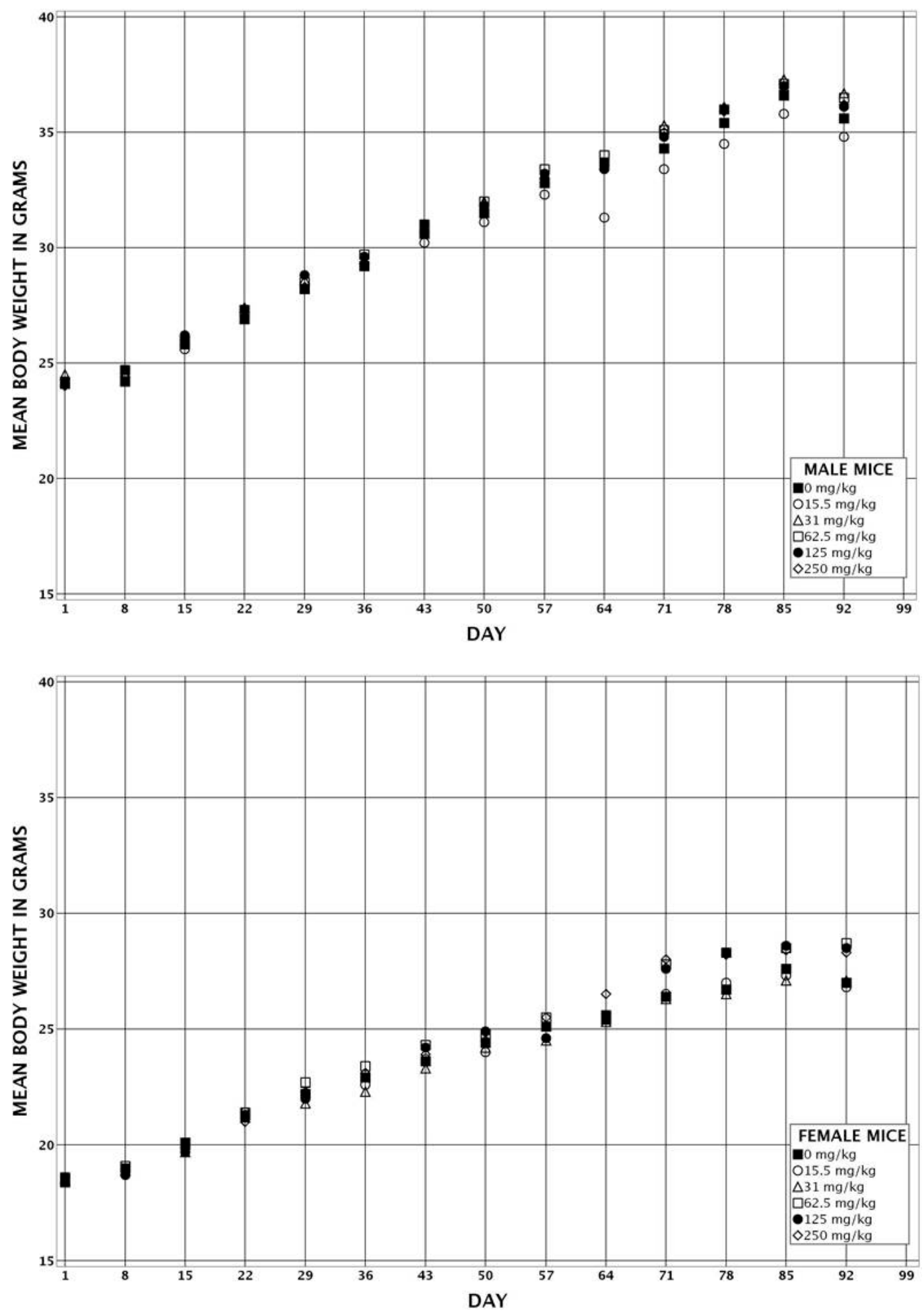

Figure 4. Growth Curves for Male and Female Mice Administered Gum Guggul Extract by Gavage for Three Months 
A dose-related trend of decreased relative kidney weights with increasing dose was observed in female mice, although no dosed group exhibited significantly lower absolute or relative kidney weights, suggesting the finding is spurious and not treatment related. Therefore, there were no statistically significant organ weight changes related to administration of the tested GGE formulation (Appendix F).

There were no dose-related microscopic findings (Appendix F).

Cholesterol concentrations were significantly increased in $62.5 \mathrm{mg} / \mathrm{kg} /$ day or greater females and phospholipid concentrations were significantly increased in $250 \mathrm{mg} / \mathrm{kg} /$ day females, relative to vehicle controls (Table 16).

Table 16. Select Clinical Chemistry Data for Mice in the Three-month Gavage Study of Gum Guggul Extract ${ }^{\mathrm{a}, \mathrm{b}}$

\begin{tabular}{|c|c|c|c|c|c|c|}
\hline & 0 mg/kg/day & 15.5 mg/kg/day & $31 \mathrm{mg} / \mathrm{kg} / \mathrm{day}$ & $62.5 \mathrm{mg} / \mathrm{kg} / \mathrm{day}$ & 125 mg/kg/day & $250 \mathrm{mg} / \mathrm{kg} /$ day \\
\hline $\mathbf{n}$ & 15 & 15 & 15 & 15 & 15 & 15 \\
\hline \multicolumn{7}{|l|}{ Female } \\
\hline Cholesterol (mg/dL) & $146.4 \pm 2.7^{* *}$ & $157.7 \pm 7.3$ & $158.5 \pm 4.7$ & $167.3 \pm 6.8^{*}$ & $168.5 \pm 4.4^{* *}$ & $174.7 \pm 5.2^{* *}$ \\
\hline Phospholipids (mg/dL) & $310.9 \pm 6.8^{* *}$ & $339.6 \pm 16.4$ & $332.2 \pm 10.1$ & $341.2 \pm 13.5$ & $332.8 \pm 8.4$ & $369.6 \pm 7.6^{* *}$ \\
\hline
\end{tabular}

Statistical significance for a treatment group indicates a significant pairwise test compared to the vehicle control group. Statistical significance for the vehicle control group indicates a significant trend test.

*Statistically significant at $\mathrm{p} \leq 0.05$; $* * \mathrm{p} \leq 0.01$.

${ }^{a}$ Data are presented as mean \pm standard error.

bStatistical analysis performed by Jonckheere's (trend) and Shirley’s or Dunn’s (pairwise) tests.

Male mice administered 62.5, 125, and $250 \mathrm{mg} / \mathrm{kg} /$ day GGE formulation exhibited statistically significant lower mean total numbers of homogenization-resistant spermatids (23\%, 18\%, and $37 \%$ lower, respectively), and mean total numbers of homogenization-resistant spermatids/mg testis (21\%, 17\%, and 32\% lower, respectively) relative to the vehicle control group (Table 17). These mice also displayed lower mean numbers of cauda epididymal sperm (15\%, 13\%, and $24 \%$ lower, respectively), and mean numbers of cauda sperm/mg (13\%, 12\%, and 26\% lower, respectively). Testis weight in the $250 \mathrm{mg} / \mathrm{kg} /$ day group was lower (12\%) relative to the vehicle control group, and the trend test was significant. The contralateral testicular weights were similar to vehicle control weights. There were no histopathological findings in the testes or epididymides. Given the concurrent responses (lower spermatid and sperm counts), GGE exhibited the potential to be a reproductive toxicant in male mice. 
Table 17. Select Sperm Count Endpoints for Mice in the Three-month Gavage Study of Gum Guggul Extract ${ }^{\mathrm{a}}$

\begin{tabular}{|c|c|c|c|c|}
\hline & $0 \mathrm{mg} / \mathrm{kg} / \mathrm{day}$ & $62.5 \mathrm{mg} / \mathrm{kg} / \mathrm{day}$ & $125 \mathrm{mg} / \mathrm{kg} /$ day & $250 \mathrm{mg} / \mathrm{kg} / \mathrm{day}$ \\
\hline $\mathbf{n}$ & 10 & 10 & 10 & 10 \\
\hline \multicolumn{5}{|l|}{ Weights (g) ${ }^{b}$} \\
\hline L. cauda epididymis & $0.015 \pm 0.001$ & $0.015 \pm 0.001$ & $0.014 \pm 0.000$ & $0.014 \pm 0.001$ \\
\hline L. epididymis & $0.040 \pm 0.003$ & $0.042 \pm 0.001$ & $0.042 \pm 0.001$ & $0.040 \pm 0.002$ \\
\hline L. testis & $0.111 \pm 0.001^{*}$ & $0.109 \pm 0.002$ & $0.110 \pm 0.003$ & $0.098 \pm 0.008$ \\
\hline \multicolumn{5}{|l|}{ Spermatid Measurements ${ }^{\mathrm{c}}$} \\
\hline Spermatid heads $\left(10^{3} / \mathrm{mg}\right.$ testis $)$ & $253.1 \pm 14.3^{* *}$ & $200.3 \pm 8.2^{* *}$ & $209.7 \pm 15.5^{*}$ & $172.1 \pm 16.6^{* *}$ \\
\hline Spermatid heads (10/testis) & $28.2 \pm 1.7^{* *}$ & $21.8 \pm 1.0^{*}$ & $23.1 \pm 2.0^{*}$ & $17.7 \pm 2.3^{* *}$ \\
\hline \multicolumn{5}{|l|}{ Epididymal Spermatozoal Measurements ${ }^{c}$} \\
\hline Sperm motility (\%) & $85.9 \pm 0.5$ & $85.5 \pm 0.9$ & $85.6 \pm 0.3$ & $85.2 \pm 0.5$ \\
\hline Sperm (103/mg cauda epididymis) & $1604.5 \pm 99.8$ & $1399.7 \pm 106.2$ & $1418.9 \pm 101.6$ & $1192.1 \pm 151.9$ \\
\hline Cauda epididymis sperm count (millions) & $23.3 \pm 1.3$ & $19.9 \pm 1.2$ & $20.3 \pm 1.8$ & $17.8 \pm 2.4$ \\
\hline
\end{tabular}

Statistical significance for a treatment group indicates a significant pairwise test compared to the vehicle control group. Statistical significance for the vehicle control group indicates a significant trend test.

*Statistically significant at $\mathrm{p} \leq 0.05 ; * * \mathrm{p} \leq 0.01$.

a Data are presented as mean \pm standard error.

'Statistical analysis performed by Jonckheere's (trend) and the Williams or Dunnett (pairwise) tests.

'Statistical analysis performed by Jonckheere’s (trend) and Shirley's or Dunn's (pairwise) tests.

Both male and female mice exhibited dose-related increases in hepatic CYP2B and CYP3A activity following administration of the tested GGE formulation, suggesting increased CAR and PXR activities (Table 18). CYP2B activity was significantly increased in $250 \mathrm{mg} / \mathrm{kg} /$ day female mice, relative to vehicle controls. CYP3A activity was significantly increased in 125 and $250 \mathrm{mg} / \mathrm{kg} /$ day male mice and in $250 \mathrm{mg} / \mathrm{kg} /$ day female mice, relative to the vehicle control groups. 
Table 18. Cytochrome P450 Measurements for Mice in the Three-month Gavage Study of Gum Guggul Extract ${ }^{\mathrm{a}, \mathrm{b}}$

\begin{tabular}{|c|c|c|c|c|c|c|}
\hline & 0 mg/kg/day & 15.5 mg/kg/day & $31 \mathrm{mg} / \mathrm{kg} / \mathrm{day}$ & $62.5 \mathrm{mg} / \mathrm{kg} /$ day & 125 mg/kg/day & $250 \mathrm{mg} / \mathrm{kg} /$ day \\
\hline $\mathbf{n}$ & 5 & 5 & 5 & 5 & 5 & 5 \\
\hline \multicolumn{7}{|l|}{ Male } \\
\hline $\begin{array}{l}\text { СYР2B } \\
\text { (pmol/mg/min) }\end{array}$ & $11.468 \pm 0.936 *$ & $9.804 \pm 0.701$ & $11.224 \pm 0.873$ & $10.536 \pm 0.783$ & $11.072 \pm 1.021$ & $16.440 \pm 0.833$ \\
\hline $\begin{array}{l}\text { CYP3A } \\
\text { (pmol/mg/min) }\end{array}$ & $803.8 \pm 55.0^{* *}$ & $802.8 \pm 58.2$ & $920.0 \pm 80.3$ & $965.4 \pm 57.5$ & $1080.0 \pm 21.7^{*}$ & $1740.0 \pm 126.8^{* *}$ \\
\hline \multicolumn{7}{|l|}{ Female } \\
\hline $\begin{array}{l}\text { CYP2B } \\
\quad(\mathrm{pmol} / \mathrm{mg} / \mathrm{min})\end{array}$ & $14.920 \pm 0.984 * *$ & $14.620 \pm 1.116$ & $16.780 \pm 1.386$ & $16.520 \pm 1.548$ & $17.600 \pm 1.051$ & $24.380 \pm 1.554^{* *}$ \\
\hline $\begin{array}{l}\text { CYP3A } \\
\quad(\mathrm{pmol} / \mathrm{mg} / \mathrm{min})\end{array}$ & $1290.0 \pm 59.7^{* *}$ & $1200.6 \pm 192.7$ & $1205.6 \pm 111.1$ & $1402.0 \pm 87.3$ & $1502.0 \pm 95.6$ & $1922.0 \pm 144.8^{* *}$ \\
\hline \multicolumn{7}{|c|}{$\begin{array}{l}\text { Statistical significance for a treatment group indicates a significant pairwise test compared to the } \\
\text { significance for the vehicle control group indicates a significant trend test. } \\
* \text { Statistically significant at } \mathrm{p} \leq 0.05 ;{ }^{* *} \mathrm{p} \leq 0.01 \text {. } \\
\mathrm{CYP}=\text { cytochrome P } 450 \text {. } \\
\text { aData are presented as mean } \pm \text { standard error. } \\
\text { 'Statistical analysis performed by Jonckheere’s (trend) and Shirley’s or Dunn’s (pairwise) tests. }\end{array}$} \\
\hline
\end{tabular}

\section{Genetic Toxicology}

Administration of the GGE formulation for 3 months by gavage did not increase the frequencies of micronucleated reticulocytes (immature erythrocytes) or mature erythrocytes in peripheral blood samples obtained from male and female Sprague Dawley rats (dose range 62.5$1,000 \mathrm{mg} / \mathrm{kg} /$ day) and B6C3F1/N mice (dose range 15.5-250 mg/kg/day) (Appendix B). In addition, no significant changes in the percentage of immature erythrocytes were seen in mice, suggesting that exposure to the GGE formulation did not induce bone marrow toxicity or alter erythropoiesis in these animals. Small increases in percent polychromatic erythrocytes (\% PCE) were observed in rats, but due to the magnitude of the responses, which fell within the laboratory historical control ranges, the increases were not considered biologically significant.

\section{Human In Vitro Activity Assays}

The effects of a GGE formulation and its constituent sterols $Z$ - and $E$-guggulsterone were further investigated using human in vitro assay systems (Table 19, Table 20; Appendix F). Effects on CYP enzyme activity were evaluated in human liver microsomes incubated with a GGE formulation (lot G51177/H), E-guggulsterone, or Z-guggulsterone, all normalized to 0.3, 1, or $10 \mu \mathrm{M}$ guggulsterone concentrations. At a concentration normalized to $0.3 \mu \mathrm{M}$ guggulsterone, the GGE formulation was associated with inhibition of CYP2C19 activity (approximately 56\% lower) relative to control. At a concentration normalized to $10 \mu \mathrm{M}$ guggulsterone, the GGE formulation was associated with inhibition of CYP2D6 (approximately 47\% lower) and CYP3A4-catalyzed testosterone 6 $\beta$-hydroxylase (approximately 74\% lower) activities, relative to control (Table 19). A dose-related inhibition of CYP2C9 was also observed following GGE treatment with statistically significant decreases observed at $0.3 \mu \mathrm{M}$ (approximately $11 \%$ lower), $1 \mu \mathrm{M}$ (approximately 30\%), and $10 \mu \mathrm{M}$ (approximately 86\%). E- and Z-guggulsterones exhibited a similar, but lesser magnitude of inhibition of CYP2C9 (approximately 34\%) at a concentration of $10 \mu \mathrm{M}$ (Table 20). In contrast to the GGE formulation, guggulsterone isomers did not exhibit 
any significant inhibition of CYP2D6 but did inhibit CYP4A9/11 (28-34\%) enzymatic activity. E-guggulsterone displayed an isomer specific inhibition of CYP2C8 activity (18-40\%), however, this effect did not display a concentration-response dependent trend.

Membrane vesicles expressing human Pgp were incubated with GGE (lot G51177/H) and individual guggulsterones normalized to $0.3,1$, or $10 \mu \mathrm{M}$ guggulsterone concentrations to assess test article effects on Pgp ATPase activity (Table 19, Table 20). The GGE formulation induced a dose-related increase in Pgp ATPase activity; the activity levels induced at $10 \mu \mathrm{M}$ guggulsterone were comparable to levels exhibited by the assay positive control, verapamil. Pgp ATPase activity was also increased by $E$ - and Z-guggulsterone treatments.

Xenopus laevis oocytes expressing hNTCP were incubated with GGE (lot G51177/H) normalized to $0.3,1$, or $10 \mu \mathrm{M}$ guggulsterone concentrations to assess test article effects on hNTCP transporter activity (Table 19). The GGE formulation induced a dose-related decrease in the uptake of hNTCP substrate, taurocholic acid. At a concentration normalized to $10 \mu \mathrm{M}$ guggulsterone, GGE was associated with an approximately 90\% decrease in hNTCP transporter activity. 
Table 19. Summary of Human In Vitro Enzyme Activity Following Exposure to Gum Guggul Extract ${ }^{\mathrm{a}, \mathrm{b}, \mathrm{c}}$

\begin{tabular}{|c|c|c|c|c|c|}
\hline & $\mathbf{0} \boldsymbol{\mu M}$ & $0.3 \mu \mathrm{M}$ & $1 \mu \mathrm{M}$ & $10 \mu \mathrm{M}$ & Verapamil $(20 \mu M)^{d}$ \\
\hline \multicolumn{6}{|c|}{ Human Liver Microsomes (nmol/min/mg protein) } \\
\hline 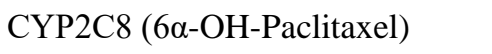 & $0.101 \pm 0.009(2)$ & $0.073 \pm 0.002(2)$ & $0.072 \pm 0.018(3)$ & $0.071 \pm 0.013(2)$ & - \\
\hline CYP2C9 (4-OH-Tolbutamide) & $0.085 \pm 0.001^{* *}(3)$ & $0.076 \pm 0.003 *(3)$ & $0.060 \pm 0.001^{* *}(3)$ & $0.012 \pm 0.001^{* *}(3)$ & - \\
\hline CYP2C19 (4-OH-Mephenytoin) ${ }^{\mathrm{e}}$ & $7.079 \pm 0.253(2)$ & $3.137 \pm 0.732(2)$ & $6.390 \pm 0.822(3)$ & $7.274 \pm 1.385(3)$ & - \\
\hline CYP2D6 (Dextrorphan) & $0.079 \pm 0.004(3)$ & $0.085 \pm 0.001(3)$ & $0.083 \pm 0.003(3)$ & $0.042 \pm 0.004(3)$ & - \\
\hline CYP3A4 (6ß-OH-Testosterone) & $2.427 \pm 0.205^{*}(3)$ & $2.068 \pm 0.054(3)$ & $2.074 \pm 0.143(2)$ & $0.632 \pm 0.057(2)$ & - \\
\hline CYP4A9/11 (12-OH-Lauric Acid) & $1.323 \pm 0.053(3)$ & $1.223 \pm 0.052(3)$ & $1.234 \pm 0.047(3)$ & $1.439 \pm 0.036(3)$ & - \\
\hline \multicolumn{6}{|c|}{ Membrane Vesicles (nmol/min/mg protein) } \\
\hline P-glycoprotein ATPase Activity & $0.807 \pm 0.426^{* *}(6)$ & $3.070 \pm 0.900(2)$ & $8.455 \pm 0.615 *(2)$ & $39.045 \pm 0.095 * *(2)$ & $44.053 \pm 1.109 * *(6)$ \\
\hline
\end{tabular}

\section{Xenopus laevis Oocytes (pmol TCA/oocyte/45 min)}

NTCP-Mediated Uptake of TCA $\quad 0.396 \pm 0.112 * *(7) \quad 0.306 \pm 0.042(6) \quad 0.227 \pm 0.072(7) \quad 0.044 \pm 0.008 * *(5)$

Statistical significance for a treatment group indicates a significant pairwise test compared to the control group. Statistical significance for the control group indicates a significant trend test.

*Statistically significant at $\mathrm{p} \leq 0.05 ; * * \mathrm{p} \leq 0.01$.

CYP = cytochrome P450; TCA = taurocholic acid.

${ }^{\mathrm{a} G G E}$ formulation = lot G51177/H.

${ }^{6}$ Data are presented as mean \pm standard error (n).

'Statistical analysis for all but the verapamil group performed by Jonckheere’s (trend) and Shirley's or Dunn's (pairwise) tests.

${ }^{d}$ Statistical analysis for the verapamil group compared to control performed by the Wilcoxon rank-sum test. Positive controls were only run for the ATPase activity assay.

${ }^{\mathrm{e}} \mathrm{CYP} 2 \mathrm{C} 19$ activity presented as $\mathrm{pmol} / \mathrm{min} / \mathrm{mg}$ protein. 


\section{Table 20. Summary of Human In Vitro Enzyme Activity Following Exposure to E- or Z-Guggulsterone ${ }^{\mathrm{a}, \mathrm{b}}$}

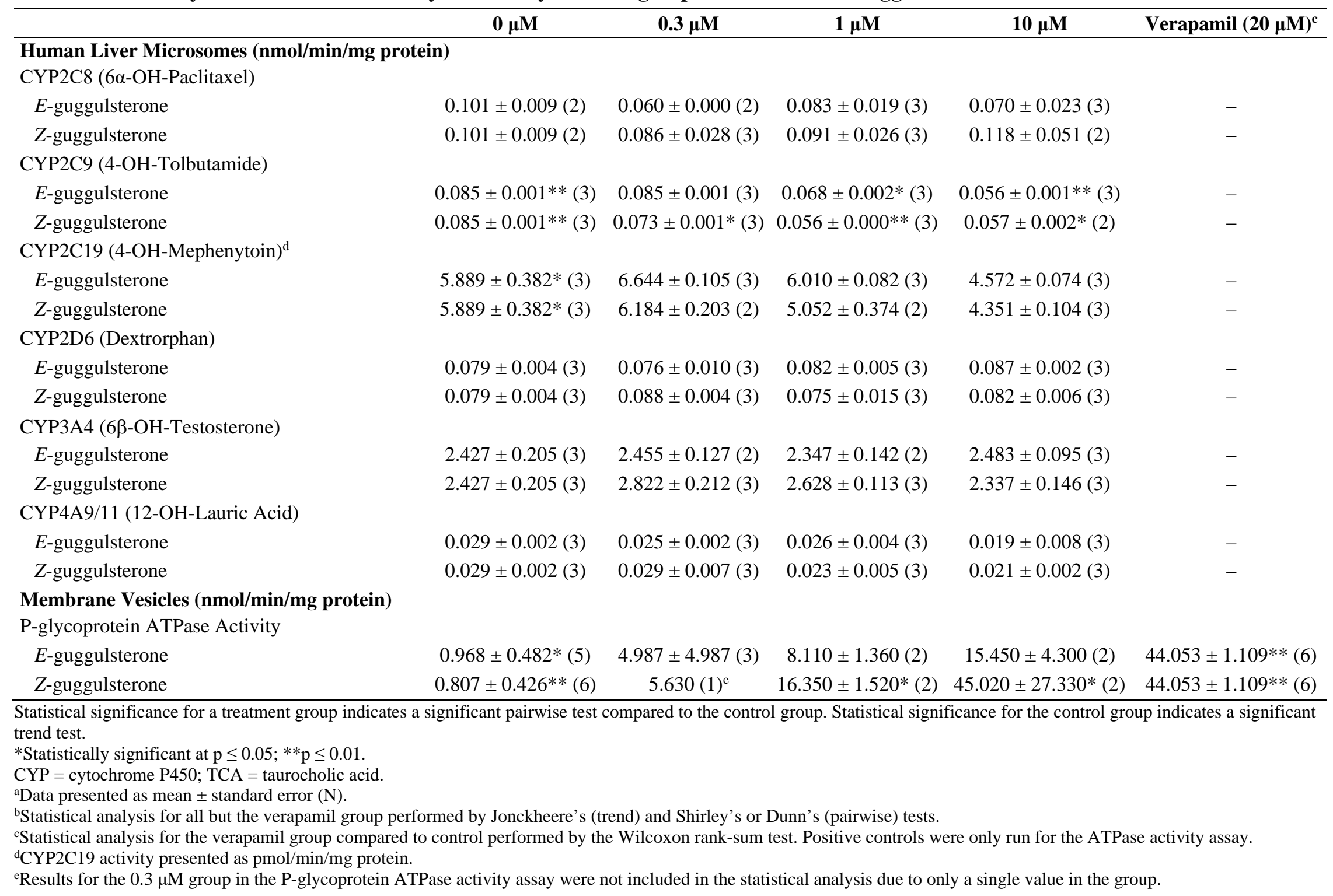




\section{Discussion}

Gum guggul extracts (GGEs) are substances commonly used in traditional Ayurvedic medicine for the treatment of hyperlipidemia, obesity, diabetes, atherosclerosis, and inflammatory conditions such as arthritis. ${ }^{1 ; 87-89 ; 12 ; 90}$ In the United States, GGEs are marketed as dietary supplements that will help control serum lipid and cholesterol concentrations and stimulate the thyroid gland. GGE was nominated for study by the National Institute of Environmental Health Sciences for toxicological characterization because of its expanding use as a dietary supplement and a lack of available information to adequately assess safe use in humans. In alignment with the National Toxicology Program's (NTP) Dietary Supplements research program, 28-day and 3-month studies were conducted to evaluate the subchronic toxicity of a GGE formulation.

Gugulipid $^{\circledR}$ 2.5\% granules formulation was procured as a representative GGE formulation due to its commercial availability and standardized phytochemical profile, which is labeled to contain 2.5\% of the presumed active constituents, Z- and E-guggulsterone. After sieving, the tested GGE formulation contained only $1.46 \%$ guggulsterone content and significant levels of excipients (approximately 62.2\%), including magnesium carbonate and corn starch, among others. These excipient levels were not controlled for in the vehicle groups and therefore should be a consideration in the toxicological interpretations of these studies.

In the current 28-day and 3-month gavage studies, no treatment-related effects on survival, body weight, or gross or microscopic pathology findings were observed following administration of the tested GGE formulation up to $1,000 \mathrm{mg} / \mathrm{kg} /$ day in Hsd:Sprague Dawley ${ }^{\circledR} \mathrm{SD}^{\circledR}$ rats and up to $250 \mathrm{mg} / \mathrm{kg} /$ day in B6C3F1/N mice.

Increases in globulin concentrations were observed in rats at both day 28 (males and females) and day 92 (females only). Globulins are a heterogeneous population of proteins that include immunoglobulins, transport proteins, and acute phase proteins, among others, and are produced by lymphocytes (immunoglobulins) or the liver. A common cause of increased globulins is inflammation, but no indications of inflammation were observed. An explanation for the increase in globulin concentrations in this study is not known.

A previous study suggested that GGEs increase total triiodothyronine $\left(\mathrm{T}_{3}\right)$ serum concentrations. ${ }^{46}$ Thyroid-stimulatory activity-defined as increased thyroid tissue peroxidase and protease activities, and increased ${ }^{131}$ Iodine uptake by the thyroid gland-was observed in rats following administration of the individual gum guggul phytochemical constituent, Z-guggulsterone, suggesting it might be the active pharmacological agent inducing this effect. ${ }^{37}$ In the current study, serum thyroid stimulating hormone (TSH) concentrations were significantly increased in female rats dosed with 500 or $1,000 \mathrm{mg} / \mathrm{kg} /$ day for 28 days. Increased TSH is associated with decreased thyroid function; however, there was no correlative decrease in thyroxine $\left(T_{4}\right)$ or $T_{3}$ concentrations, and these changes were not observed in the 3-month study. Other statistically significant changes in thyroid hormone concentrations were small and lacked a dose response in male and female rats and were not attributed to administration of the tested GGE formulation. Therefore, purported thyroid-stimulatory effects suggested by other studies were not found in this study.

Due to the reported pharmacological efficacy of GGE consumption for prevention of hypercholesterolemia and cardiovascular disease, additional measures of serum phospholipid, 
triglyceride, and cholesterol concentrations were assessed in 28-day and 3-month animal studies. ${ }^{6 ; 1 ; 26}$ In the current study, disparate effects on serum lipid concentrations were evident between different test species, sex, and duration of exposure. Small dose-related increases in serum cholesterol and phospholipid concentrations were observed in female mice administered a GGE formulation for 3 months. This observation coincides with a recent study that found consumption of a GGE to cause hypercholesterolemia and increased incidence of atherosclerosis in wildtype C57BL/6 and atherosclerosis-prone transgenic male mice. ${ }^{91}$ In the current studies, decreased serum cholesterol, phospholipid, and bile acid concentrations occurred in 28-daytreated male rats but were not observed following 3 months of treatment. Additionally, bile acid concentrations were significantly decreased in all dosed groups of female rats at day 92 . The nuclear farnesoid X receptor (FXR), plays a major role in the formation of bile acids from cholesterol by regulation of bile salt export pump (BSEP) and cholesterol 7 alpha-hydroxylase (cytochrome P450 [CYP] 7A1) through a positive feed-forward and a negative feedback mechanism, respectively. ${ }^{15}$ Findings by Deng et al. ${ }^{15}$ demonstrated that although guggulsterone antagonizes FXR, it also up-regulates BSEP independent of FXR, demonstrating two opposite effects on BSEP. Guggulsterone's direct up-regulation of BSEP is dominant over its FXR-mediated antagonism, and is a plausible mechanism for the hypolipidemic effect of GGEs. ${ }^{15 ;} 92$ Increases in BSEP result in increased bile acid excretion, which might be reflected in lower serum bile acid concentrations.

In the 3-month studies, GGE formulation exposure via oral gavage exhibited the potential to be a reproductive toxicant in male mice, but not in rats, as evidenced by decreased testicular spermatid head counts and a corresponding decrease in testicular weights with increasing dose. In contrast, testicular spermatid head counts were significantly increased in male rats administered up to $1,000 \mathrm{mg} / \mathrm{kg} / \mathrm{day}$, fourfold higher than the highest dose administered to mice. No corresponding decreases in sperm motility or cauda epididymal sperm counts were noted in male mice. Additionally, no microscopic findings were noted in the male reproductive tract of mice or rats. Guggulsterone has been shown to bind to the androgen receptor, among other steroid binding receptors, and affects receptor activation in in vitro model systems. ${ }^{93}$; 94 Further studies that examine functional effects on fertility are needed to definitively evaluate the potential reproductive toxicity of GGEs.

In the current studies, dose-related increases in hepatic CYP2B and CYP3A activity, indicative of constitutive androstane receptor (CAR) and pregnane $X$ receptor (PXR) activation, occurred in treated male and female rats and mice at both 28-day and 3-month time points. Length of exposure was considered a determinant for the magnitude of GGE-associated increases in CYP2B activity observed in 1,000 $\mathrm{mg} / \mathrm{kg} /$ day male and female rats. However, low basal CYP3A activity and a lower overall magnitude of induction were evident in dosed female rats (3-month study). The tested GGE formulation increased liver weights in male and female rats (28-day and 3-month studies); however, no histologic lesions of the liver were observed. Apparent liver weight increases likely represent an adaptive response due to increased expression of xenobiotic metabolism enzymes. Liver weight effects were more pronounced in rats, which could be attributed to the rats' receiving a higher dose on a $\mathrm{mg} / \mathrm{kg} /$ day basis. Neither sex nor length of exposure was considered a determinant for the magnitude of GGE-associated increases in CYP2B or CYP3A activity in mice.

In vitro incubations of human hepatic microsomes with the procured GGE formulation normalized to $10 \mu \mathrm{M}$ guggulsterones resulted in significant inhibition of CYP2C9, 
CYP3A4-mediated testosterone 6 $\beta$-hydroxylase, and CYP2C19 metabolic activity. However, treatments of $Z$ - or E-guggulsterone constituents in isolation did not demonstrate a similar level of CYP inhibition, suggesting that other formulation constituents likely contribute to observed activities. Both the tested GGE formulation and individual guggulsterone isomers increased human Pgp ATPase activity, suggesting that guggulsterone constituents may be substrates for the human Pgp transporter. GGE formulation treatment also significantly attenuated taurocholate uptake in hNTCP assays, suggesting effects on bile acid uptake/excretion pathways. These results indicate that GGE constituents can influence the activity of multiple endogenous enzymes and transporters and suggest a potential for botanical-drug interactions that could alter bioavailability, efficacy, or toxicity of prescription drugs when taken concomitantly with products containing GGE. Prescription drugs targeted by these enzymes/transporters include the anticoagulant warfarin, nonsteroidal anti-inflammatory drugs, cholesterol-lowering statins, and rosuvastatin. ${ }^{95}$; 96 Recent studies report increasing use of botanical supplements in combination with prescribed and over-the-counter medication among U.S. adults aged 57-85 years. ${ }^{97}$ Combinatorial use of dietary supplements with marketed pharmaceuticals can lead to pharmacokinetic interactions, which can have dire influences on the efficacy of a drug or result in significant toxicity. Given the purported clinical indications for GGEs to reduce serum total cholesterol, low-density lipoprotein, and triglycerides, and to increase high-density lipoprotein concentrations, it is plausible that individuals may consume GGE-containing products in combination with clinically prescribed or over-the-counter medications. CYP enzymes are involved in the metabolism of roughly $75 \%$ of marketed drugs. ${ }^{98}$ Induction of CYP2 and CYP3 family enzymes by PXR and CAR constitute two major xenobiotic metabolism pathways involved in drug bioactivation or removal. Therefore, observed alterations in drug metabolism and excretion pathways following the administration of the GGE formulation support increased potential for altered pharmacokinetic/pharmacodynamic parameters of pharmaceuticals subject to metabolism by these enzymatic pathways. This explanation is supported by the observation that the beta blocker propranolol and the antihypertensive drug diltiazem show decreased bioavailability when taken concurrently with gum guggul. ${ }^{43}$

The tested GGE formulation did not induce bone marrow toxicity or alter erythropoiesis as evidenced by no increases in the frequency of micronucleated reticulocytes or erythrocytes in peripheral blood of male or female rats or mice after 3 months of exposure.

In the 3-month studies, the most sensitive measures of GGE formulation administration in each species and sex were increased hepatic CYP2B activity in male rats (lowest-observed-effect level [LOEL] = $125 \mathrm{mg} / \mathrm{kg} /$ day), decreased serum bile acid concentrations in female rats (LOEL $=62.5 \mathrm{mg} / \mathrm{kg} /$ day), decreased testicular spermatid head counts in male mice (LOEL = $62.5 \mathrm{mg} / \mathrm{kg} /$ day), and increased serum cholesterol concentrations in female mice $(\mathrm{LOEL}=62.5 \mathrm{mg} / \mathrm{kg} /$ day $)$.

The recommended daily intake of GGE formulations is highly variable among different manufacturers. The Indian Pharmacopeia bases its recommended daily intake levels of GGEs on the concentration of guggulsterones, such that consumption equates to $75 \mathrm{mg}$ guggulsterones (25 mg, three times a day). ${ }^{28}$ Assuming a daily intake of $75 \mathrm{mg}$ of guggulsterones and an adult weight of $60 \mathrm{~kg}$, average human daily consumption would equate to $1.25 \mathrm{mg}$ guggulsterones/kg/day or $85.6 \mathrm{mg}$ GGE formulation/kg/day based on the $1.46 \%$ guggulsterone content of the tested formulation. Interspecies differences in guggulsterone isomer metabolism have not been reported. In a previously conducted clinical trial, individuals were treated with 


\section{Gum Guggul, NTP TOX 99}

a guggulipid formulation at doses of up to $150 \mathrm{mg}$ guggulsterones/day for 8 weeks, with adverse reports limited to low incidences of diarrhea and the development of a hypersensitivity skin rash. ${ }^{36}$ 


\section{Conclusions}

Under the conditions of the 3-month gavage studies, administration of the selected GGE formulation resulted in increased globulin concentrations and decreased bile acid, cholesterol, and phospholipid concentrations in rats, whereas increases in cholesterol and phospholipid concentrations were observed in mice. Decreased mean number of homogenization-resistant spermatids was evident in mice administered the GGE formulation, suggesting the testes might be a target organ of GGE toxicity (lowest-observed-effect level $=62.5 \mathrm{mg} / \mathrm{kg} /$ day). Male and female rats displayed significantly increased absolute and relative liver weights that were related to the GGE formulation dose administered. Additionally, increased hepatic CYP3A and CYP2B activity was observed in both test species, and metabolic potential was altered in human in vitro assays, suggesting an increased potential for dietary supplement-drug pharmacokinetic interactions. 


\section{References}

1. Shah R, Gulati V, Palombo EA. Pharmacological properties of guggulsterones, the major active components of gum guggul. Phytother Res. 2012; 26(11):1594-1605.

http://dx.doi.org/10.1002/ptr.4647

2. Atal CK, Gupta OP, Afaq SH. Commiphora mukul: Source of guggal in Indian systems of medicine. Econ Bot. 1975; 29(3):209-218. http://dx.doi.org/10.1007/BF02873167

3. Dastur JF. Medicinal plants of India and Pakistan. Bombay, India: Taraporevala and Sons; 1977.

4. Indian Council of Medical Research. Medicinal plants of India. New Delhi, India; 1987.

5. Sarup P, Bala S, Kamboj S. Pharmacology and phytochemistry of oleo-gum resin of Commiphora wightii (guggulu). Scientifica. 2015; 2015:1-14.

http://dx.doi.org/10.1155/2015/138039

6. Deng R. Therapeutic effects of guggul and its constituent guggulsterone: Cardiovascular benefits. Cardiovasc Drug Rev. 2007; 25(4):375-390. http://dx.doi.org/10.1111/j.15273466.2007.00023.X

7. Bajaj AG, Dev S. Chemistry of ayurvedic crude drugs-V: Guggulu (resin from commiphora mukul) - 5 some new steroidal components and, stereochemistry of guggulsterol-I at C-20 and C-22. Tetrahedron. 1982; 38(19):2949-2954. http://dx.doi.org/10.1016/0040-4020(82)85024-2

8. Mesrob B, Nesbitt C, Misra R, Pandey RC. High-performance liquid chromatographic method for fingerprinting and quantitative determination of E- and Z-guggulsterones in Commiphora mukul resin and its products. J Chromatogr B Biomed Appl. 1998; 720(1-2):189-196.

http://dx.doi.org/10.1016/S0378-4347(98)00433-2

9. Chander R, Khanna AK, Kapoor NK. Lipid lowering activity of guggulsterone from Commiphora mukul in hyperlipaemic rats. Phytother Res. 1996; 10(6):508-511. http://dx.doi.org/10.1002/(SICI)1099-1573(199609)10:6<508::AID-PTR895>3.0.CO;2-P

10. Cheon JH, Kim JS, Kim JM, Kim N, Jung HC, Song IS. Plant sterol guggulsterone inhibits nuclear factor-kappaB signaling in intestinal epithelial cells by blocking IkappaB kinase and ameliorates acute murine colitis. Inflamm Bowel Dis. 2006; 12(12):1152-1161. http://dx.doi.org/10.1097/01.mib.0000235830.94057.c6

11. Meselhy MR. Inhibition of LPS-induced NO production by the oleogum resin of Commiphora wightii and its constituents. Phytochemistry. 2003; 62(2):213-218. http://dx.doi.org/10.1016/S0031-9422(02)00388-6

12. Singh RB, Niaz MA, Ghosh S. Hypolipidemic and antioxidant effects of Commiphora mukul as an adjunct to dietary therapy in patients with hypercholesterolemia. Cardiovasc Drugs Ther. 1994; 8(4):659-664.

13. Urizar NL, Liverman AB, Dodds DNT, Silva FV, Ordentlich P, Yan Y, Gonzalez FJ, Heyman RA, Mangelsdorf DJ, Moore DD. A natural product that lowers cholesterol as an 
antagonist ligand for FXR. Science. 2002; 296(5573):1703-1706.

http://dx.doi.org/10.1126/science.1072891

14. Cui J, Huang L, Zhao A, Lew JL, Yu J, Sahoo S, Meinke PT, Royo I, Peláez F, Wright SD. Guggulsterone is a farnesoid $\mathrm{X}$ receptor antagonist in coactivator association assays but acts to enhance transcription of bile salt export pump. J Biol Chem. 2003; 278(12):10214-10220. http://dx.doi.org/10.1074/jbc.M209323200

15. Deng R, Yang D, Radke A, Yang J, Yan B. The hypolipidemic agent guggulsterone regulates the expression of human bile salt export pump: dominance of transactivation over farsenoid $\mathrm{X}$ receptor-mediated antagonism. J Pharmacol Exp Ther. 2007; 320(3):1153-1162.

http://dx.doi.org/10.1124/jpet.106.113837

16. Brobst DE, Ding X, Creech KL, Goodwin B, Kelley B, Staudinger JL. Guggulsterone activates multiple nuclear receptors and induces CYP3A gene expression through the pregnane $\mathrm{X}$ receptor. J Pharmacol Exp Ther. 2004; 310(2):528-535.

http://dx.doi.org/10.1124/jpet.103.064329

17. Kulhari A, Sheorayan A, Chaudhury A, Sarkar S, Kalia RK. Quantitative determination of guggulsterone in existing natural populations of Commiphora wightii (Arn.) Bhandari for identification of germplasm having higher guggulsterone content. Physiol Mol Biol Plants. 2014; 21(1):71-81. http://dx.doi.org/10.1007/s12298-014-0271-1

18. Bhatt JR, Nair MNB, Ram HYM. Enhancement of oleo-gum resin production in Commiphora wightii by improved tapping technique. Curr Sci. 1989; 58(7):349-357.

19. Samanta JN, Mandal K, Maiti S. A novel pathovar of Xanthomonas axonopodis causes gumming of Guggal (Commiphora wightii). Eur J Plant Pathol. 2013; 135(1):115-125. http://dx.doi.org/10.1007/s10658-012-0070-X

20. Ved D, Saha D, Ravikumar K, Haridasan K. Commiphora wightii. The IUCN Red List of Threatened Species; 2015. https://www.iucnredlist.org/species/31231/50131117

21. Saini LS, Rajput SK, Rathore TR, Tomar UK. Non-destructive harvesting of oleo-gum resin in Commiphora wightii (Arnott) Bhandari-A critically endangered plant. Ind Crops Prod. 2018; 113:259-265. http://dx.doi.org/10.1016/j.indcrop.2018.01.057

22. Dixit AM, Subba Rao SV. Observation on distribution and habitat characteristics of Gugal (Commiphora wightii) in the arid region of Kachchh, Gujarat (India). Trop Ecol. 2000; 41(1):8188.

23. United States Pharmacoepia (USP). Dietary supplements compendium: Guggul. 2015. p. 117-119.

24. Clarke TC, Black LI, Stussman BJ, Barnes PM, Nahin RL. Trends in the use of complementary health approaches among adults: United States, 2002-2012. Natl Health Stat Report. 2015; (79):1.

25. Shipkowski KA, Betz JM, Birnbaum LS, Bucher JR, Coates PM, Hopp DC, MacKay D, Oketch-Rabah H, Walker NJ, Welch C et al. Naturally complex: Perspectives and challenges 
associated with Botanical Dietary Supplement Safety assessment. Food Chem Toxicol. 2018; 118:963-991. http://dx.doi.org/10.1016/j.fct.2018.04.007

26. Ulbricht C, Basch E, Szapary P, Hammerness P, Axentsev S, Boon H, Kroll D, Garraway L, Vora M, Woods J. Guggul for hyperlipidemia: A review by the Natural Standard Research Collaboration. Complement Ther Med. 2005; 13(4):279-290.

http://dx.doi.org/10.1016/j.ctim.2005.08.003

27. World Health Organization (WHO). Gummi gugguli. In: WHO Monographs on Selected Medicinal Plants Vol 3. 2007. p. 169-181.

28. Indian Ministry of Health and Family Welfare. Indian pharmacopoeia. Vol 2. New Delhi, India: Delhi: Controller of Publications; 1996. p. 357-358.

29. Badmaev V, Majeed M. The 99\% guggulsterones tragedy. Nutraceuticals. 2004; p. 11-12.

30. Agarwal RC, Singh SP, Saran RK, Das SK, Sinha N, Asthana OP, Gupta PP, Nityanand S, Dhawan BN, Agarwal SS. Clinical trial of gugulipid--a new hypolipidemic agent of plant origin in primary hyperlipidemia. Indian J Med Res. 1986; 84:626-634.

31. Gopal K, Saran RK, Nityanand S, Gupta PP, Hasan M, Das SK, Sinha N, Agarwal SS. Clinical trial of ethyl acetate extract of gum gugulu (gugulipid) in primary hyperlipidemia. J Assoc Physicians India. 1986; 34(4):249-251.

32. Kuppurajan K, Rajagopalan SS, Rao TK, Sitaraman R. Effect of guggulu (Commiphora mukul--Engl.) on serum lipids in obese, hypercholesterolemic and hyperlipemic cases. J Assoc Physicians India. 1978; 26(5):367-373.

33. Malhotra SC, Ahuja MM, Sundaram KR. Long term clinical studies on the hypolipidaemic effect of Commiphora mukul (Guggulu) and clofibrate. Indian J Med Res. 1977; 65(3):390-395.

34. Nityanand S, Srivastava JS, Asthana OP. Clinical trials with gugulipid. A new hypolipidaemic agent. J Assoc Physicians India. 1989; 37(5):323-328.

35. Verma SK, Bordia A. Effect of Commiphora mukul (gum guggulu) in patients of hyperlipidemia with special reference to HDL-cholesterol. Indian J Med Res. 1988; 87:356-360.

36. Szapary PO, Wolfe ML, Bloedon LT, Cucchiara AJ, DerMarderosian AH, Cirigliano MD, Rader DJ. Guggulipid for the treatment of hypercholesterolemia: A randomized controlled trial. JAMA. 2003; 290(6):765-772. http://dx.doi.org/10.1001/jama.290.6.765

37. Tripathi YB, Malhotra OP, Tripathi SN. Thyroid stimulating action of Z-guggulsterone obtained from Commiphora mukul. Planta Med. 1984; 50(1):78-80. http://dx.doi.org/10.1055/s$\underline{2007-969626}$

38. Abdel-Rahman A, Anyangwe N, Carlacci L, Casper S, Danam RP, Enongene E, Erives G, Fabricant D, Gudi R, Hilmas CJ. The safety and regulation of natural products used as foods and food ingredients. Toxicol Sci. 2011; 123(2):333-348.

39. Verma N, Singh SK, Gupta RC. Pharmacokinetics of guggulsterone after intravenous and oral administration in rats. Pharm Pharmacol Commun. 1999; 5(5):349-354. 
40. Chhonker YS, Chandasana H, Mukkavilli R, Prasad YD, Laxman TS, Vangala S, Bhatta RS. Assessment of in vitro metabolic stability, plasma protein binding, and pharmacokinetics of Eand Z-guggulsterone in rat. Drug Test Anal. 2016; 8(9):966-975.

http://dx.doi.org/10.1002/dta.1885

41. Bhatta RS, Kumar D, Chhonker YS, Jain GK. Simultaneous estimation of E- and Z- isomers of guggulsterone in rabbit plasma using liquid chromatography tandem mass spectrometry and its application to pharmacokinetic study. Biomed Chromatogr. 2011; 25(9):1054-1060. http://dx.doi.org/10.1002/bmc.1574

42. Yang D, Yang J, Shi D, Xiao D, Chen Y-T, Black C, Deng R, Yan B. Hypolipidemic agent Z-guggulsterone: Metabolism interplays with induction of carboxylesterase and bile salt export pump. J Lipid Res. 2012; 53(3):529-539. http://dx.doi.org/10.1194/jlr.M014688

43. Dalvi SS, Nayak VK, Pohujani SM, Desai NK, Kshirsagar NA, Gupta KC. Effect of gugulipid on bioavailability of diltiazem and propranolol. J Assoc Physicians India. 1994; 42(6):454-455.

44. Badmaev V, Majeed M, Pachetti B, Prakash L. Standardization of Commiphora mukul in dislipidemia and cardiovascular disease. NUTRAfoods. 2003; 2(2):45-51.

45. Bagi MK, Kakrani HK, Kalyani GA, Satyanarayana D, Manvi FV. Preliminary pharmacological studies of essential oil from Commiphora mukul. Fitoterapia. 1985; 56.

46. Panda S, Kar A. Gugulu (Commiphora mukul) induces triiodothyronine production: Possible involvement of lipid peroxidation. Life Sci. 1999; 65(12):137-141.

http://dx.doi.org/10.1016/S0024-3205(99)00369-0

47. Bordia A, Chuttani SK. Effect of gum guggulu on fibrinolysis and platelet adhesiveness in coronary heart disease. Indian J Med Res. 1979; 70:992-996.

48. Gaur SPS, Garg RK, Kar AM, Purohit YK, Gupta A. Gugulipid, a new hypolipidaemic agent, in patients of acute ischaemic stroke: Effect on clinical outcome, platelet function and serum lipids. Asia Pacific J Pharmacol. 1997; 12(3-4):65-69.

49. Sahni S, Hepfinger CA, Sauer KA. Guggulipid use in hyperlipidemia: Case report and review of the literature. Am J Health Syst Pharm. 2005; 62(16):1690-1692.

http://dx.doi.org/10.2146/ajhp040580

50. Grieco A, Miele L, Pompili M, Biolato M, Vecchio FM, Grattagliano I, Gasbarrini G. Acute hepatitis caused by a natural lipid-lowering product: When "alternative" medicine is no "alternative" at all. J Hepatol. 2009; 50(6):1273-1277.

http://dx.doi.org/10.1016/j.jhep.2009.02.021

51. Food and Drug Administration (FDA). MedWatch: The FDA safety information and adverse event reporting program (online). Silver Spring, MD; 2014.

https://www.fda.gov/safety/medwatch/default.htm [Accessed: November 12, 2018]

52. Amma MK, Malhotra N, Suri RK, Arya OP, Dani HM, Sareen K. Effect of oleoresin of gum guggul (Commiphora mukul) on the reproductive organs of female rat. Indian J Exp Biol. 1978; 16(9):1021-1023. 
53. Indian Ministry of Health and Family Welfare. Studies on gugglu. New Delhi, India: Central Council for Research in Ayurveda and Siddha; 1989.

54. Yamada T, Sugimoto K. Guggulsterone and its role in chronic diseases. In: Drug Discovery from Mother Nature. Springer; 2016. p. 329-361.

55. Frawley RP, Smith M, Cesta MF, Hayes-Bouknight S, Blystone C, Kissling GE, Harris S, Germolec D. Immunotoxic and hepatotoxic effects of perfluoro-n-decanoic acid (PFDA) on female Harlan Sprague-Dawley rats and B6C3F1/N mice when administered by oral gavage for 28 days. J Immunotoxicol. 2018; 15(1):41-52.

56. Xue-jun Y, De-xiang L, Hechuan W, Yu Z. A study on the mutagenicity of 102 raw pharmaceuticals used in Chinese traditional medicine. Mutat Res. 1991; 260(1):73-82. http://dx.doi.org/10.1016/0165-1218(91)90082-W

57. Macha MA, Matta A, Chauhan SS, Siu KWM, Ralhan R. Guggulsterone targets smokeless tobacco induced PI3K/Akt pathway in head and neck cancer cells. PLoS One. 2011; 6(2). http://dx.doi.org/10.1371/journal.pone.0014728

58. Yamada T, Osawa S, Ikuma M, Kajimura M, Sugimoto M, Furuta T, Iwaizumi M, Sugimoto K. Guggulsterone, a plant-derived inhibitor of NF-TB, suppresses CDX2 and COX-2 expression and reduces the viability of esophageal adenocarcinoma cells. Digestion. 2014; 90(3):208-217. http://dx.doi.org/10.1159/000365750

59. American Herbal Productions Association (AHPA). Heavy metals: Analysis and limits in herbal dietary supplements. Silver Spring, MD: AHPA; 2009. http://www.naturalhealthresearch.org/wp-content/uploads/2013/02/09_1214_AHPA_HeavyMetals-White-Paper-Revised.pdf

60. International Council for Harmonisation of Technical Requirements for Pharmaceuticals for Human Use (ICH). Guideline for elemental impurities Q3D(R1). Amsterdam, The Netherlands: European Medicines Agency, Committee for Human Medicinal Products; 2019.

61. Maronpot R, Boorman G. Interpretation of rodent hepatocellular proliferative alterations and hepatocellular tumors in chemical safety assessment. Toxicol Pathol. 1982; 10(2):71-78.

62. Boorman G, Montgomery C, Eustis S, Wolfe M, McConnell E, Hardisty J. Quality assurance in pathology for rodent carcinogenicity studies In: Milman H, Weisburger E, editors. Handbook of Carcinogen Testing. Park Ridge, NJ: Noyes Publications; 1985. p. 345-357.

63. Gart JJ, Chu KC, Tarone RE. Statistical issues in interpretation of chronic bioassay tests for carcinogenicity. J Natl Cancer Inst. 1979; 62(4):957-974.

64. Armitage P. Statistical methods in medical research. New York, NY: John Wiley and Sons; 1971. p. 362-365.

65. Dunnett CW. A multiple comparison procedure for comparing several treatments with a control. J Am Stat Assoc. 1955; 50(272):1096-1121.

66. Williams D. A test for differences between treatment means when several dose levels are compared with a zero-dose control. Biometrics. 1971; 27:103-117. 
67. Williams D. The comparison of several dose levels with a zero dose control. Biometrics. 1972:519-531.

68. Shirley E. A non-parametric equivalent of Williams' test for contrasting increasing dose levels of a treatment. Biometrics. 1977:386-389.

69. Williams D. A note on Shirley's nonparametric test for comparing several dose levels with a zero-dose control. Biometrics. 1986:183-186.

70. Dunn OJ. Multiple comparisons using rank sums. Technometrics. 1964; 6(3):241-252.

71. Jonckheere AR. A distribution-free k-sample test against ordered alternatives. Biometrika. 1954; 41(1/2):133-145.

72. Dixon W, Massey F. Introduction to statistical analysis. 2nd ed. New York, NY: McGraw Hill; 1957. p. 145-147, 276-278, 412.

73. Wilcoxon F. Individual comparisons by ranking methods. Biometrics. 1945; 1:80-83.

74. Code of Federal Regulations (CFR). 21:Part 58.

75. Witt KL, Livanos E, Kissling GE, Torous DK, Caspary W, Tice RR, Recio L. Comparison of flow cytometry- and microscopy-based methods for measuring micronucleated reticulocyte frequencies in rodents treated with nongenotoxic and genotoxic chemicals. Mutat Res. 2008; 649(1-2):101-113. http://dx.doi.org/10.1016/j.mrgentox.2007.08.004

76. Kissling GE, Dertinger SD, Hayashi M, MacGregor JT. Sensitivity of the erythrocyte micronucleus assay: Dependence on number of cells scored and inter-animal variability. Mutat Res. 2007; 634(1-2):235-240. http://dx.doi.org/10.1016/j.mrgentox.2007.07.010

77. Igl B-W, Bitsch A, Bringezu F, Chang S, Dammann M, Frötschl R, Harm V, Kellner R, Krzykalla V, Lott J. The rat bone marrow micronucleus test: statistical considerations on historical negative control data. Regul Toxicol Pharmacol. 2019; 102:13-22.

78. Hickman D, Wang J-P, Wang Y, Unadkat JD. Evaluation of the selectivity of in vitro probes and suitability of organic solvents for the measurement of human cytochrome P450 monooxygenase activities. Drug Metab Disposition. 1998; 26(3):207-215.

79. Harris JW, Rahman A, Kim B-R, Guengerich FP, Collins JM. Metabolism of taxol by human hepatic microsomes and liver slices: participation of cytochrome P450 3A4 and an unknown P450 enzyme. Cancer Res. 1994; 54(15):4026-4035.

80. Miners JO, Smith KJ, Robson RA, McManus ME, Veronese ME, Birkett DJ. Tolbutamide hydroxylation by human liver microsomes: Kinetic characterisation and relationship to other cytochrome P-450 dependent xenobiotic oxidations. Biochem Pharmacol. 1988; 37(6):11371144.

81. Koop DR. Hydroxylation of p-nitrophenol by rabbit ethanol-inducible cytochrome P-450 isozyme 3a. Mol Pharmacol. 1986; 29(4):399-404.

82. Laurenzana EM, Sorrels SL, Owens SM. Antipeptide antibodies targeted against specific regions of rat CYP2D1 and human CYP2D6. Drug Metab Disposition. 1995; 23(2):271-278. 
83. Clarke SE, Baldwin SJ, Bloomer JC, Ayrton AD, Sozio RS, Chenery RJ. Lauric acid as a model substrate for the simultaneous determination of cytochrome P450 2E1 and 4A in hepatic microsomes. Chem Res Toxicol. 1994; 7(6):836-842.

84. Patki KC, von Moltke LL, Greenblatt DJ. In vitro metabolism of midazolam, triazolam, nifedipine, and testosterone by human liver microsomes and recombinant cytochromes p450: role of cyp3a4 and cyp3a5. Drug Metab Disposition. 2003; 31(7):938-944.

85. Wood AW, Ryan D, Thomas P, Levin W. Regio-and stereoselective metabolism of two C19 steroids by five highly purified and reconstituted rat hepatic cytochrome P-450 isozymes. J Biol Chem. 1983; 258(14):8839-8847.

86. National Toxicology Program (NTP). TOX-99: Pathology tables, survival and growth curves from NTP short-term, immunotoxicology, in vitro activity (human), and micronucleus studies. Research Triangle Park, NC; 2020. https://doi.org/10.22427/NTP-DATA-TOX-99

87. Sharma B, Salunke R, Srivastava S, Majumder C, Roy P. Effects of guggulsterone isolated from Commiphora mukul in high fat diet induced diabetic rats. Food Chem Toxicol. 2009; 47(10):2631-2639. http://dx.doi.org/10.1016/j.fct.2009.07.021

88. Sharma JN, Sharma JN. Comparison of the anti-inflammatory activity of Commiphora mukul (an indigenous drug) with those of phenylbutazone and ibuprofen in experimental arthritis induced by mycobacterial adjuvant. Arzneimittelforschung. 1977; 27(7):1455-1457.

89. Shishodia S, Harikumar KB, Dass S, Ramawat KG, Aggarwal BB. The guggul for chronic diseases: Ancient medicine, modern targets. Anticancer Res. 2008; 28(6A):3647-3664.

90. Yang JY, Della-Fera MA, Baile CA. Guggulsterone inhibits adipocyte differentiation and induces apoptosis in 3T3-L1 cells. Obesity (Silver Spring). 2008; 16(1):16-22.

http://dx.doi.org/10.1038/oby.2007.24

91. Leiva A, Contreras-Duarte S, Amigo L, Sepulveda E, Boric M, Quinones V, Busso D, Rigotti A. Gugulipid causes hypercholesterolemia leading to endothelial dysfunction, increased atherosclerosis, and premature death by ischemic heart disease in male mice. PLoS One. 2017; 12(9):e0184280. http://dx.doi.org/10.1371/journal.pone.0184280

92. Deng R, Yang D, Yang J, Yan B. Oxysterol 22(R)-hydroxycholesterol induces the expression of the bile salt export pump through nuclear receptor farsenoid $\mathrm{X}$ receptor but not liver $\mathrm{X}$ receptor. J Pharmacol Exp Ther. 2006; 317(1):317-325.

http://dx.doi.org/10.1124/jpet.105.097758

93. Bovee TFH, Schoonen WGEJ, Hamers ARM, Bento MJ, Peijnenburg AACM. Screening of synthetic and plant-derived compounds for (anti)estrogenic and (anti)androgenic activities. Anal Bioanal Chem. 2008; 390(4):1111-1119. http://dx.doi.org/10.1007/s00216-007-1772-3

94. Burris TP, Montrose C, Houck KA, Osborne HE, Bocchinfuso WP, Yaden BC, Cheng CC, Zink RW, Barr RJ, Hepler CD et al. The hypolipidemic natural product guggulsterone is a promiscuous steroid receptor ligand. Mol Pharmacol. 2005; 67(3):948-954.

http://dx.doi.org/10.1124/mol.104.007054 
95. Ho RH, Tirona RG, Leake BF, Glaeser H, Lee W, Lemke CJ, Wang Y, Kim RB. Drug and bile acid transporters in Rosuvastatin hepatic uptake: Function, expression, and pharmacogenetics. Gastroenterology. 2006; 130(6):1793-1806.

http://dx.doi.org/10.1053/j.gastro.2006.02.034

96. Memorial Sloan-Kettering Cancer Center. Guggul (Commiphora mukul). 2012. https://www.mskcc.org/cancer-care/integrative-medicine/herbs/guggul

97. Qato DM, Alexander GC, Conti RM, Johnson M, Schumm P, Lindau ST. Use of prescription and over-the-counter medications and dietary supplements among older adults in the United States. JAMA. 2008; 300(24):2867-2878.

98. Guengerich FP. Cytochrome P450s and other enzymes in drug metabolism and toxicity. AAPS J. 2006; 8(1):E101-E111. http://dx.doi.org/10.1208/aapsj080112

99. Dertinger SD, Camphausen K, MacGregor JT, Bishop ME, Torous DK, Avlasevich S, Cairns S, Tometsko CR, Menard C, Muanza T. Three-color labeling method for flow cytometric measurement of cytogenetic damage in rodent and human blood. Environ Mol Mutag. 2004; 44(5):427-435. 
Gum Guggul, NTP TOX 99

\section{Appendix A. Estrous Cycle Characterization}

\section{Tables}

Table A-1. Estrous Cycle Characterization for Female Mice in the Three-month Gavage Study of Gum Guggul Extract.................................................................... A-2

\section{Figures}

Figure A-1. Vaginal Cytology Plots for Female Mice in the Three-month Gavage Study of Gum Guggul Extract. 
Gum Guggul, NTP TOX 99

Table A-1. Estrous Cycle Characterization for Female Mice in the Three-month Gavage Study of Gum Guggul Extract

\begin{tabular}{|c|c|c|c|c|}
\hline & $0 \mathrm{mg} / \mathrm{kg} / \mathrm{day}$ & $62.5 \mathrm{mg} / \mathrm{kg} / \mathrm{day}$ & $125 \mathrm{mg} / \mathrm{kg} /$ day & $250 \mathrm{mg} / \mathrm{kg} / \mathrm{day}$ \\
\hline $\mathbf{n}$ & 10 & 10 & 10 & 9 \\
\hline Number of Estrous Cycles ${ }^{\mathrm{a}}$ & $2.2 \pm 0.25$ & $2.4 \pm 0.16$ & $1.8 \pm 0.20$ & $2.1 \pm 0.26$ \\
\hline Estrous Cycle Length (days) ${ }^{\mathrm{a}}$ & $4.5 \pm 0.32$ & $4.6 \pm 0.28$ & $4.4 \pm 0.26$ & $4.1 \pm 0.18$ \\
\hline \multicolumn{5}{|l|}{ Estrous Stages (\% of cycle) } \\
\hline Diestrus & 38.1 & 31.9 & 43.8 & 44.4 \\
\hline Proestrus & 0.0 & 0.6 & 0.0 & 0.6 \\
\hline Estrus & 45.6 & 49.4 & 40.0 & 43.8 \\
\hline Metestrus & 14.4 & 13.8 & 10.0 & 8.1 \\
\hline Not clear ${ }^{b}$ & 1.9 & 4.4 & 6.3 & 3.1 \\
\hline
\end{tabular}




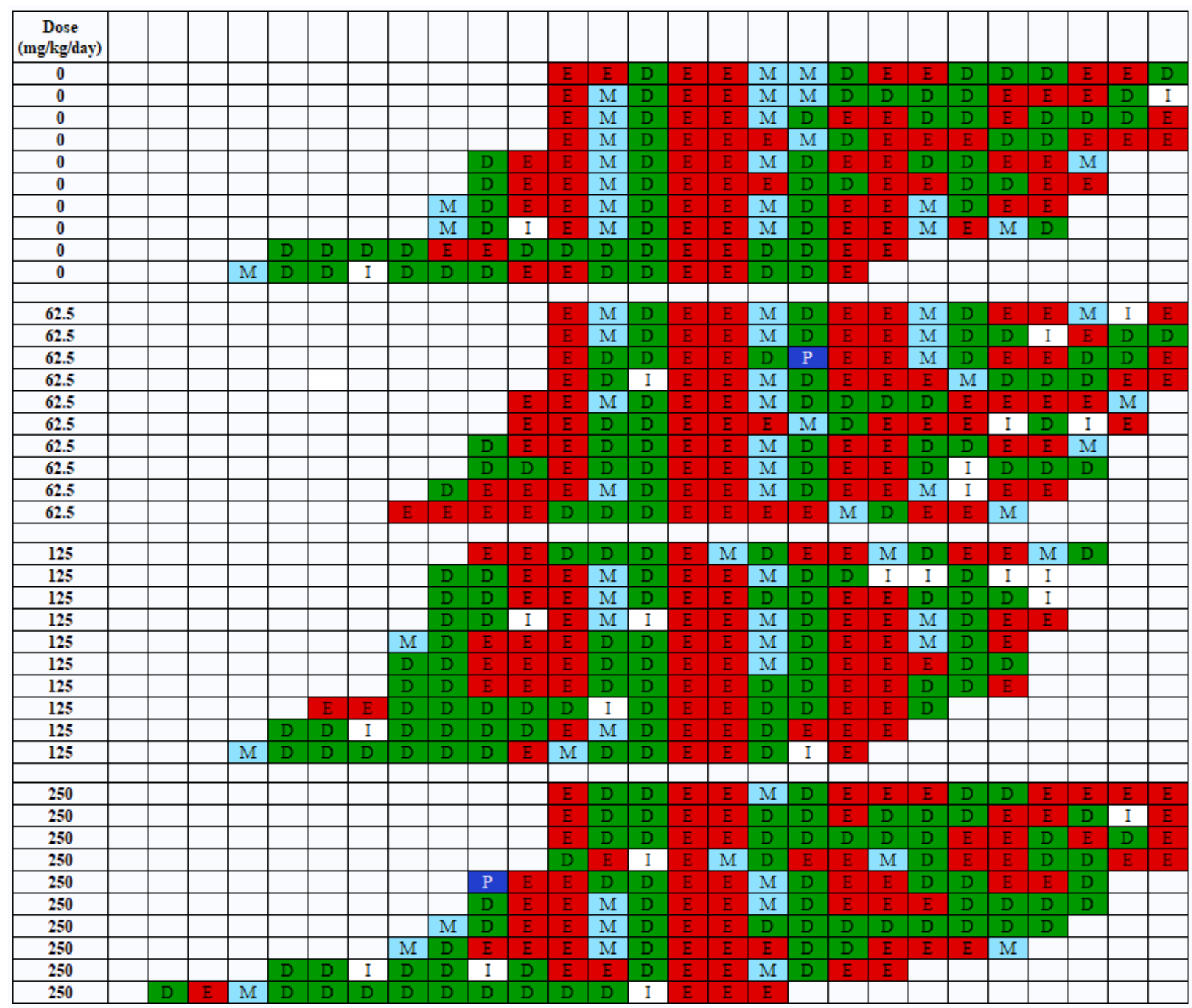

Figure A-1. Vaginal Cytology Plots for Female Mice in the Three-month Gavage Study of Gum Guggul Extract

$\mathrm{I}$ = insufficient number of cells to determine stage; $\mathrm{D}$ = diestrus; $\mathrm{P}=$ proestrus; $\mathrm{E}$ = estrus; $\mathrm{M}$ = metestrus. 


\section{Appendix B. Genetic Toxicology}

\section{Table of Contents}

B.1. Peripheral Blood Micronucleus Test Protocol ..................................................................2

B.2. Evaluation Protocol .....................................................................................................

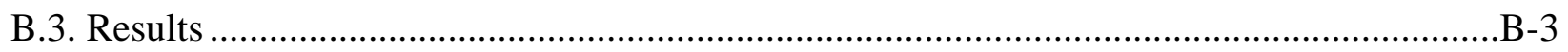

\section{Tables}

Table B-1. Frequency of Micronuclei in Peripheral Blood Erythrocytes of Rats in the Three-month Gavage Study of Gum Guggul Extract....

Table B-2. Frequency of Micronuclei in Peripheral Blood Erythrocytes of Mice in the Three-month Gavage Study of Gum Guggul Extract. 


\section{B.1. Peripheral Blood Micronucleus Test Protocol}

At termination of the 3-month toxicity studies of GGE, blood samples (approximately $200 \mu \mathrm{L}$ ) were collected from male and female rats and mice, placed in EDTA-coated tubes, and shipped overnight to the testing laboratory. On arrival, blood samples were fixed in ultracold methanol using a MicroFlowPLUS Kit (Litron Laboratories, Rochester, NY) according to the manufacturer's instructions. Fixed samples were stored in a $-80^{\circ} \mathrm{C}$ freezer until analysis. Thawed blood samples were analyzed for frequency of micronucleated immature erythrocytes (polychromatic erythrocytes, PCEs, reticulocytes) and mature erythrocytes (normochromatic erythrocytes, NCEs) using a flow cytometer ${ }^{75}$; both the mature and the immature erythrocyte populations can be analyzed separately by employing special cell surface markers to differentiate the two cell types. Because the very young reticulocyte subpopulation (CD71-positive cells) can be targeted using this technique, rat blood samples can be analyzed for damage that occurred in the bone marrow within the past 24 to 48 hours, before the rat spleen appreciably alters the percentage of micronucleated reticulocytes in circulation. ${ }^{99}$ In mice, both the immature and mature erythrocyte populations can be evaluated for micronucleus frequency because the mouse spleen does not sequester and eliminate damaged erythrocytes. Damaged erythrocytes achieve steady state in the peripheral blood of mice following 4 weeks of continuous exposure. Approximately 20,000 reticulocytes and $1 \times 10^{6}$ erythrocytes were analyzed per animal for frequency of micronucleated cells, and the percentage of immature erythrocytes (\% PCE) was calculated as a measure of bone marrow toxicity resulting from chemical exposure.

Prior experience with the large number of cells scored using flow cytometric scoring techniques ${ }^{76}$ suggests it is reasonable to assume that the proportion of micronucleated reticulocytes is approximately normally distributed. The statistical tests selected for trend and for pairwise comparisons with the vehicle control group depend on whether the variances among the groups are equal. Levene's test at $\alpha=0.05$ is used to test for equal variances and for which linear regression is used to test for a linear trend with dose; the Williams test is used to test for pairwise differences between each treatment group and the vehicle control group. In the case of unequal variances, Jonckheere's test is used to test for linear trend and Dunn's test is used for pairwise comparisons of each treatment group with the vehicle control group. To correct for multiple pairwise comparisons, the $\mathrm{p}$ value for each comparison with the vehicle control group is multiplied by the number of comparisons made. In the event that this product is greater than 1.00, it is replaced with 1.00. Trend tests and pairwise comparisons with the vehicle controls are considered statistically significant at $\mathrm{p} \leq 0.025$.

In the micronucleus test, a positive result is based, preferably, on the presence of both a significant trend and at least one significantly elevated dose group compared to the corresponding control group. In addition, historical control data are used to evaluate the biological significance of any observed response. Both statistical significance and biological significance are considered when arriving at a call. The presence of either a significant trend or a single significant dose group generally results in an equivocal call. The absence of both a trend and a significant dose group results in a negative call. Ultimately, the scientific staff determines the final call after considering the results of statistical analyses, reproducibility of any effects observed (in acute studies), and the magnitudes of those effects. 


\section{B.2. Evaluation Protocol}

These are the basic guidelines for arriving at an overall assay result for assays performed by NTP. Statistical as well as biological factors are considered. For an individual assay, the statistical procedures for data analysis have been described in the preceding protocols. There have been instances, however, in which multiple samples of a chemical were tested in the same assay, and different results were obtained among these samples and/or among laboratories. Results from more than one aliquot or from more than one laboratory are not simply combined into an overall result. Rather, all the data are critically evaluated, particularly with regard to pertinent protocol variations, in determining the weight of evidence for an overall conclusion of chemical activity in an assay. In addition to multiple aliquots, the in vitro assays have another variable that must be considered in arriving at an overall test result. In vitro assays are conducted with and without exogenous metabolic activation. Results obtained in the absence of activation are not combined with results obtained in the presence of activation; each testing condition is evaluated separately. The summary table in the Abstract of this Technical Report presents a result that represents a scientific judgment of the overall evidence for activity of the chemical in an assay.

\section{B.3. Results}

Administration of the GGE formulation for 3 months by gavage did not increase the frequencies of micronucleated reticulocytes (immature erythrocytes) or mature erythrocytes in peripheral blood samples obtained from male and female Sprague Dawley rats (dose range 62.5$1,000 \mathrm{mg} / \mathrm{kg} /$ day) and B6C3F1/N mice (dose range 15.5-250 mg/kg/day) (Table B-1, Table B-2). In addition, no significant changes in the percentage of immature erythrocytes were seen in mice, suggesting that exposure to the GGE formulation did not induce bone marrow toxicity or alter erythropoiesis in these animals. Small increases in \%PCE were observed in rats, but due to the magnitude of the responses, which fell within the laboratory historical control ranges, the increases were not considered biologically significant. 
Table B-1. Frequency of Micronuclei in Peripheral Blood Erythrocytes of Rats in the Three-month Gavage Study of Gum Guggul Extract ${ }^{\mathrm{a}}$

\begin{tabular}{|c|c|c|c|c|c|c|}
\hline & $\begin{array}{l}\text { Micronucleated } \\
\text { PCEs/1,000 PCEs }\end{array}$ & P Value ${ }^{c}$ & $\begin{array}{c}\text { Micronucleated } \\
\text { NCEs/1,000 NCEs }\end{array}$ & P Value ${ }^{c}$ & PCEs (\%) ${ }^{b}$ & P Value \\
\hline $\mathbf{n}$ & 5 & 5 & 5 & 5 & 5 & 5 \\
\hline \multicolumn{7}{|l|}{ Male } \\
\hline \multicolumn{7}{|c|}{ GGE (mg/kg/day) } \\
\hline 0 & $0.690 \pm 0.117$ & - & $0.113 \pm 0.019$ & - & $0.960 \pm 0.033$ & - \\
\hline 62.5 & $0.390 \pm 0.100$ & 0.9406 & $0.072 \pm 0.012$ & 1.0000 & $0.955 \pm 0.032$ & 1.0000 \\
\hline 125 & $0.460 \pm 0.070$ & 0.9730 & $0.108 \pm 0.030$ & 1.0000 & $0.992 \pm 0.094$ & 1.0000 \\
\hline 250 & $0.500 \pm 0.084$ & 0.9811 & $0.182 \pm 0.021$ & 0.2461 & $1.035 \pm 0.018$ & 1.0000 \\
\hline 500 & $0.430 \pm 0.056$ & 0.9852 & $0.100 \pm 0.015$ & 1.0000 & $0.973 \pm 0.081$ & 1.0000 \\
\hline 1,000 & $0.600 \pm 0.076$ & 0.8951 & $0.245 \pm 0.065$ & 0.2117 & $1.453 \pm 0.129$ & 0.0317 \\
\hline Trend $^{\mathrm{d}}$ & $\mathrm{p}=0.3490$ & - & $\mathrm{p}=0.0117$ & - & $\mathrm{p}=0.0069$ & - \\
\hline \multicolumn{7}{|l|}{ Female } \\
\hline \multicolumn{7}{|c|}{ GGE (mg/kg/day) } \\
\hline 0 & $0.770 \pm 0.090$ & - & $0.188 \pm 0.037$ & - & $0.583 \pm 0.054$ & - \\
\hline 62.5 & $0.540 \pm 0.114$ & 0.9489 & $0.198 \pm 0.019$ & 0.6847 & $0.874 \pm 0.062$ & 0.0156 \\
\hline 125 & $0.410 \pm 0.070$ & 0.9774 & $0.120 \pm 0.014$ & 0.7699 & $0.898 \pm 0.114$ & 0.0162 \\
\hline 250 & $0.480 \pm 0.093$ & 0.9846 & $0.164 \pm 0.027$ & 0.8034 & $0.922 \pm 0.131$ & 0.0138 \\
\hline 500 & $0.630 \pm 0.102$ & 0.9798 & $0.225 \pm 0.045$ & 0.6390 & $0.917 \pm 0.129$ & 0.0124 \\
\hline 1,000 & $0.520 \pm 0.075$ & 0.9829 & $0.151 \pm 0.028$ & 0.6516 & $1.033 \pm 0.040$ & 0.0014 \\
\hline Trend $^{d}$ & $\mathrm{p}=0.6883$ & - & $\mathrm{p}=0.5877$ & - & $\mathrm{p}=0.0181$ & - \\
\hline
\end{tabular}

PCE = polychromatic erythrocyte; NCE = normochromatic erythrocyte.

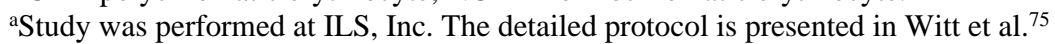

bData presented as mean \pm standard error.

'Pairwise comparisons with the vehicle control group performed using the Williams or Dunn tests ( $\mathrm{p} \leq 0.025)$.

${ }^{\mathrm{d}}$ Dose-related trends evaluated by linear regression of Jonckheere's test $(\mathrm{p} \leq 0.025)$. 
Table B-2. Frequency of Micronuclei in Peripheral Blood Erythrocytes of Mice in the Three-month Gavage Study of Gum Guggul Extract ${ }^{\mathrm{a}}$

\begin{tabular}{lcccccc}
\hline & $\begin{array}{c}\text { Micronucleated } \\
\text { PCEs/1,000 PCEs }^{\mathbf{b}}\end{array}$ & P Value $^{\mathbf{c}}$ & $\begin{array}{c}\text { Micronucleated }^{\text {NCEs/1,000 NCEs }}{ }^{\mathbf{b}} \\
\mathbf{n}\end{array}$ P Value $^{\mathbf{c}}$ & PCEs (\%) $^{\mathbf{b}}$ & P Value $^{\mathbf{c}}$ \\
\hline Male & 5 & 5 & 5 & 5 & 5 & 5 \\
GGE (mg/kg/day) & & & & & & \\
$\quad 0$ & $2.340 \pm 0.185$ & - & $1.482 \pm 0.019$ & - & $1.285 \pm 0.039$ & - \\
15.5 & $2.070 \pm 0.200$ & 0.7310 & $1.469 \pm 0.033$ & 0.8250 & $1.425 \pm 0.062$ & 0.2337 \\
31 & $2.320 \pm 0.110$ & 0.6531 & $1.484 \pm 0.022$ & 0.8940 & $1.323 \pm 0.040$ & 0.2774 \\
62.5 & $2.355 \pm 0.112$ & 0.6871 & $1.428 \pm 0.015$ & 0.9157 & $1.363 \pm 0.050$ & 0.2982 \\
125 & $2.370 \pm 0.178$ & 0.7063 & $1.398 \pm 0.032$ & 0.9265 & $1.437 \pm 0.052$ & 0.0690 \\
250 & $2.170 \pm 0.096$ & 0.7201 & $1.431 \pm 0.022$ & 0.9335 & $1.415 \pm 0.055$ & 0.0706 \\
Trend & $\mathrm{p}=0.6130$ & - & $\mathrm{p}=0.9716$ & - & $\mathrm{p}=0.1369$ & - \\
\hline Female & & & & & & \\
GGE (mg/kg/day) & & & & & & \\
0 & $1.910 \pm 0.196$ & - & $0.994 \pm 0.033$ & - & $1.216 \pm 0.092$ & - \\
15.5 & $2.235 \pm 0.135$ & 0.4860 & $1.089 \pm 0.027$ & 0.0603 & $1.345 \pm 0.137$ & 0.5908 \\
31 & $1.763 \pm 0.085$ & 0.5663 & $1.090 \pm 0.023$ & 0.0718 & $1.398 \pm 0.152$ & 0.6575 \\
62.5 & $1.910 \pm 0.154$ & 0.5994 & $1.019 \pm 0.031$ & 0.0763 & $1.348 \pm 0.091$ & 0.7019 \\
125 & $2.070 \pm 0.090$ & 0.6194 & $1.036 \pm 0.014$ & 0.0775 & $1.431 \pm 0.140$ & 0.7233 \\
250 & $1.610 \pm 0.108$ & 0.6316 & $1.020 \pm 0.016$ & 0.0779 & $1.296 \pm 0.249$ & 0.7365 \\
Trend $^{\mathrm{d}}$ & $\mathrm{p}=0.9643$ & - & $\mathrm{p}=0.8025$ & - & $\mathrm{p}=0.7869$ & - \\
\hline PCE & & & & & &
\end{tabular}

PCE = polychromatic erythrocyte; NCE = normochromatic erythrocyte.

aStudy was performed at ILS, Inc. The detailed protocol is presented in Witt et al. ${ }^{75}$

bData presented as mean \pm standard error.

'Pairwise comparisons with the vehicle control group performed using the Williams or Dunn tests ( $\mathrm{p} \leq 0.025)$.

${ }^{\mathrm{d}}$ Dose-related trends evaluated by linear regression of Jonckheere's test $(\mathrm{p} \leq 0.025)$. 


\section{Appendix C. Chemical Characterization and Dose Formulation Studies}

\section{Table of Contents}

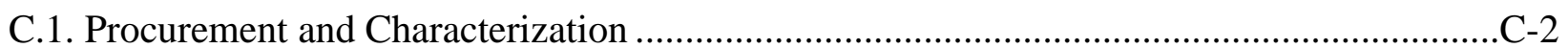

C.2. Preparation and Analysis of Dose Formulations.............................................................

\section{Tables}

Table C-1. Chromatography Systems Used in the Three-month Gavage Studies of Gum

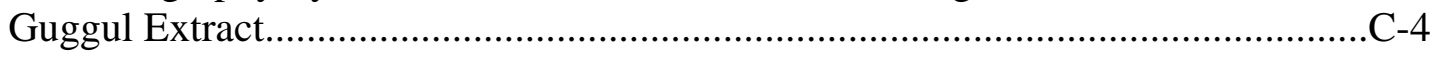

Table C-2. Preparation and Storage of Dose Formulations in the Three-month Gavage Studies of Gum Guggul Extract ........................................................................

Table C-3. Results of Analyses of Dose Formulations Administered to Rats and Mice in the Three-month Gavage Studies of Gum Guggul Extract ..................................... 


\section{C.1. Procurement and Characterization}

\section{C.1.1. Gum Guggul Extract Formulation}

Gugulipid $^{\circledR}$ (gum guggul extract; GGE) was obtained from Sabinsa Corporation (Piscataway, NJ) in two lots (G51177/H and G60493/H). Preliminary characterization confirmed the two lots were similar. Identity, purity, and stability analyses were conducted by the analytical chemistry laboratory at MRIGlobal (Kansas City, MO) and by the study laboratory at Battelle (Columbus, $\mathrm{OH})$. Reports on analyses performed in support of these GGE studies are on file at the National Institute of Environmental Health Sciences.

Gugulipid $^{\circledR}$ is a cream-to-pale yellow granular powder. Analysis of lots $\mathrm{G} 51177 / \mathrm{H}$ and G60493/H by high-performance liquid chromatography (HPLC) with ultraviolet (UV) detection showed the levels of $Z$ - and $E$-guggulsterone, respectively, to be $0.85 \%$ and $1.30 \%$ in lot $\mathrm{G} 60493 / \mathrm{H}$ and $1.14 \%$ and $1.31 \%$ in lot $\mathrm{G} 51177 / \mathrm{H}$. These were similar to the manufacturer-reported guggulsterone values of 2.53\% (lot G60493/H) and 2.7\% (G51177/H).

The two lots were combined by Battelle (Columbus, OH) to create lot 04172009. To combine and homogenize the lots, one-third each of lots G51177/H and G60493/H was transferred, in alternating layers, to a $1-\mathrm{ft}^{3}$ twin shell blender and blended for 15 minutes. The homogenized lot was repackaged into amber glass bottles and assigned lot 04172009

Lot 04172009 was subjected to gravity sieve in bulk using an 80-mesh sieve (Note: this was needed to ensure that the corn oil formulations could pass through the gavage needle). The material that passed through was assigned lot 07172009. The lot was transferred to a large plastic bag and mixed by kneading and rotating for approximately 15 minutes. Samples were removed from the top (left, middle, and right) and bottom (left, middle, and right) of the bag for homogeneity determination. Homogeneity of lot 07172009 was confirmed with respect to $Z$ - and E-guggulsterone using HPLC/UV.

Lots 04172009 and 07172009 were analyzed by the study laboratory using infrared (IR) spectroscopy, nuclear magnetic resonance (NMR) spectroscopy, weight loss by drying, water content by Karl Fischer analysis, scanning electron microscopy (SEM) with energy dispersive $\mathrm{X}$-ray spectroscopy (EDS), magnesium content by inductively coupled plasma-atomic emission mass spectrometry, X-ray diffraction (XRD), and mass spectrometry (MS). The purity determination and quantitation of $Z$ - and $E$-guggulsterone content were conducted by HPLC-UV detection (system A). Additional details on the chromatography systems used are presented in Table C-1. One aliquot of lots 04172009 and 07172009 was submitted to Covance Laboratories, Inc. (Madison, WI) for nutritional and contaminant analyses.

IR spectra showed the presence of the excipients magnesium carbonate and corn starch. Both IR and NMR spectra were complex, and signatures of gum guggul-specific constituents could not be confirmed (data not shown). XRD analysis showed the presence of magnesium oxide, hydrated magnesium carbonate, and talc as excipients. HPLC/UV analysis by system A detected 79 peaks with areas greater than or equal to $0.05 \%$ for both lots. The levels of $Z$ - and $E$-guggulsterone, respectively, were $0.87 \%$ and $1.22 \%$ in lot 04172009 and $0.65 \%$ and $0.82 \%$ in lot 07172009 . Mass spectrometric analyses (lot 04172009 only) confirmed the presence of $Z$ - and $E$ guggulsterone, isomers of $Z$-guggulsterol, 20- $\beta$-hydroxy-4-pregnen-3-one, 20- $\alpha$-hydroxy-4pregnen-3-one, guggulsterol VI, and guggulsterol V. Contaminant analyses showed the presence 
of low levels of lead, antimony, and molybdenum. Arsenic, aflatoxins (B1, B2, G1, G2), ochratoxin, and zearalenone could not be determined due to matrix interferences. Pesticide levels were below the limits of quantitation of 0.01 or $0.02 \mathrm{ppm}$. Summary results of these analyses are shown in Table 1. Additionally, nutritional assessments identified total fat levels of $5.61 \%$ and $3.63 \%$, carbohydrate levels of $55.5 \%$ and $57.3 \%$, and protein levels of $<0.100 \%$ and $<0.100 \%$, in lots 04172009 and 07172009 , respectively. Therefore, it was concluded that sieving of the test formulation caused minimal alteration of the assessed nutritional content.

Individual aliquots of lot 07172009 were removed for use as frozen reference standards and archive samples. The remaining was stored in large, amber plastic bags at room temperature. Frozen reference standards were stored at $-20^{\circ} \mathrm{C}$. Lot 07172009 was used in the 3-month studies.

\section{C.1.2. Corn Oil}

Corn oil was obtained from Sigma-Aldrich (St. Louis, MO) in a single lot (128K0040) and used as the vehicle in the 3-month studies. Twice during the study period, potentiometric titration was used to determine the peroxide content, which was below the rejection level of $3 \mathrm{mEq} / \mathrm{kg}$.

\section{C.2. Preparation and Analysis of Dose Formulations}

Dose formulations were prepared three times over the course of the study using the GGE formulation (lot 07172009) and corn oil (Table C-2). Formulations were prepared at concentrations of $12.5,25,50,100$, and $200 \mathrm{mg} / \mathrm{mL}$ (rats) or 1.55, 3.1, 6.25, 12.5, and $25 \mathrm{mg} / \mathrm{mL}$ (mice). Quantification stock solutions used Z- and E-guggulsterone isomers at target concentrations of 0.8654 and $0.4808 \mathrm{mg} / \mathrm{mL}$ in tetrahydrofuran. Quantification of these isomers using HPLC/UV (system B) showed the dosing formulations were within 10\% of expected values.

Homogeneity studies of the $1.55,12.5,25$, and $200 \mathrm{mg} / \mathrm{mL}$ formulations were also performed using HPLC/UV (system B). Relative standard deviations (RSDs) were within 5\% of target for each concentration, and thus homogeneity was deemed sufficient. Because the formulas were suspensions, continuous stirring was required to ensure homogeneity. Gavagability was confirmed using 25 and $200 \mathrm{mg} / \mathrm{mL}$ formulations of GGE (lot 04172009) in corn oil. Dispensing the aliquots occurred in approximately 5 seconds for a $1 \mathrm{~mL}$ dose using a 20- or 18-gauge needle, with an RSD within $5 \%$ of the target dose.

Each preadministration and postadministration (animal room) dose formulation of GGE was analyzed three times (July 20, August 17, and September 18, 2009). All preadministration formulations were within $10 \%$ of the target concentration. Animal room samples were determined to be within $10 \%$ of the target (Table C-3).

GGE formulations were stored in sealed glass containers at concentrations of $1.55 \mathrm{mg} / \mathrm{mL}$ or higher at room temperature for up to 42 days. Stability was confirmed for these conditions up to 42 days. 
Table C-1. Chromatography Systems Used in the Three-month Gavage Studies of Gum Guggul Extract

\begin{tabular}{llll}
\hline Chromatography & Detection System & \multicolumn{1}{c}{ Column } & \multicolumn{1}{c}{ Mobile Phase } \\
\hline System A & & & \\
HPLC & UV $(245 \mathrm{~nm})$ & $\begin{array}{l}\text { Alltech, Adsorbosphere HS; } \\
150 \times 4.6 \mathrm{~mm}, 5 \mu \mathrm{m}\end{array}$ & $\begin{array}{l}30 / 70 \text { acetonitrile: ASTM Type I } \\
\text { water; flow rate } 1 \mathrm{~mL} / \mathrm{min}\end{array}$ \\
System B & & Zorbax, Eclipse XDB; $150 \times 4.6 \mathrm{~mm}$, & $\begin{array}{l}45 / 55 \text { acetonitrile: } 0.1 \% \text { formic } \\
\text { acid in water; flow rate } \\
\text { HPLC }\end{array}$ \\
& UV $(254 \mathrm{~nm})$ & $3.5 \mu \mathrm{mL} / \mathrm{min}$ \\
\hline
\end{tabular}

Table C-2. Preparation and Storage of Dose Formulations in the Three-month Gavage Studies of Gum Guggul Extract

\title{
Three-month Studies
}

\begin{abstract}
Preparation
Prior to use in the dose formulation, approximately 1,325 grams of the Gugulipid ${ }^{\circledR}$ extract was sieved through an 80-mesh sieve. An appropriate amount of the sieved GGE formulation was weighed, then transferred into a calibrated mixing container with a stir bar. The weighing container was rinsed with the corn oil vehicle three times and transferred to the mixing container. The vehicle was transferred in increments while stirring to ensure the GGE formulation was wetted until the mixing container was diluted to the final volume with corn oil. The formulation was mixed for approximately 15 minutes at a rate that produced a vigorous vortex without creating excess foam. Dose formulations were prepared four times.
\end{abstract}

\section{Chemical Lot Number}

07172009

Maximum Storage Time

42 days

Storage Conditions

Stored in sealed clear glass bottles at room temperature $\left(17-25^{\circ} \mathrm{C}\right)$.

Study Laboratory

Battelle (Columbus, OH) 
Table C-3. Results of Analyses of Dose Formulations Administered to Rats and Mice in the Three-month Gavage Studies of Gum Guggul Extract ${ }^{\mathrm{a}}$

\begin{tabular}{|c|c|c|c|c|}
\hline Date Prepared & Date Analyzed & $\begin{array}{c}\text { Target } \\
\text { Concentration } \\
(\mathbf{m g} / \mathrm{mL})^{\mathbf{b}, \mathbf{c}}\end{array}$ & $\begin{array}{c}\text { Determined } \\
\text { Concentration } \\
(\mathrm{mg} / \mathrm{mL})\end{array}$ & $\begin{array}{c}\text { Difference from } \\
\text { Target (\%) }\end{array}$ \\
\hline \multicolumn{5}{|l|}{ Mice } \\
\hline \multirow[t]{6}{*}{ July 20, 2009} & July 21, 2009 & 0 & BLOQ & NA \\
\hline & & 1.55 & $1.43 \pm 0.05$ & -8.5 \\
\hline & & 3.1 & $2.95 \pm 0.02$ & -5.1 \\
\hline & & 6.25 & $6.02 \pm 0.11$ & -3.8 \\
\hline & & 12.5 & $12.0 \pm 0.2$ & -3.9 \\
\hline & & 25 & $23.8 \pm 0.1$ & -4.9 \\
\hline \multirow[t]{6}{*}{ August 17, 2009} & August 18, 2009 & 0 & BLOQ & NA \\
\hline & & 1.55 & $1.62 \pm 0.04$ & 4.5 \\
\hline & & 3.1 & $3.15 \pm 0.03$ & 1.5 \\
\hline & & 6.25 & $6.34 \pm 0.02$ & 1.5 \\
\hline & & 12.5 & $12.9 \pm 0.1$ & 2.8 \\
\hline & & 25 & $26.1 \pm 0.2$ & 4.3 \\
\hline \multirow[t]{6}{*}{ September 18, 2009} & September 23, 2009 & 0 & BLOQ & NA \\
\hline & & 1.55 & $1.64 \pm 0.02$ & 5.7 \\
\hline & & 3.1 & $3.07 \pm 0.03$ & -0.9 \\
\hline & & 6.25 & $6.26 \pm 0.03$ & 0.2 \\
\hline & & 12.5 & $12.6 \pm 0.1$ & 1.0 \\
\hline & & 25 & $25.4 \pm 0.1$ & 1.6 \\
\hline \multicolumn{5}{|l|}{ Rats } \\
\hline \multirow[t]{6}{*}{ July 20, 2009} & July 20, 2009 & 0 & BLOQ & NA \\
\hline & & 12.5 & $12.0 \pm 0.2$ & -3.9 \\
\hline & & 25 & $23.8 \pm 0.1$ & -4.9 \\
\hline & & 50 & $47.0 \pm 0.2$ & -6.3 \\
\hline & & 100 & $93.7 \pm 0.6$ & -6.7 \\
\hline & & 200 & $190 \pm 2$ & -5.5 \\
\hline \multirow[t]{6}{*}{ August 17, 2009} & August 18, 2009 & 0 & BLOQ & NA \\
\hline & & 12.5 & $12.9 \pm 0.1$ & 2.8 \\
\hline & & 25 & $26.1 \pm 0.2$ & 4.3 \\
\hline & & 50 & $48.6 \pm 2.8$ & -3.2 \\
\hline & & 100 & $93.1 \pm 0.4$ & -7.5 \\
\hline & & 200 & $195 \pm 2$ & -2.7 \\
\hline
\end{tabular}




\section{Gum Guggul, NTP TOX 99}

\begin{tabular}{|c|c|c|c|c|}
\hline Date Prepared & Date Analyzed & $\begin{array}{c}\text { Target } \\
\text { Concentration } \\
(\mathbf{m g} / \mathbf{m L})^{\mathbf{b}, \mathbf{c}}\end{array}$ & $\begin{array}{c}\text { Determined } \\
\text { Concentration } \\
(\mathrm{mg} / \mathrm{mL})\end{array}$ & $\begin{array}{c}\text { Difference from } \\
\text { Target (\%) }\end{array}$ \\
\hline \multirow[t]{6}{*}{ September 18, 2009} & September 23, 2009 & 0 & BLOQ & NA \\
\hline & & 12.5 & $12.6 \pm 0.1$ & 1.0 \\
\hline & & 25 & $25.4 \pm 0.1$ & 1.6 \\
\hline & & 50 & $55.3 \pm 0.5$ & 9.6 \\
\hline & & 100 & $101 \pm 1$ & 1.2 \\
\hline & & 200 & $216 \pm 5$ & 7.3 \\
\hline \multicolumn{5}{|c|}{ Animal Room Samples } \\
\hline \multicolumn{5}{|l|}{ Mice } \\
\hline \multirow[t]{6}{*}{ July 20, 2009} & August 25, 2009 & 0 & BLOQ & NA \\
\hline & & 1.55 & $1.47 \pm 0.01$ & -5.2 \\
\hline & & 3.1 & $2.96 \pm 0.01$ & -4.6 \\
\hline & & 6.25 & $6.15 \pm 0.21$ & -1.7 \\
\hline & & 12.5 & $12.4 \pm 0.1$ & -1.1 \\
\hline & & 25 & $24.3 \pm 0.2$ & -2.9 \\
\hline \multirow[t]{6}{*}{ August 17, 2009} & September 30, 2009 & 0 & BLOQ & NA \\
\hline & & 1.55 & $1.63 \pm 0.03$ & 4.7 \\
\hline & & 3.1 & $3.37 \pm 0.03$ & 8.1 \\
\hline & & 6.25 & $5.99 \pm 0.05$ & -4.3 \\
\hline & & 12.5 & $11.7 \pm 0.3$ & -6.9 \\
\hline & & 25 & $23.7 \pm 0.1$ & -5.5 \\
\hline \multirow[t]{6}{*}{ September 18, 2009} & October 30, 2009 & 0 & BLOQ & NA \\
\hline & & 6.25 & $6.65 \pm 0.07$ & 6.4 \\
\hline & & 12.5 & $12.3 \pm 0.1$ & -1.3 \\
\hline & & 25 & $24.0 \pm 0.1$ & -4.0 \\
\hline & November 12, 2009 & 1.55 & $1.65 \pm 0.04$ & 6.5 \\
\hline & & 3.1 & $3.10 \pm 0.06$ & -1.1 \\
\hline \multicolumn{5}{|l|}{ Rats } \\
\hline \multirow[t]{6}{*}{ July 20, 2009} & August 25, 2009 & 0 & BLOQ & NA \\
\hline & & 12.5 & $12.2 \pm 0.2$ & -2.8 \\
\hline & & 25 & $24.7 \pm 0.1$ & -1.2 \\
\hline & & 50 & $49.0 \pm 0.2$ & -2.0 \\
\hline & & 100 & $99.6 \pm 1.5$ & -0.5 \\
\hline & & 200 & $201 \pm 4$ & 0.6 \\
\hline
\end{tabular}


Gum Guggul, NTP TOX 99

\begin{tabular}{|c|c|c|c|c|}
\hline Date Prepared & Date Analyzed & $\begin{array}{c}\text { Target } \\
\text { Concentration } \\
(\mathrm{mg} / \mathrm{mL})^{\mathbf{b}, \mathbf{c}}\end{array}$ & $\begin{array}{c}\text { Determined } \\
\text { Concentration } \\
(\mathrm{mg} / \mathrm{mL})\end{array}$ & $\begin{array}{c}\text { Difference from } \\
\text { Target (\%) }\end{array}$ \\
\hline \multirow[t]{6}{*}{ August 17, 2009} & September 30, 2009 & 0 & BLOQ & NA \\
\hline & & 12.5 & $12.5 \pm 0.3$ & 0.0 \\
\hline & & 25 & $23.5 \pm 0.0$ & -6.4 \\
\hline & & 50 & $47.8 \pm 0.5$ & -4.6 \\
\hline & & 100 & $96.6 \pm 1.2$ & -3.5 \\
\hline & & 200 & $193 \pm 4$ & -3.5 \\
\hline \multirow[t]{6}{*}{ September 18, 2009} & October 30, 2009 & 0 & BLOQ & NA \\
\hline & & 12.5 & $12.5 \pm 0.1$ & 0.3 \\
\hline & & 25 & $24.1 \pm 0.1$ & -3.7 \\
\hline & & 50 & $48.7 \pm 0.7$ & -2.6 \\
\hline & & 100 & $97.8 \pm 0.5$ & -2.2 \\
\hline & & 200 & $195 \pm 1$ & -2.6 \\
\hline
\end{tabular}

BLOQ = below the limit of quantification; GGE = gum guggul extract; NA = not applicable.

a Data shown as mean \pm standard deviation.

${ }^{\mathrm{b}}$ For rats, dosing volume $=5 \mathrm{~mL} / \mathrm{kg} .12 .5 \mathrm{mg} / \mathrm{L}=62.5 \mathrm{mg} / \mathrm{kg} / \mathrm{day} ; 25 \mathrm{mg} / \mathrm{L}=125 \mathrm{mg} / \mathrm{kg} / \mathrm{day} ; 50 \mathrm{mg} / \mathrm{L}=250 \mathrm{mg} / \mathrm{kg} / \mathrm{day}$; $100 \mathrm{mg} / \mathrm{L}=500 \mathrm{mg} / \mathrm{kg} /$ day; $200 \mathrm{mg} / \mathrm{L}=1,000 \mathrm{mg} / \mathrm{kg} / \mathrm{day}$.

${ }^{c}$ For mice, dosing volume = $10 \mathrm{~mL} / \mathrm{kg} .1 .55 \mathrm{mg} / \mathrm{L}=15.5 \mathrm{mg} / \mathrm{kg} / \mathrm{day} ; 3.1 \mathrm{mg} / \mathrm{L}=31 \mathrm{mg} / \mathrm{kg} / \mathrm{day} ; 6.25 \mathrm{mg} / \mathrm{L}=62.5 \mathrm{mg} / \mathrm{kg} / \mathrm{day}$; $12.5 \mathrm{mg} / \mathrm{L}=125 \mathrm{mg} / \mathrm{kg} /$ day; $25 \mathrm{mg} / \mathrm{L}=250 \mathrm{mg} / \mathrm{kg} /$ day. 


\section{Appendix D. Ingredients, Nutrient Composition, and Contaminant Levels in NTP-2000 Rat and Mouse Ration}

\section{Tables}

Table D-1. Ingredients of NTP-2000 Rat and Mouse Ration ............................................... D-2

Table D-2. Vitamins and Minerals Added to NTP-2000 Rat and Mouse Ration ..................... D-2

Table D-3. Nutrient Composition of NTP-2000 Rat and Mouse Ration ................................. D-3

Table D-4. Contaminant Levels in NTP-2000 Rat and Mouse Ration ..................................... D-4 
Table D-1. Ingredients of NTP-2000 Rat and Mouse Ration

\begin{tabular}{|c|c|c|}
\hline Ingredients & & Percent by Weight \\
\hline Ground Hard Winter Wheat & & 22.26 \\
\hline Ground \#2 Yellow Shelled Corn & & 22.18 \\
\hline Wheat Middlings & & 15.0 \\
\hline Oat Hulls & & 8.5 \\
\hline Alfalfa Meal (Dehydrated, 17\% Protein) & & 7.5 \\
\hline Purified Cellulose & & 5.5 \\
\hline Soybean Meal (49\% Protein) & & 5.0 \\
\hline Fish Meal (60\% Protein) & & 4.0 \\
\hline Corn Oil (without Preservatives) & & 3.0 \\
\hline Soy Oil (without Preservatives) & & 3.0 \\
\hline Dried Brewer’s Yeast & & 1.0 \\
\hline Calcium Carbonate (USP) & & 0.9 \\
\hline Vitamin Premix $^{\mathrm{a}}$ & & 0.5 \\
\hline Mineral Premix ${ }^{b}$ & & 0.5 \\
\hline Calcium Phosphate, Dibasic (USP) & & 0.4 \\
\hline Sodium Chloride & & 0.3 \\
\hline Choline Chloride (70\% Choline) & & 0.26 \\
\hline Methionine & & 0.2 \\
\hline \multicolumn{3}{|l|}{$\begin{array}{l}\text { USP = United States Pharmacopeia } \\
\text { aWheat middlings as a carrier. } \\
\text { bCalcium carbonate as a carrier. }\end{array}$} \\
\hline 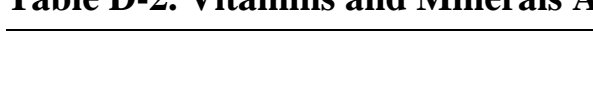 & Amount & Source \\
\hline \multicolumn{3}{|l|}{ Vitamins } \\
\hline A & 4,000 IU & Stabilized vitamin A palmitate or acetate \\
\hline $\mathrm{D}$ & $1,000 \mathrm{IU}$ & D-activated animal sterol \\
\hline $\mathrm{K}$ & $1.0 \mathrm{mg}$ & Menadione (MSBC) \\
\hline$\alpha$-Tocopheryl Acetate & $100 \mathrm{IU}$ & - \\
\hline Niacin & $23 \mathrm{mg}$ & - \\
\hline Folic Acid & $1.1 \mathrm{mg}$ & $\alpha$-Calcium pantothenate \\
\hline$\alpha$-Pantothenic Acid & $10 \mathrm{mg}$ & - \\
\hline Riboflavin & $3.3 \mathrm{mg}$ & Thiamine mononitrate \\
\hline Thiamin & $4 \mathrm{mg}$ & - \\
\hline $\mathrm{B}_{12}$ & $52 \mu \mathrm{g}$ & - \\
\hline Pyridoxine & $6.3 \mathrm{mg}$ & Pyridozine hydrochloride \\
\hline
\end{tabular}




\begin{tabular}{lcl}
\hline & Amount & \multicolumn{1}{c}{ Source } \\
\hline Biotin & $0.2 \mathrm{mg}$ & $\alpha$-Biotin \\
Minerals & & \\
Magnesium & $514 \mathrm{mg}$ & Magnesium oxide \\
Iron & $35 \mathrm{mg}$ & Iron sulfate \\
Zinc & $12 \mathrm{mg}$ & Zinc oxide \\
Manganese & $10 \mathrm{mg}$ & Manganese oxide \\
Copper & $2.0 \mathrm{mg}$ & Copper sulfate \\
Iodine & $0.2 \mathrm{mg}$ & Calcium iodate \\
Chromium & $0.2 \mathrm{mg}$ & Chromium acetate \\
\hline
\end{tabular}

MSBC = menadione sodium bisulfite complex.

aPer kg of finished product.

Table D-3. Nutrient Composition of NTP-2000 Rat and Mouse Ration

\begin{tabular}{lccc}
\hline \multicolumn{1}{c}{ Nutrient } & Mean \pm Standard Deviation & Range & $\begin{array}{c}\text { Number of } \\
\text { Samples }\end{array}$ \\
\hline Protein (\% by weight) & $14.54 \pm 0.27$ & $14.1-14.8$ & 5 \\
Crude Fat (\% by weight) & $8.12 \pm 0.28$ & $7.7-8.4$ & 5 \\
Crude Fiber (\% by weight) & $8.86 \pm 1.25$ & $7.1-10.6$ & 5 \\
Ash (\% by weight) & $5.096 \pm 0.86$ & $4.99-5.21$ & 5 \\
Amino Acids (\% of total diet) & & & \\
Arginine & $0.802 \pm 0.075$ & $0.67-0.97$ & 28 \\
Cystine & $0.220 \pm 0.022$ & $0.15-0.25$ & 28 \\
Glycine & $0.703 \pm 0.038$ & $0.62-0.80$ & 28 \\
Histidine & $0.342 \pm 0.071$ & $0.27-0.68$ & 28 \\
Isoleucine & $0.549 \pm 0.041$ & $0.43-0.66$ & 28 \\
Leucine & $1.097 \pm 0.064$ & $0.96-1.24$ & 28 \\
Lysine & $0.700 \pm 0.106$ & $0.31-0.86$ & 28 \\
Methionine & $0.410 \pm 0.042$ & $0.26-0.49$ & 28 \\
Phenylalanine & $0.623 \pm 0.047$ & $0.47-0.72$ & 28 \\
Threonine & $0.512 \pm 0.042$ & $0.43-0.61$ & 28 \\
Tryptophan & $0.155 \pm 0.027$ & $0.11-0.20$ & 28 \\
Tyrosine & $0.420 \pm 0.066$ & $0.28-0.54$ & 28 \\
Valine & $0.666 \pm 0.040$ & $0.55-0.73$ & 28 \\
Essential Fatty Acids (\% of total diet) & & & 28 \\
Linoleic & $3.88 \pm 0.455$ & $1.89-4.55$ & 28 \\
Linolenic & $0.30 \pm 0.065$ & $0.007-0.368$ & \\
\hline
\end{tabular}


Gum Guggul, NTP TOX 99

\begin{tabular}{|c|c|c|c|}
\hline Nutrient & Mean \pm Standard Deviation & Range & $\begin{array}{c}\text { Number of } \\
\text { Samples }\end{array}$ \\
\hline \multicolumn{4}{|l|}{ Vitamins } \\
\hline Vitamin A (IU/kg) & $3,650 \pm 91$ & $2,780-4,780$ & 5 \\
\hline Vitamin D (IU/kg) & $1,000^{\mathrm{a}}$ & - & - \\
\hline$\alpha$-Tocopherol (ppm) & $2,543 \pm 13,044$ & $27.0-69,100$ & 28 \\
\hline Thiamine (ppm) ${ }^{\mathrm{b}}$ & $8.08 \pm 1.73$ & $6.4-11.0$ & 5 \\
\hline Riboflavin (ppm) & $8.06 \pm 2.83$ & $4.20-17.50$ & 28 \\
\hline Niacin (ppm) & $78.6 \pm 8.26$ & $66.4-98.2$ & 28 \\
\hline Pantothenic Acid (ppm) & $26.6 \pm 11.22$ & $17.4-81.0$ & 28 \\
\hline Pyridoxine (ppm) $)^{\mathrm{b}}$ & $9.78 \pm 2.08$ & $6.44-14.3$ & 28 \\
\hline Folic Acid (ppm) & $1.58 \pm 0.44$ & $1.15-3.27$ & 28 \\
\hline Biotin (ppm) & $0.32 \pm 0.09$ & $0.20-0.704$ & 28 \\
\hline Vitamin $B_{12}(\mathrm{ppb})$ & $50.6 \pm 35.5$ & $18.3-174.0$ & 28 \\
\hline Choline (as Chloride) (ppm) & $2,615 \pm 635$ & $1,160-3,790$ & 28 \\
\hline \multicolumn{4}{|l|}{ Minerals } \\
\hline Calcium (\%) & $0.895 \pm 0.039$ & $0.857-0.96$ & 5 \\
\hline Phosphorus (\%) & $0.534 \pm 0.017$ & $0.504-0.547$ & 5 \\
\hline Potassium (\%) & $0.667 \pm 0.030$ & $0.626-0.733$ & 28 \\
\hline Chloride (\%) & $0.393 \pm 0.045$ & $0.300-0.517$ & 28 \\
\hline Sodium (\%) & $0.197 \pm 0.026$ & $0.160-0.283$ & 28 \\
\hline Magnesium (\%) & $0.217 \pm 0.055$ & $0.185-0.490$ & 28 \\
\hline Sulfur (\%) & $0.170 \pm 0.029$ & $0.116-0.209$ & 14 \\
\hline Iron (ppm) & $191.6 \pm 36.8$ & $135-311$ & 28 \\
\hline Manganese (ppm) & $50.1 \pm 9.59$ & $21.0-73.1$ & 28 \\
\hline Zinc (ppm) & $57.4 \pm 26.0$ & $43.3-184.0$ & 28 \\
\hline Copper (ppm) & $7.53 \pm 2.53$ & $3.21-16.3$ & 28 \\
\hline Iodine (ppm) & $0.531 \pm 0.201$ & $0.158-0.972$ & 28 \\
\hline Chromium (ppm) & $0.684 \pm 0.258$ & $0.330-1.380$ & 27 \\
\hline Cobalt (ppm) & $0.225 \pm 0.154$ & $0.086-0.864$ & 26 \\
\hline \multicolumn{4}{|l|}{$\begin{array}{l}\text { }{ }^{2} \text { From formulation. } \\
\text { bAs hydrochloride. }\end{array}$} \\
\hline \multicolumn{4}{|c|}{ Table D-4. Contaminant Levels in NTP-2000 Rat and Mouse Ration ${ }^{a}$} \\
\hline & Mean \pm Standard Deviation ${ }^{b}$ & \multicolumn{2}{|c|}{ Number of Samples } \\
\hline \multicolumn{4}{|l|}{ Contaminants } \\
\hline Arsenic (ppm) & $0.2776 \pm 0.021$ & \multicolumn{2}{|c|}{5} \\
\hline Cadmium (ppm) & $0.0626 \pm 0.006$ & \multicolumn{2}{|c|}{5} \\
\hline
\end{tabular}


Gum Guggul, NTP TOX 99

\begin{tabular}{|c|c|c|c|}
\hline & Mean \pm Standard Deviation ${ }^{b}$ & Range & Number of Samples \\
\hline Lead (ppm) & $0.2508 \pm 0.356$ & $0.08-0.89$ & 5 \\
\hline Mercury (ppm) & $<0.02$ & - & 5 \\
\hline Selenium (ppm) & $0.2314 \pm 0.034$ & $0.20-0.27$ & 5 \\
\hline Aflatoxins (ppm) & $<5.00$ & - & 5 \\
\hline Nitrate Nitrogen (ppm) ${ }^{\mathrm{c}}$ & $22.54 \pm 12.0$ & $10.0-35.9$ & 5 \\
\hline Nitrite Nitrogen $(\mathrm{ppm})^{\mathrm{c}}$ & 0.61 & - & 5 \\
\hline BHA $(\mathrm{ppm})^{\mathrm{d}}$ & $<1.0$ & - & 5 \\
\hline BHT (ppm) $)^{d}$ & $<1.0$ & - & 5 \\
\hline Aerobic Plate Count (CFU/g) & $<10.0$ & - & 5 \\
\hline Coliform (MPN/g) & 3.0 & - & 5 \\
\hline Escherichia coli (MPN/g) & $<10$ & - & 5 \\
\hline Salmonella (MPN/g) & Negative & - & 5 \\
\hline Total Nitrosamines (ppb) ${ }^{\mathrm{e}}$ & $11.6 \pm 4.6$ & $6.1-16.2$ & 5 \\
\hline N-Ndimethylamine (ppb) & $4.1 \pm 3.3$ & $1.1-9.6$ & 5 \\
\hline N-Npyrrolidine (ppb) ${ }^{\mathrm{e}}$ & $7.4 \pm 2.5$ & $5.0-11.0$ & 5 \\
\hline \multicolumn{4}{|l|}{ Pesticides (ppm) } \\
\hline$\alpha-\mathrm{BHC}$ & $<0.01$ & - & 5 \\
\hline$\beta$-BHC & $<0.02$ & - & 5 \\
\hline$\gamma$-BHC & $<0.01$ & - & 5 \\
\hline$\delta$-BHC & $<0.01$ & - & 5 \\
\hline Heptachlor & $<0.01$ & - & 5 \\
\hline Aldrin & $<0.01$ & - & 5 \\
\hline Heptachlor Epoxide & $<0.01$ & - & 5 \\
\hline DDE & $<0.01$ & - & 5 \\
\hline DDD & $<0.01$ & - & 5 \\
\hline DDT & $<0.01$ & - & 5 \\
\hline HCB & $<0.01$ & - & 5 \\
\hline Mirex & $<0.01$ & - & 5 \\
\hline Methoxychlor & $<0.05$ & - & 5 \\
\hline Dieldrin & $<0.01$ & - & 5 \\
\hline Endrin & $<0.01$ & - & 5 \\
\hline Telodrin & $<0.01$ & - & 5 \\
\hline Chlordane & $<0.05$ & - & 5 \\
\hline Toxaphene & $<0.10$ & - & 5 \\
\hline Estimated PCBs & $<0.20$ & - & 5 \\
\hline Ronnel & $<0.01$ & - & 5 \\
\hline
\end{tabular}


Gum Guggul, NTP TOX 99

\begin{tabular}{lccc}
\hline & Mean \pm Standard Deviation $^{\mathbf{b}}$ & Range & Number of Samples \\
\hline Ethion & $<0.02$ & - & 5 \\
Trithion & $<0.05$ & - & 5 \\
Diazinon & $<0.10$ & - & 5 \\
Methyl Chlorpyrifos & 0.13 & - & 5 \\
Methyl Parathion & $<0.02$ & - & 5 \\
Ethyl Parathion & $<0.02$ & - & 5 \\
Malathion & 0.09 & - & 5 \\
Endosulfan I & $<0.01$ & - & 5 \\
Endosulfan II & $<0.01$ & - & 5 \\
Endosulfane Sulfate & $<0.03$ & - & 5 \\
\hline
\end{tabular}

$\overline{\mathrm{CFU}}$ = colony-forming units; MPN = most probable number; $\mathrm{BHC}$ = hexachlorocyclohexane or benzene hexachloride;

PCB = polychlorinated biphenyl.

${ }^{a}$ All samples were irradiated.

${ }^{b}$ For values less than the limit of detection, the detection limit is given as the mean.

'Sources of contamination: alfalfa, grains, and fish meal.

${ }^{\mathrm{d}}$ Sources of contamination: soy oil and fish meal.

eAll values were corrected for percent recovery. 
Gum Guggul, NTP TOX 99

\section{Appendix E. Sentinel Animal Program \\ Table of Contents}

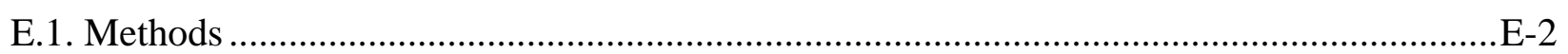

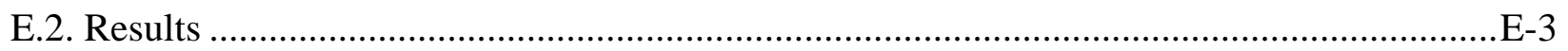

\section{Table}

Table E-1. Methods and Results for Sentinel Animal Testing in Three-month Study...............E-2 


\section{E.1. Methods}

Rodents used in the National Toxicology Program are produced in optimally clean facilities to eliminate potential pathogens that could affect study results. The Sentinel Animal Program is part of the periodic monitoring of animal health that occurs during the toxicological evaluation of chemical compounds. Under this program, the disease state of the rodents is monitored via serology on sera from extra (sentinel) animals in the study rooms. The sentinel animals and the study animals are subject to identical environmental conditions. Furthermore, the sentinel animals come from the same production source and weanling groups as the animals used for the studies of test compounds.

Blood samples were collected and allowed to clot, and the serum was separated. All samples were processed appropriately with serology performed by the Rodent Animal Diagnostic Laboratory, University of Missouri, (currently IDEXX BioResearch), Columbia, MO for determination of the presence of pathogens. The laboratory methods and agents for which testing was performed are tabulated below; the times at which samples were collected during the studies are also listed.

Blood was collected from five rats and five mice per sex at 4 weeks after the start of dosing and at the end of the study (Table E-1).

Table E-1. Methods and Results for Sentinel Animal Testing in Three-month Study

\begin{tabular}{ll}
\hline \multicolumn{1}{c}{ Method and Test } & \multicolumn{1}{c}{ Time of Collection } \\
\hline Rats & \\
Multiplex Fluorescent Immunoassay & \\
Kilham's rat virus & 4 weeks, study termination \\
Mycoplasma pulmonis & 4 weeks, study termination \\
Parvo NS-1 & 4 weeks, study termination \\
Pneumonia virus of mice (PVM) & 4 weeks, study termination \\
Rat coronavirus/sialodacryoadenitis virus & 4 weeks, study termination \\
Rat minute virus & 4 weeks, study termination \\
Rat parvovirus & 4 weeks, study termination \\
Rat theilovirus & 4 weeks, study termination \\
Sendai & 4 weeks, study termination \\
Theiler's murine encephalomyelitis virus & 4 weeks, study termination \\
strain GDVII (TMEV GDVII) & \\
Toolan's H-1 & 4 weeks, study termination \\
Mice & \\
Multiplex Fluorescent Immunoassay & \\
Ectromelia virus & 4 weeks, study termination \\
Epizootic diarrhea of infant mice & 4 weeks, study termination \\
Lymphocytic choriomeningitis virus & 4 weeks, study termination \\
\hline
\end{tabular}


Gum Guggul, NTP TOX 99

\begin{tabular}{ll}
\hline \multicolumn{1}{c}{ Method and Test } & \multicolumn{1}{c}{ Time of Collection } \\
\hline Minute virus of mice & 4 weeks, study termination \\
Mouse hepatitis virus & 4 weeks, study termination \\
Mouse norovirus & 4 weeks, study termination \\
Mouse parvovirus & 4 weeks, study termination \\
Mycoplasma pulmonis & 4 weeks, study termination \\
Parvo NS-1 & 4 weeks, study termination \\
PVM & 4 weeks, study termination \\
Reovirus & 4 weeks, study termination \\
Sendai & 4 weeks, study termination \\
TMEV GDVII & 4 weeks, study termination \\
\hline
\end{tabular}

\section{E.2. Results}

All test results were negative. 


\section{Appendix F. Supplemental Data}

Tables with supplemental data can be found here: https://doi.org/10.22427/NTP-DATA-TOX$\underline{99}$.

\section{F.1. Twenty-eight-day Interim Study in Rats}

E03 - Growth Curves

E04 - Mean Body Weights and Survival Table

P03 - Incidence Rates of Non-Neoplastic Lesions by Anatomic Site

P04 - Neoplasms by Individual Animal

P05 - Incidence Rates of Neoplasms by Anatomic Site (Systemic Lesions Abridged)

P08 - Statistical Analysis of Primary Tumors

P09 - Non-Neoplastic Lesions by Individual Animal

P10 - Statistical Analysis of Non-Neoplastic Lesions

P14 - Individual Animal Pathology Data

P18 - Incidence Rates of Non-Neoplastic Lesions by Anatomic Site with Average Severity Grades

P40 - Survival Curves

PA06 - Organ Weights Summary

PA41 - Clinical Chemistry Summary

PA43 - Hematology Summary

PA49 - Cytochrome Activity Summary

R07 - Hormone Summary

\section{F.2. Twenty-eight-day Interim Study in Mice}

E03 - Growth Curves

E04 - Mean Body Weights and Survival Table

P03 - Incidence Rates of Non-Neoplastic Lesions by Anatomic Site

P04 - Neoplasms by Individual Animal

P05 - Incidence Rates of Neoplasms by Anatomic Site (Systemic Lesions Abridged)

P08 - Statistical Analysis of Primary Tumors 
P09 - Non-Neoplastic Lesions by Individual Animal

P10 - Statistical Analysis of Non-Neoplastic Lesions

P14 - Individual Animal Pathology Data

P18 - Incidence Rates of Non-Neoplastic Lesions by Anatomic Site with Average Severity Grades

P40 - Survival Curves

PA06 - Organ Weights Summary

PA41 - Clinical Chemistry Summary

PA49 - Cytochrome Activity Summary

\section{F.3. Three-month Study in Rats}

E03 - Growth Curves

E04 - Mean Body Weights and Survival Table

E05 - Clinical Observations Summary

P03 - Incidence Rates of Non-Neoplastic Lesions by Anatomic Site

P04 - Neoplasms by Individual Animal

P05 - Incidence Rates of Neoplasms by Anatomic Site (Systemic Lesions Abridged)

P09 - Non-Neoplastic Lesions by Individual Animal

P10 - Statistical Analysis of Non-Neoplastic Lesions

P14 - Individual Animal Pathology Data

P18 - Incidence Rates of Non-Neoplastic Lesions by Anatomic Site with Average Severity Grades

P40 - Survival Curves

PA06 - Organ Weights Summary

PA41 - Clinical Chemistry Summary

PA43 - Hematology Summary

PA49 - Cytochrome Activity Summary

R06 - Andrology Summary

R07 - Hormone Summary 


\section{F.4. Three-month Study in Mice}

E03 - Growth Curves

E04 - Mean Body Weights and Survival Table

E05 - Clinical Observations Summary

P03 - Incidence Rates of Non-Neoplastic Lesions by Anatomic Site

P04 - Neoplasms by Individual Animal

P05 - Incidence Rates of Neoplasms by Anatomic Site (Systemic Lesions Abridged)

P09 - Non-Neoplastic Lesions by Individual Animal

P10 - Statistical Analysis of Non-Neoplastic Lesions

P14 - Individual Animal Pathology Data

P18 - Incidence Rates of Non-Neoplastic Lesions by Anatomic Site with Average Severity Grades

P40 - Survival Curves

PA06 - Organ Weights Summary

PA41 - Clinical Chemistry Summary

PA49 - Cytochrome Activity Summary

R06 - Andrology Summary

\section{F.5. Four-week Immunotoxicity Study}

E03 - Growth Curves

E04 - Mean Body Weights and Survival Table

E05 - Clinical Observations Summary

P03 - Incidence Rates of Non-Neoplastic Lesions by Anatomic Site

P04 - Neoplasms by Individual Animal

P05 - Incidence Rates of Neoplasms by Anatomic Site (Systemic Lesions Abridged)

P09 - Non-Neoplastic Lesions by Individual Animal

P10 - Statistical Analysis of Non-Neoplastic Lesions

P14 - Individual Animal Pathology Data 
P18 - Incidence Rates of Non-Neoplastic Lesions by Anatomic Site with Average Severity Grades

P40 - Survival Curves

F.6. In Vitro Assays (Human)

F.6.1. Gum Guggul Extract

PA49 - Cytochrome Activity

\section{F.6.2. E-guggulsterone}

PA49 - Cytochrome Activity

F.6.3. Z-guggulsterone

PA49 - Cytochrome Activity

F.7. Genetic Toxicology

F.7.1. Study G05066

G04 - In Vivo Micronucleus Summary Data

F.7.2. Study G05066B

G04 - In Vivo Micronucleus Summary Data 


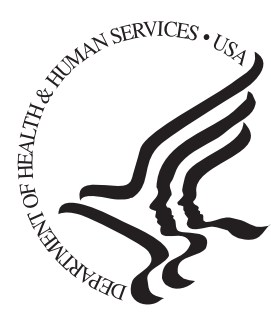

\section{National Toxicology Program}

\section{NTP Central Data Management, MD EC-03}

National Institute of Environmental Health Sciences

P.O. Box 12233

Research Triangle Park, NC 27709

http://ntp.niehs.nih.gov 